The Free Internet Journal

for Organic Chemistry
Paper

Arkivoc 2018, part ii, 145-169

Organic Chemistry

\title{
Cyanine-cyanine hybrid structure as a stabilized polyelectrochromic system: synthesis, stabilities, and redox behavior of di(1-azulenyl)methylium units connected with electron-accepting $\pi$-electron systems
}

\author{
Shunji Ito, ${ }^{\text {a }}$ Ryuta Sekiguchi, ${ }^{\text {}}$ Akira Mizushima, ${ }^{a}$ Kohei Kudo, ${ }^{\text {J Jun Kawakami, }}{ }^{\text {a }}$ and Taku Shoji ${ }^{\text {b }}$ \\ ${ }^{a}$ Graduate School of Science and Technology, Hirosaki University, Hirosaki 036-8561, Aomori, Japan \\ ${ }^{b}$ Department of Chemistry, Faculty School of Science, Shinshu University, Matsumoto 390-8621, Nagano, Japan \\ Email: itsnj@hirosaki-u.ac.jp
}

Dedicated to Professor Kenneth K. Laali on the occasion of his 65th birthday

Received 05-10-2017

Accepted 09-23-2017

Published on line 11-26-2017

\section{Abstract}

This paper describes preparation of the two-types of cations composed of di(1-azulenyl)methylium units based on a new structural principle of cyanine-cyanine $(\mathrm{C}-\mathrm{C})$ hybrid for the design of polyelectrochromic materials. Voltammetric analysis of these cations revealed the idealized reversible two-step, two-electron redox properties. Two-step color changes presumed by their $\mathrm{C}-\mathrm{C}$ hybrid structure were revealed by their electrochemical reduction. The scope of the creation of the stabilized polyelectrochromic materials taking the new structural principle with azulene skeletons is demonstrated by two-types of examples.
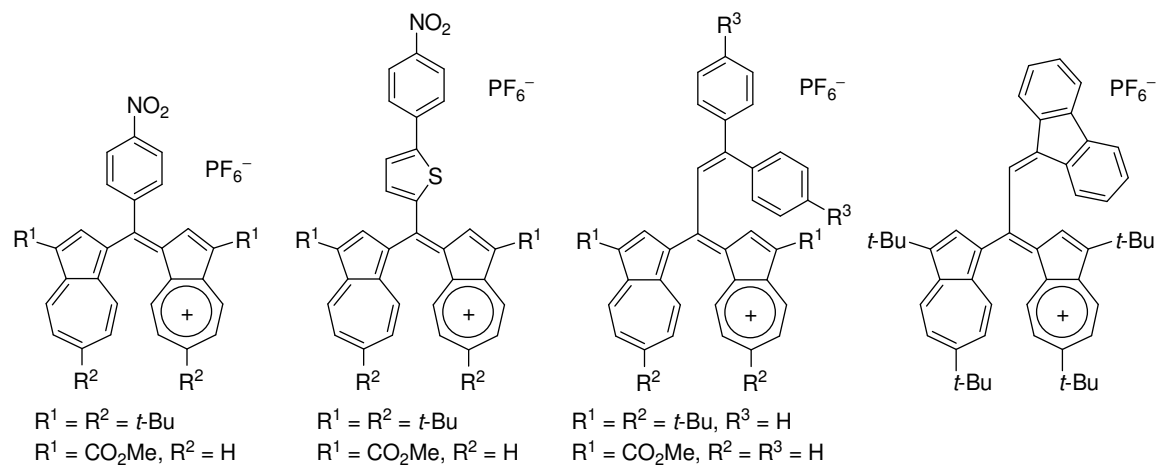

$\mathrm{R}^{1}=\mathrm{R}^{2}=t-\mathrm{Bu}, \mathrm{R}^{3}=\mathrm{H}$

$\mathrm{R}^{1}=\mathrm{CO}_{2} \mathrm{Me}, \mathrm{R}^{2}=\mathrm{R}^{3}=\mathrm{H}$

$\mathrm{R}^{1}=\mathrm{R}^{2}=t-\mathrm{Bu}, \mathrm{R}^{3}=\mathrm{F}$

$\mathrm{R}^{1}=\mathrm{R}^{2}=t-\mathrm{Bu}, \mathrm{R}^{3}=\mathrm{NO}_{2}$

Keywords: Azulene, multi-electron redox system, polyelectrochromism, cyanine, voltammetry 


\section{Introduction}

Electrochromism is observed in reversible redox systems, which exhibit significant color changes in different oxidation states. ${ }^{1-2}$ Stabilization of the redox cycle is very important in construction of potentially useful electrochromic materials, because the molecules utilized for the application require high redox-stability. Construction of organic molecules that contain multiple redox-active chromophores is required for the preparation of novel polyelectrochromic materials, which respond to different potentials with a variety of colors. ${ }^{3}$

Previously, Hünig et al. proposed a concept of violene-cyanine (V-C) hybrid to produce stabilized organic electrochromic materials. ${ }^{4-7}$ The hybrid is constructed by the violene-type redox system containing delocalized closed-shell polymethine (e.g., cyanine) dyes as one or two end groups. The hybrid is expected to provide a color of a cyanine dye by an overall two-electron transfer as illustrated by the general structure with a cyanine end group in both terminals (Scheme 1). However, multiple-color changes important for the polyelectrochromic materials will not be established by the hybrid structure.

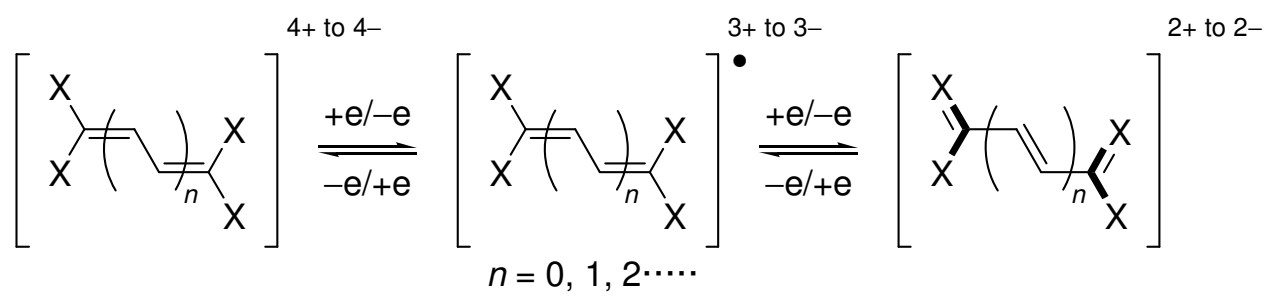

Scheme 1. General structure of the Hünig's V-C hybrid system. The presumed cyanine substructures generated by the two-electron transfer are represented in bold line in the Scheme.

To produce novel polyelectrochromic materials that exhibit multiple-color changes, we have recently proposed a molecular design from the cyanine-based polymethine dye. ${ }^{8-9}$ The cyanine dyes, themselves does not possess good electrochemical properties, because of their ionic structures. However, either one or two end groups of the cyanine-based polymethine dye are replaced by another cyanine unit, in that case, two-step redox activities with multiple-color changes should be induced. We call this molecular design cyanine-cyanine (C-C) hybrid. Herein we demonstrate the new structural principle for the polyelectrochromic materials by the preparation of two-types of the $\mathrm{C}-\mathrm{C}$ hybrid structure composed of $\mathrm{di}(1$-azulenyl)methylium units as a stabilized cyanine end group. ${ }^{10-17}$

\section{Results and Discussion}

Structural Principle. Electronic nature of the terminal groups constituted the cyanine end group is very important for the design of the $\mathrm{C}-\mathrm{C}$ hybrid with high redox stability. The hybrid structure in Scheme 2 represents the hybrid constructed by the two cyanine units composed of equal-electronic nature, in which a cyanine substructure should be induced in either reduced or oxidized form.

In contrast, the hybrid structure could be constructed by the two cyanine units with push and pull electronic nature. The general structure illustrated in Scheme 3 represents such an example. In this case, the cyanine structure $\boldsymbol{A}$ in Scheme 3 will be transform into structure $\boldsymbol{C}$ by two-electron transfer via a neutral radical state $\boldsymbol{B}$. Expected species $\boldsymbol{A}$ and $\boldsymbol{C}$ in Scheme 3 should represent the closed shell systems. The neutral radical state $\boldsymbol{B}$ 
may also be stabilized by capto-dative substitution effect in common with those of violene-type electrochromics, from which higher persistency would be expected. ${ }^{18-20}$ Therefore, the three-colored states will be stabilized by the $\mathrm{C}-\mathrm{C}$ hybrid constructed by two cyanine units with push and pull electronic nature represented in Scheme 3. Di(1-azulenyl)(6-azulenyl)methylium ions (1a-c ${ }^{+}$) would exemplify this type of the C$\mathrm{C}$ hybrid, in which cyanine substructure should be induced in both reduced and oxidized forms (Scheme 4). ${ }^{21}$

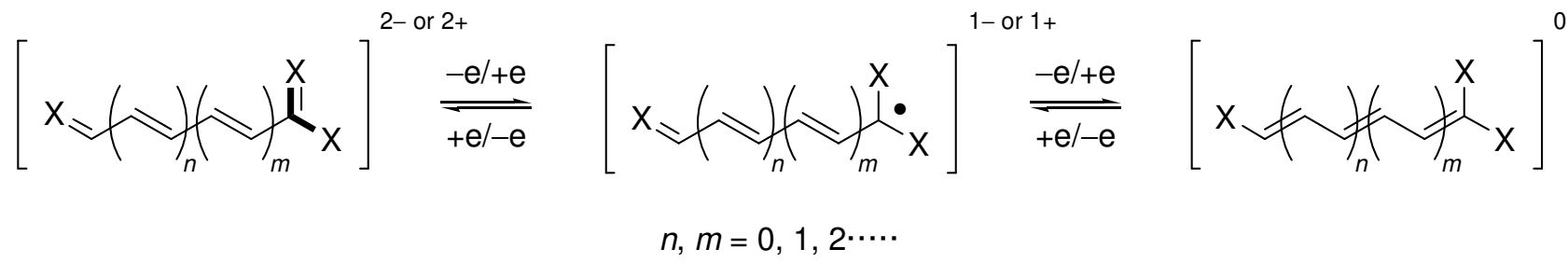

Scheme 2. General structure of the $\mathrm{C}-\mathrm{C}$ hybrid prepared by three terminal groups $(\mathrm{X})$ with same electronic nature. The presumed cyanine substructures generated by the two-electron transfer are represented in bold line in the Scheme.

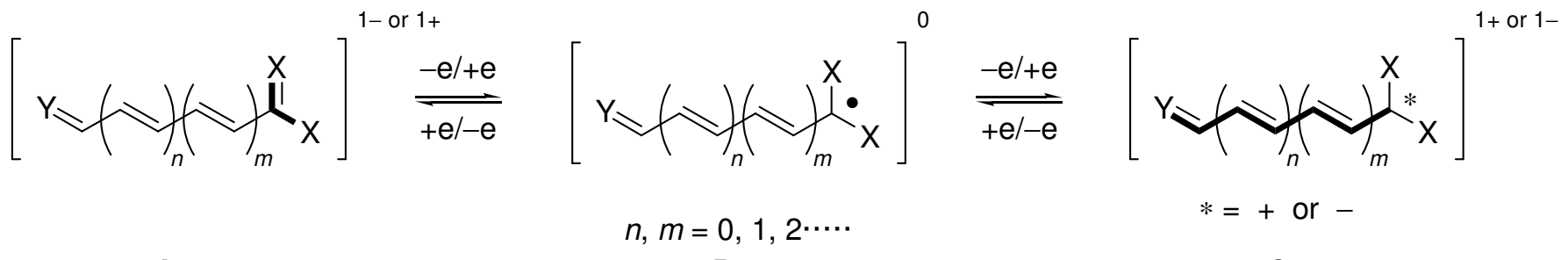

$\boldsymbol{A}$

B

C

Scheme 3. General structure of the $\mathrm{C}-\mathrm{C}$ hybrid prepared by three terminal groups $(\mathrm{X}$ and $\mathrm{Y})$ with push and pull electronic nature. The presumed cyanine substructures generated by the two-electron transfer are represented in bold line in the Scheme.

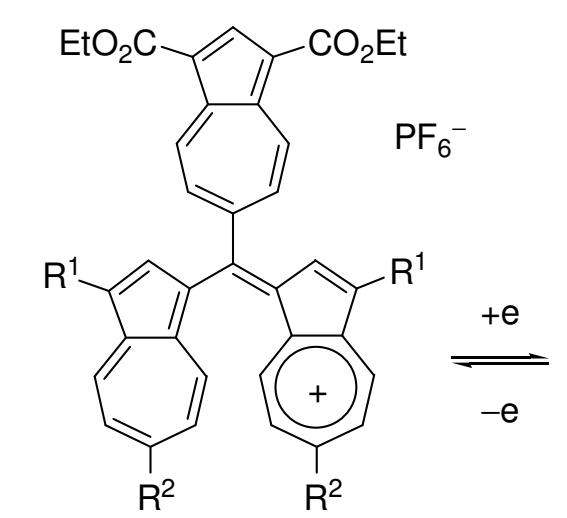

$1 a^{+} \cdot P F_{6}^{-}: R^{1}=R^{2}=H$

$\mathbf{1 b}^{+} \cdot \mathrm{PF}_{6}^{-}: \mathrm{R}^{1}=\mathrm{R}^{2}=t-\mathrm{Bu}$

$1 c^{+} \cdot \mathrm{PF}_{6}^{-}: \mathrm{R}^{1}=\mathrm{H}, \mathrm{R}^{2}=\mathrm{OMe}$

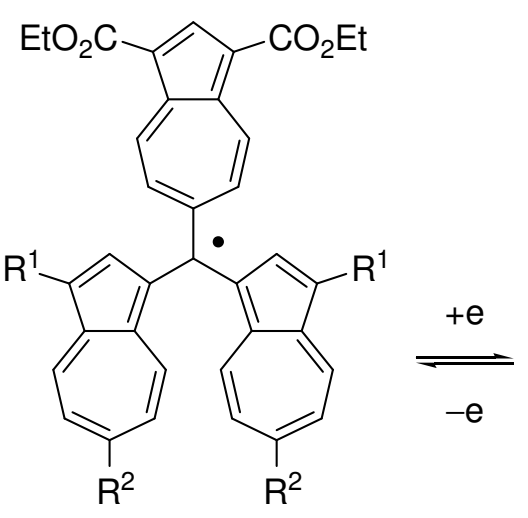

$1^{\bullet}$

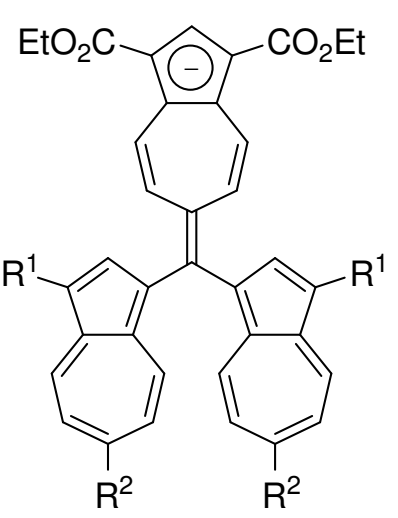

$1^{-}$

Scheme 4. An example of the C-C hybrid prepared by the three terminal groups by azulenyl groups.

When the $\mathrm{C}-\mathrm{C}$ hybrid is constructed by two cyanine end groups with equal-electronic nature, a defect of conjugation will arise in the core cyanine unit in either reduced or oxidized form because the core unit is 
constructed by odd number of polymethine chain..$^{8-9}$ In contrast, the $\mathrm{C}-\mathrm{C}$ hybrid structure constructed by two cyanine end groups with push and pull electronic nature should avoid such disadvantage in the conjugation in the core cyanine unit as illustrated in Scheme 5. Both the colored species $\boldsymbol{D}$ and $\boldsymbol{F}$ in Scheme 5 should also represent the closed shell systems. Therefore, the stabilized three-colored states will be achieved by the twotypes of the $\mathrm{C}-\mathrm{C}$ hybrid structure constructed by the cyanine units with push and pull electronic nature illustrated by the general structures in Schemes 3 and 5 with oxidation levels varying from 1+ to 1-.

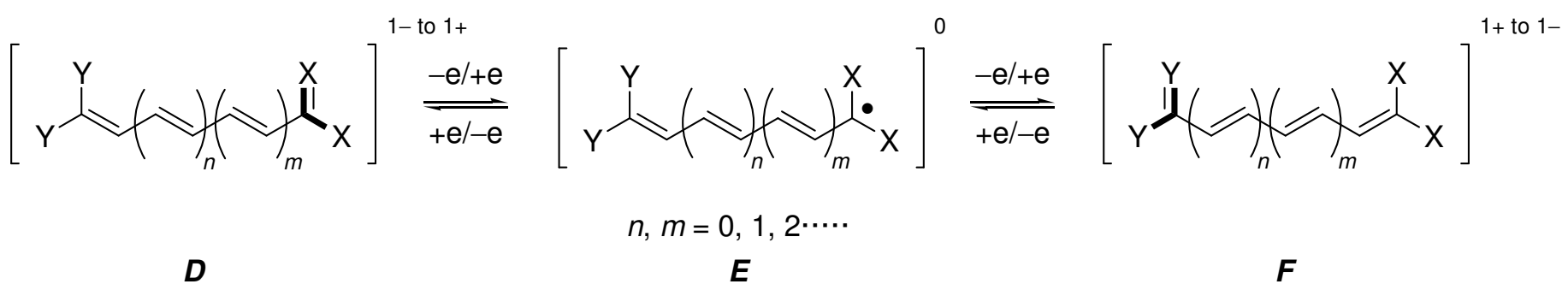

Scheme 5. General structure of the $\mathrm{C}-\mathrm{C}$ hybrid prepared by four terminal groups $(\mathrm{X}$ and $\mathrm{Y})$ with push and pull electronic nature. The presumed cyanine substructures generated by the two-electron transfer are represented in bold line in the Scheme.

For the construction of the new hybrid system represented the general structures in Schemes 3 and 5, it is very important to select highly colored polymethine end groups with high stability. We selected di(1azulenyl)methylium units as an end group for the construction of the $\mathrm{C}-\mathrm{C}$ hybrid due to their high stability and also their strong absorption in visible region owing to the cyanine-like structure as demonstrated by our previous work. $^{10-17}$

Two di(1-azulenyl)methylium units with bis(3,6-di-tert-butyl and 3-methoxycarbonyl) substituents were applied to examine the substituent effect on the azulene rings (Schemes 6-9). Introduction of the tert-butyl group into the azulene rings should increase their thermodynamic stabilities and also reversibility of both electrochemical reduction and oxidation states. 3-Methoxycarbonyl derivatives might increase the stability in their presumed anionic state to decrease the strong electron-donating character of the 1-azulenyl groups.

As the electron-withdrawing core cyanine unit for the preparation of the $\mathrm{C}-\mathrm{C}$ hybrid illustrated in Scheme 3, we selected 4-nitrophenyl and 5-(4-nitrophenyl)-2-thienyl groups to examine the effect of the core cyanine unit (Schemes 6 and 7). Introduction of 2,5-thiophenediyl spacer might further stabilize the presumed twoelectron reduction state by the extension of the $\pi$-electron system with the thienoquinoidal form. ${ }^{22-25}$

To exemplify the C-C hybrid illustrated in Scheme 5, we have examined the preparation of 3,3-bis(3,6-ditert-butyl-1-azulenyl)-1,1-bis(4-nitrophenyl)propenylium ion that employed 4-nitrophenyl groups as the electron-withdrawing terminal groups. We have also examined the substituent effects at the 1,1-diaryl moiety, i.e., diphenyl, bis(4-fluorophenyl), and fluorenylidene in addition to the bis(4-nitrophenyl) terminal groups (Schemes 8 and 9). Thus, the two-types of $\mathrm{C}-\mathrm{C}$ hybrids constructed by di(1-azulenyl)methylium units as an end group $\mathbf{5} \mathbf{a}^{+}, \mathbf{5} \mathbf{b}^{+}, \mathbf{8} \mathbf{a}^{+}, \mathbf{8} \mathbf{b}^{+}, \mathbf{1 1} \mathbf{a}-\mathbf{d}^{+}$, and $\mathbf{1 4 ^ { + }}$ (Schemes 6-9) were designed as the new examples for the $C-C$ hybrid with the general structure in Schemes 3 and 5.

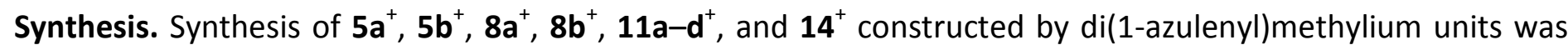

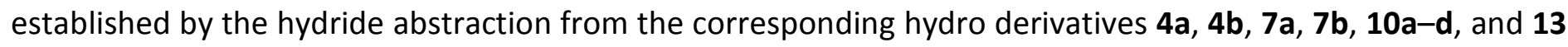
with DDQ and obtained as hexafluorophosphates by the treatment with hexafluorophosphoric acid as illustrated in Schemes 6-9. 
The reaction of 1,6-di-tert-butylazulene $(3 a)^{10}$ with 4-nitrobenzaldehyde (2) in acetic acid at room temperature afforded bis(3,6-di-tert-butyl-1-azulenyl)(4-nitrophenyl)methane (4a) in 76\% yield (Scheme 6). Similarly, bis(3,6-di-tert-butyl-1-azulenyl)[5-(4-nitrophenyl)-2-thienyl)]methane (7a) was obtained by the reaction of $3 a$ with 5-(4-nitrophenyl)thiophene-2-carbaldehyde (6), ${ }^{26}$ which was prepared by Miyaura-Suzuki cross-coupling of 2-formylthiophene-5-boronic acid with 4-iodonitrobenzene, in acetic acid at room temperature in $62 \%$ yield (Scheme 7 ).

Analogously, preparation of the corresponding bis(3-methoxycarbonyl) derivatives $\mathbf{4 b}$ and $\mathbf{7 b}$ for the precursors of $\mathbf{5} \mathbf{b}^{+}$and $\mathbf{8} \mathbf{b}^{+}$was accomplished via the reaction of methyl azulene-1-carboxylate (3b) with $\mathbf{2}$ and $\mathbf{6}$ in refluxing acetic acid $84 \%$ and $11 \%$ yields, respectively. The yield of $\mathbf{7 b}$ has been further improved to $35 \%$ by performing the reaction in a boiling mixture of acetic acid and toluene, probably due to the increasing solubility of 6 in the mixed solvent.

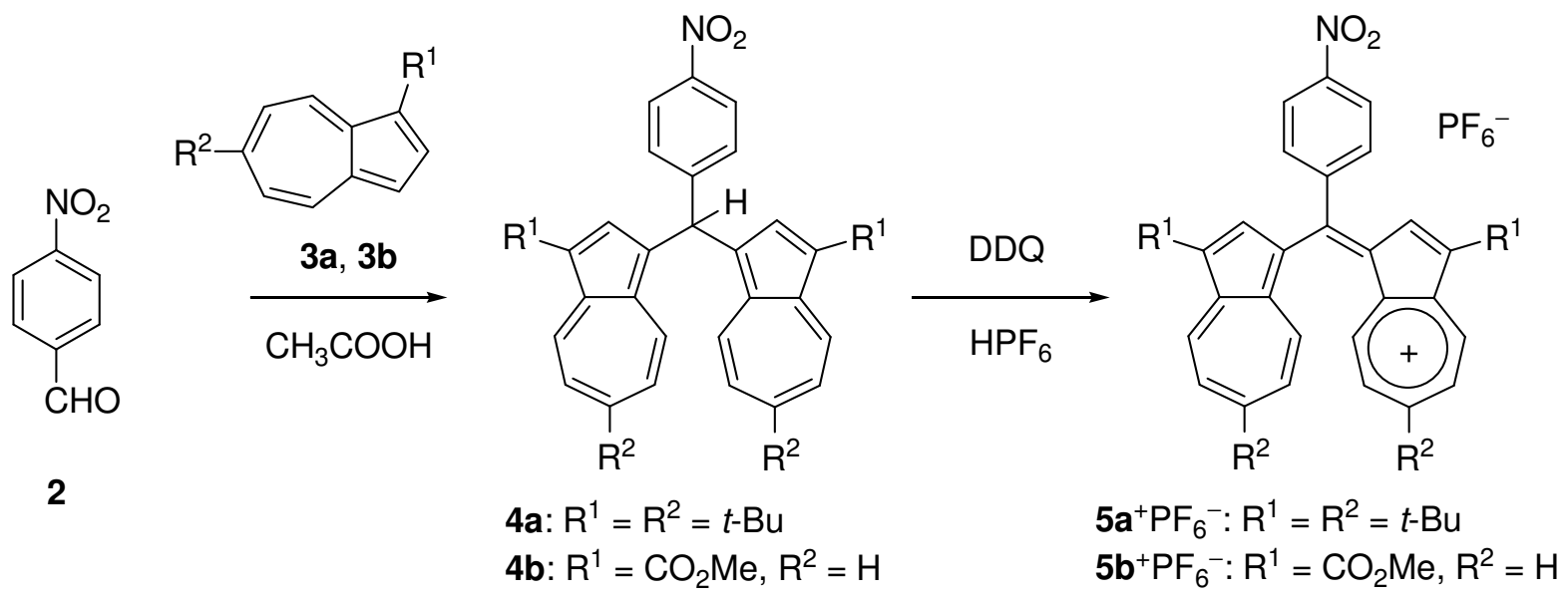

Scheme 6. Preparation of $5 \mathbf{a}^{+} \mathrm{PF}_{6}^{-}$and $5 \mathbf{b}^{+} \mathrm{PF}_{6}^{-}$.

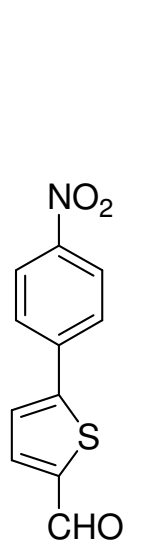

6
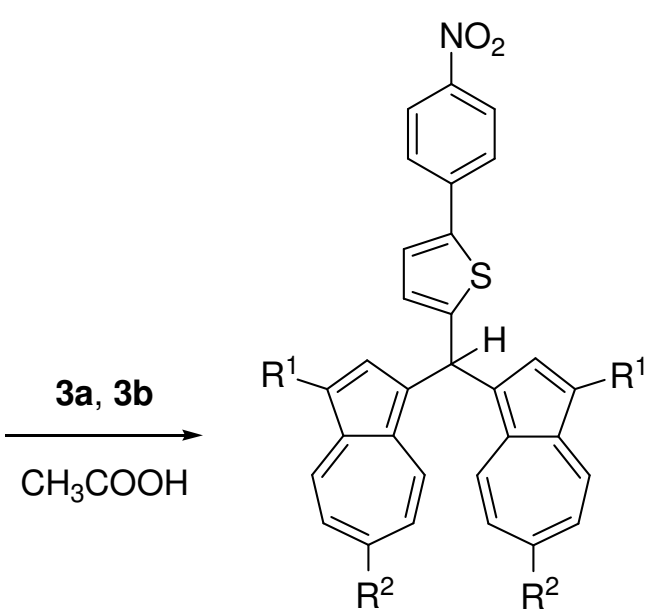

7a: $\mathrm{R}^{1}=\mathrm{R}^{2}=t-\mathrm{Bu}$

$7 b: R^{1}=\mathrm{CO}_{2} \mathrm{Me}, \mathrm{R}^{2}=\mathrm{H}$

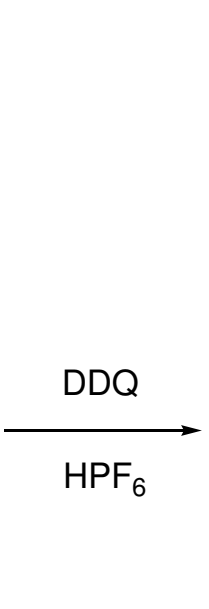

$8 \mathrm{a}^{+} \mathrm{PF}_{6}^{-}: \mathrm{R}^{1}=\mathrm{R}^{2}=t-\mathrm{Bu}$ $8 b^{+} P_{6}^{-}: R^{1}=\mathrm{CO}_{2} \mathrm{Me}, \mathrm{R}^{2}=\mathrm{H}$

Scheme 7. Preparation of $8 \mathbf{a}^{+} \mathrm{PF}_{6}^{-}$and $\mathbf{8} \mathbf{b}^{+} \mathrm{PF}_{6}^{-}$.

Furthermore, reaction of $3 a$ with 6 -phenylcinnamaldehyde (9a) in acetic acid at room temperature afforded 3,3-bis(3,6-di-tert-butyl-1-azulenyl)-1,1-diphenylpropene (10a) in 76\% yield (Scheme 8). Preparation 
of the corresponding bis(3-methoxycarbonyl) derivative $\mathbf{1 0 b}$ for the precursor of $\mathbf{1 1} \mathbf{b}^{+}$was accomplished by the similar reaction of $\mathbf{3 b}$ with $9 \mathbf{a}$ in refluxing acetic acid in $27 \%$ yield.

As similar to the reaction with 9a, 3,3-bis(3,6-di-tert-butyl-1-azulenyl)-1,1-bis(4-fluorophenyl)propene (10b) was obtained in $43 \%$ yield by the reaction of 3a with 3,3-bis(4-fluorophenyl)-2-propenal (9b), which was prepared from 4,4'-difluorobenzophenone by the reaction with $\mathrm{Et}_{3} \mathrm{~N}$ in the presence of $\mathrm{TiCl}_{4}$ followed by the hydration with saturated $\mathrm{NH}_{4} \mathrm{Cl}$ solution as reported in the literature. ${ }^{27}$ Preparation of the 4,4'-dinitro derivative, 3,3-bis(3,6-di-tert-butyl-1-azulenyl)-1,1-bis(4-nitrophenyl)propene (10d), for the precursor of $\mathbf{1 1}^{+}$ was established in $30 \%$ yield by the similar reaction of 3a with 3,3-bis(4-nitrophenyl)-2-propenal (9c), which was prepared in $27 \%$ yield by the reaction of $4,4^{\prime}$-dinitrobenzophenone ${ }^{28}$ with $\mathrm{Et}_{3} \mathrm{~N}$ in the presence of $\mathrm{TiCl}_{4}$ followed by the hydration with saturated $\mathrm{NH}_{4} \mathrm{Cl}$ solution by utilizing the preparation method for 9b. 9-[2,2Bis(3,6-di-tert-butyl-1-azulenyl)ethylidene]-9H-fluorene (13) was also obtained by the reaction of 3a with $9 H$ fluoren-9-ylidene acetaldehyde (12) ${ }^{27}$ in acetic acid at room temperature in 64\% yield (Scheme 9).<smiles>[R]c1ccc(C(=CC=O)c2ccc([R])cc2)cc1</smiles>

$3 a, 3 b$

9a: $\mathrm{R}=\mathrm{H}$

9b: $R=F$

9c: $\mathrm{R}=\mathrm{NO}_{2}$

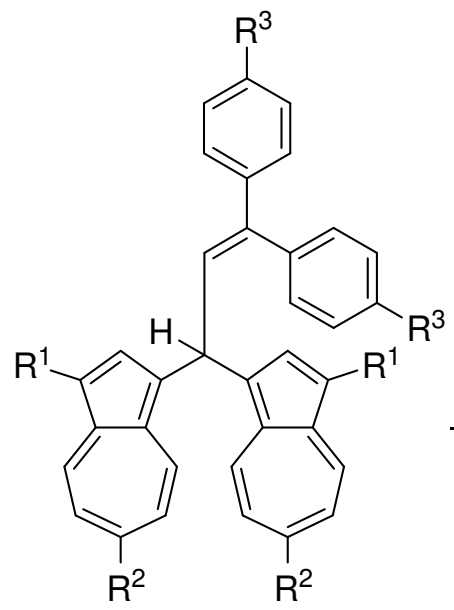

10a: $\mathrm{R}^{1}=\mathrm{R}^{2}=t-\mathrm{Bu}, \mathrm{R}^{3}=\mathrm{H}$

10b: $R^{1}=\mathrm{CO}_{2} \mathrm{Me}, \mathrm{R}^{2}=\mathrm{R}^{3}=\mathrm{H}$

10c: $\mathrm{R}^{1}=\mathrm{R}^{2}=t-\mathrm{Bu}, \mathrm{R}^{3}=\mathrm{F}$

10d: $\mathrm{R}^{1}=\mathrm{R}^{2}=t-\mathrm{Bu}, \mathrm{R}^{3}=\mathrm{NO}_{2}$

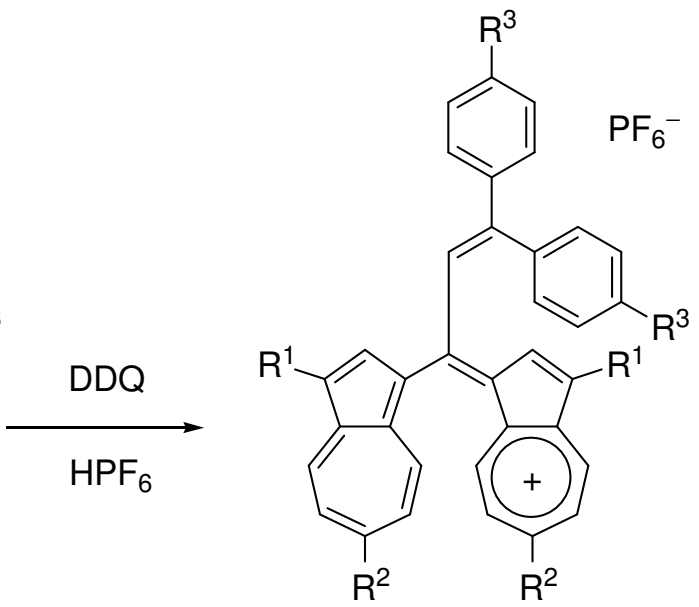

$11 \mathrm{a}^{+} \mathrm{PF}_{6}^{-}: \mathrm{R}^{1}=\mathrm{R}^{2}=t-\mathrm{Bu}, \mathrm{R}^{3}=\mathrm{H}$ $11 b^{+} P F_{6}^{-}: R^{1}=C_{2} M e, R^{2}=R^{3}=H$ $11 \mathrm{c}^{+} \mathrm{PF}_{6}^{-}: \mathrm{R}^{1}=\mathrm{R}^{2}=t-\mathrm{Bu}, \mathrm{R}^{3}=\mathrm{F}$ $11 d^{+} P F_{6}^{-}: R^{1}=R^{2}=t-B u, R^{3}=N_{2}$

Scheme 8. Preparation of $11 a-d^{+} \mathrm{PF}_{6}^{-}$.

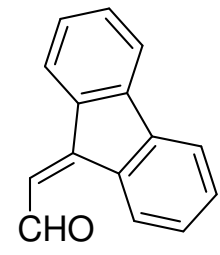

12

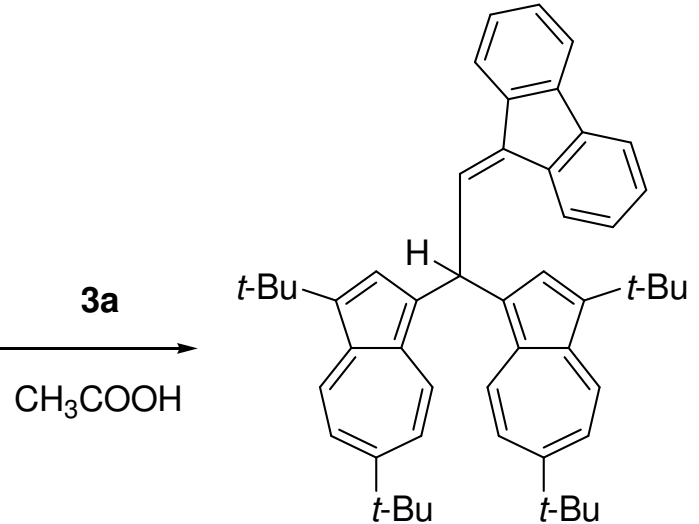

13

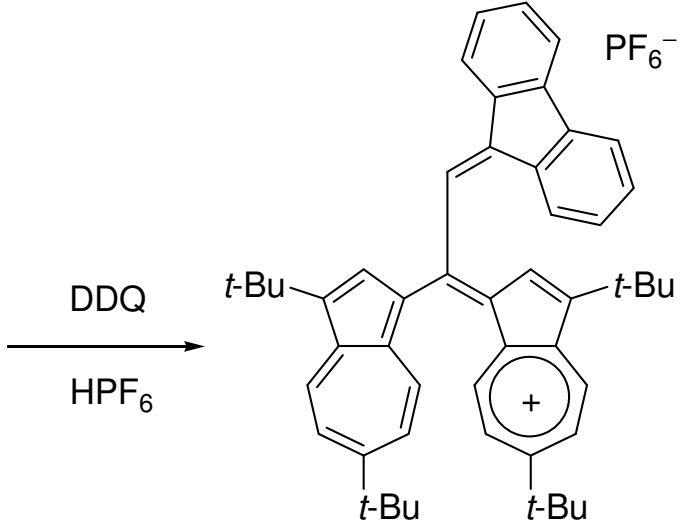

$14^{+} \mathrm{PF}_{6}^{-}$

Scheme 9. Preparation of $14^{+} \mathrm{PF}_{6}^{-}$. 
Synthesis of $\mathbf{5 a} \mathbf{a}^{+}, \mathbf{5} \mathbf{b}^{+}, \mathbf{8} \mathbf{a}^{+}, \mathbf{8} \mathbf{b}^{+}, \mathbf{1 1 a}-\mathbf{d}^{+}$, and $\mathbf{1 4} \mathbf{4}^{+}$was established by the hydride abstraction from $\mathbf{4 a}, \mathbf{4 b}, \mathbf{7 a}$, 7b, 10a-d, and 13 with DDQ at room temperature and obtained as hexafluorophosphates by the treatment with hexafluorophosphoric acid. The reaction of $\mathbf{4 a}, \mathbf{4 b}, \mathbf{7 a}$, and $\mathbf{7 b}$ with DDQ yielded $5 \mathrm{a}^{+}(58 \%), 5 \mathrm{~b}^{+}(74 \%), 8 \mathrm{a}^{+}$ $(77 \%)$, and $\mathbf{8 b ^ { + }}(33 \%)$ as a hexafluorophosphate (Schemes 6 and 7$)$. Likewise, the oxidation of 10a, 10c, and $\mathbf{1 3}$ with DDQ afforded the corresponding hexafluorophosphates $11 \mathrm{a}^{+} \mathrm{PF}_{6}{ }^{-}, \mathbf{1 1 c}^{+} \mathrm{PF}_{6}{ }^{-}$, and $14^{+} \mathrm{PF}_{6}{ }^{-}$in $74 \%, 95 \%$, and $88 \%$ yields, respectively (Schemes 8 and 9). The hexafluorophosphates $\mathbf{1 1}^{+} \mathbf{P F}_{6}{ }^{-}$and $\mathbf{1 1 d}^{+} \mathrm{PF}_{6}{ }^{-}$were obtained by the hydride abstraction from $\mathbf{1 0 b}$ and $\mathbf{1 0 d}$ with $\mathrm{DDQ}$ in the two-phase reaction of $\mathrm{CH}_{2} \mathrm{Cl}_{2}$ and $\mathrm{HPF}_{6}$ solution at room temperature in $92 \%$ and $66 \%$ yields, respectively. These new salts are stable, deep-colored crystals, and are storable in the crystalline state in spite of their cationic structure with electron-withdrawing nitro group as an end group in some cases.

Spectroscopic Properties. The two-types of $\mathrm{C}-\mathrm{C}$ hybrids $\mathbf{5 a ^ { + }}, \mathbf{5 b ^ { + }}, \mathbf{8} \mathbf{a}^{+}, \mathbf{8} \mathbf{b}^{+}, \mathbf{1 1} \mathbf{a}-\mathbf{d}^{+}$, and $\mathbf{1 4} \mathbf{4}^{+}$were fully characterized by the spectral data as shown in the Experimental Section. Mass spectra of the cation salts $5 a^{+} \mathrm{PF}_{6}^{-}, \mathbf{5} \mathbf{b}^{+} \mathrm{PF}_{6}{ }^{-}, \mathbf{8} \mathbf{a}^{+} \mathrm{PF}_{6}{ }^{-}, \mathbf{8} \mathbf{b}^{+} \mathrm{PF}_{6}{ }^{-}, \mathbf{1 1} \mathbf{a}-\mathrm{d}^{+} \mathrm{PF}_{6}{ }^{-}$, and $14^{+} \mathrm{PF}_{6}^{-}$ionized by ESI showed the correct $\left(\mathrm{M}-\mathrm{PF}_{6}\right)^{+}$ion peaks, which indicated the cationic structures of these products. The characteristic bands of the hexafluorophosphates were observed at 839-842 (strong) and 557-558 (medium) $\mathrm{cm}^{-1}$ in their IR spectra, which also supported the ionic structure of these compounds.

UV-vis spectra of these cations in acetonitrile are shown in Figures 1 and 2 . As expected by their cyaninelike substructures, these cations showed characteristic charge-transfer absorption bands in the visible region. Their absorption maxima $(\mathrm{nm})$ and coefficients $(\log \varepsilon)$ with those of di(1-azulenyl)phenylmethylium ions $15 \mathbf{a}^{+}$ and $\mathbf{1 5} \mathbf{b}^{+10}$ without the nitro substituent are summarized in Table 1 . The longest wavelength absorption of $\mathbf{5} \mathbf{a}^{+}$ $(704 \mathrm{~nm})$ and $5 \mathbf{b}^{+}(637 \mathrm{~nm})$ showed bathochromic shift by $23 \mathrm{~nm}$ and $21 \mathrm{~nm}$, respectively, compared with that of $\mathbf{1 5} \mathbf{a}^{+}(681 \mathrm{~nm})$ and $\mathbf{1 5} \mathbf{b}^{+}(616 \mathrm{~nm})$. However, $\mathbf{8} \mathbf{a}^{+}$and $\mathbf{8} \mathbf{b}^{+}$inserted with thienylene spacer for the extension of $\pi$-electron system exhibited a slight hypsochromic shift as compared with that of $\mathbf{5} \mathbf{a}^{+}$and $\mathbf{5} \mathbf{b}^{+}$. Characteristic feature of the UV-vis spectra for $8 \mathbf{a}^{+}\left(540 \mathrm{~nm}\right.$ and $702 \mathrm{~nm}$ ) and $\mathbf{8 \mathbf { b } ^ { + }}$ (536 $\mathrm{nm}$ and $630 \mathrm{~nm}$ ) was represented by two absorption bands, although that for $\mathbf{5} \mathbf{a}^{+}$and $\mathbf{5} \mathbf{b}^{+}$was characterized by a strong absorption band in this region.

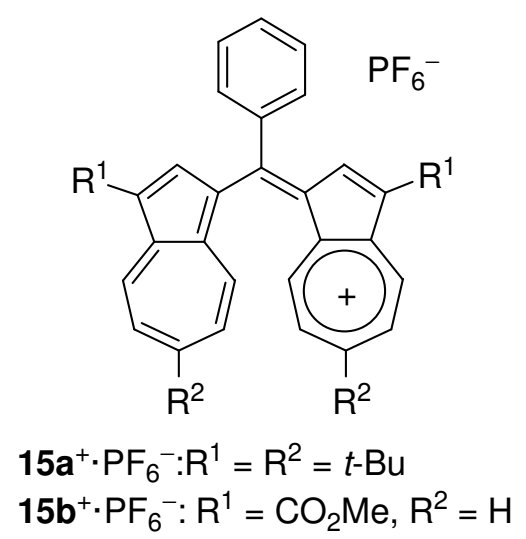

The UV-vis spectra of $\mathbf{1 1} \mathbf{a}^{+}$and $\mathbf{1 1} \mathbf{b}^{+}$in visible region were characterized by two strong absorption bands, whereas, $\mathbf{5} \mathbf{a}^{+}$and $\mathbf{5} \mathbf{b}^{+}$exhibited an absorption band in this region. The longest wavelength absorption of $\mathbf{1 1} \mathbf{a}^{+}$ $(722 \mathrm{~nm})$ and $\mathbf{1 1 b}^{+}(655 \mathrm{~nm})$ showed bathochromic shift by $41 \mathrm{~nm}$ and $39 \mathrm{~nm}$, respectively, compared with that for $\mathbf{1 5 a}^{+}$and $\mathbf{1 5 b ^ { + }}$. Electron-withdrawing substituents on the terminal phenyl groups showed a bathochromic shift by, $2 \mathrm{~nm}$ in the fluoro derivative $11 \mathrm{c}^{+}, 14 \mathrm{~nm}$ in nitro derivative $11 \mathbf{d}^{+}$, and $7 \mathrm{~nm}$ in the 
fluorenilidene derivative $14^{+}$compared with that of $11 \mathbf{a}^{+}$. As expected, 3-methoxycarbonyl-1-azulenyl groups exhibited hypsochromic shift in the longest wavelength absorption band compared with that of tert-butyl derivative $11 \mathbf{a}^{+}$. The extinction coefficients of these cations $11 \mathbf{a}-\mathbf{d}^{+}$and $14^{+}$are approximately as large as those of cations $5 a^{+}, 5 b^{+}, 8 a^{+}$, and $8 b^{+}$.

(a)

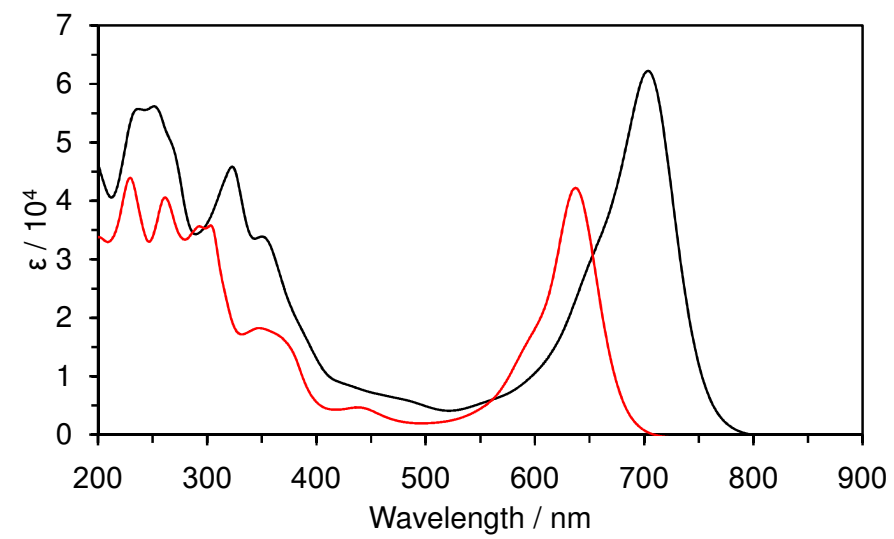

(b)

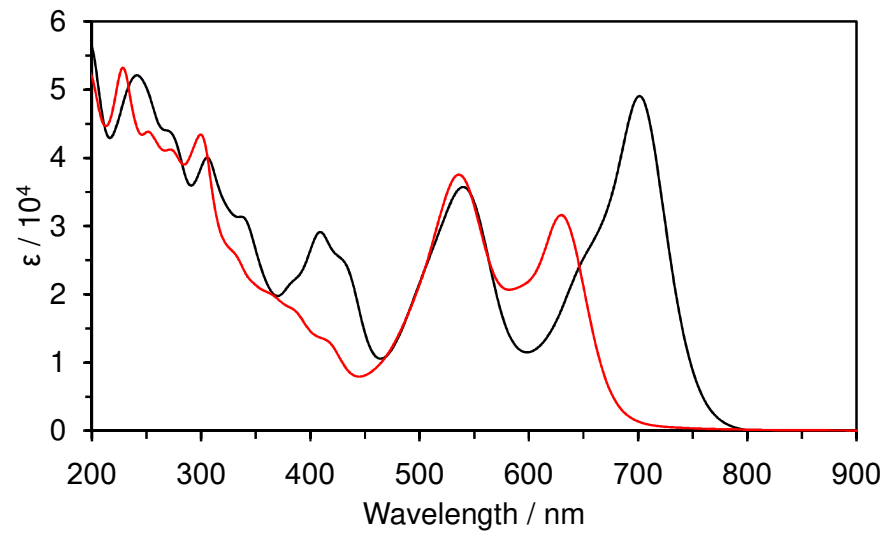

Figure 1. UV-vis Spectra: (a) $\mathbf{5} \mathbf{a}^{+}$(black line) and $\mathbf{5} \mathbf{b}^{+}$(red line); (b) $\mathbf{8} \mathbf{a}^{+}$(black line) and $\mathbf{8} \mathbf{b}^{+}$(red line) in acetonitrile.

(a)

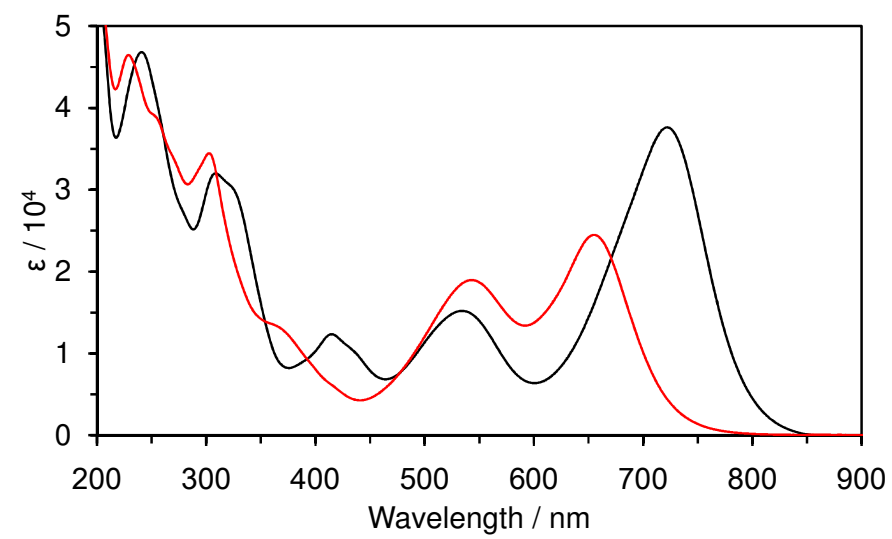

(b)

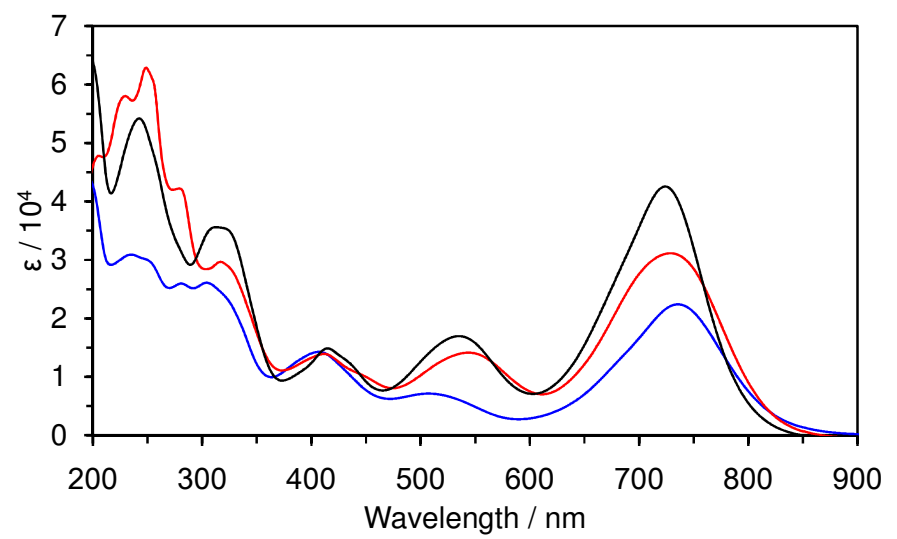

Figure 2. UV-vis Spectra: (a) $11 \mathbf{a}^{+}$(black line) and $\mathbf{1 1 b ^ { + }}$ (red line); (b) $\mathbf{1 1 c ^ { + }}$ (black line), $\mathbf{1 1 d ^ { + }}$ (blue line), and $\mathbf{1 4}{ }^{+}$ (red line) in acetonitrile.

Table 1. Longest wavelength absorption maxima $(\mathrm{nm})$ and their coefficients of $5 \mathbf{a}^{+}, \mathbf{5} \mathbf{b}^{+}, \mathbf{8} \mathbf{a}^{+}, \mathbf{8} \mathbf{b}^{+}, \mathbf{1 1 a}-\mathbf{d}^{+}, \mathbf{1 4} 4^{+}$, $15 \mathbf{a}^{+}$, and $\mathbf{1 5 b ^ { + }}$ in acetonitrile

\begin{tabular}{ccccc}
\hline Sample & $\lambda_{\max }(\log \varepsilon)$ & Sample & $\lambda_{\max }(\log \varepsilon)$ & Ref. \\
\hline \multirow{2}{*}{$\mathbf{5 a}^{+}$} & $704(4.79)$ & $\mathbf{1 1 c}^{+}$ & $535(4.23)$ & \\
& & & $524(4.63)$ & \\
$\mathbf{5 b}^{+}$ & $637(4.63)$ & $\mathbf{1 1 d}^{+}$ & $736(4.35)$ \\
& $540(4.55)$ & & $544(4.15)$ \\
$\mathbf{8 a}^{+}$ & $702(4.69)$ & $\mathbf{1 4}^{+}$ & $729(4.49)$ & \\
\hline
\end{tabular}


Table 1. Continued

\begin{tabular}{ccccc}
\hline Sample & $\lambda_{\max }(\log \varepsilon)$ & Sample & $\lambda_{\max }(\log \boldsymbol{\varepsilon})$ & Ref. \\
\hline $\mathbf{8 b}^{+}$ & $536(4.57)$ & $\mathbf{1 5 a}^{+}$ & $681(4.61)$ & 10 \\
& $630(4.50)$ & & & \\
$\mathbf{1 1}^{+}$ & $534(4.18)$ & $\mathbf{1 5 b}^{+}$ & $616(4.60)$ & 10 \\
& $722(4.58)$ & & & \\
$\mathbf{1 1} \mathbf{b}^{+}$ & $543(4.27)$ & & & \\
\hline
\end{tabular}

Thermodynamic stability. As a measure of the thermodynamic stability, the $p K_{R}{ }^{+}$value of these cations was determined spectrophotomerically in a buffer solution prepared in $50 \%$ aqueous acetonitrile. The $K_{R}{ }^{+}$scale is defined by the equilibrium constant for the reaction of a carbocation with a water molecule $\left(K_{R}^{+}=\right.$ $\left.[\mathrm{ROH}]\left[\mathrm{H}_{3} \mathrm{O}^{+}\right] /\left[\mathrm{R}^{+}\right]\right)$. Therefore, the larger $\mathrm{p} K_{\mathrm{R}}^{+}$index value $\left(\mathrm{p} K_{\mathrm{R}}^{+}=-\log K_{\mathrm{R}}^{+}\right)$indicates higher stability of the carbocation. However, the neutralization of these cations was not completely reversible attributable to the instability of the neutralized products under the highly basic conditions for the $\mathrm{p} K_{\mathrm{R}}^{+}$measurement. After the measurement, acidification of the alkaline solutions with $\mathrm{HCl}$ regenerated the characteristic absorption in the visible region in 1-89\% (Table 2). Therefore, the reported values correspond to the decomposition point started by the reaction with water molecule. The values are summarized in Table 2.

Table 2. $p K_{R}^{+}$values ${ }^{a}$ and redox potentials ${ }^{b}$ of $5 a^{+}, 5 b^{+}, 8 a^{+}, 8 b^{+}, 11 a-d^{+}, 14^{+}, 15 a^{+}$, and $15 b^{+}$

\begin{tabular}{|c|c|c|c|c|c|c|c|}
\hline Sample & $\mathrm{p} K_{\mathrm{R}}^{+}$ & $E_{1}{ }^{\text {red }}$ & $E_{2}{ }^{\text {red }}$ & $E_{1}^{\text {ox }}$ & $E_{2}^{\text {ox }}$ & $E_{1}{ }^{\text {red }}-E_{2}{ }^{\text {red }}$ & Ref. \\
\hline \multirow[t]{2}{*}{$5 a^{+}$} & $9.5 \pm 0.1(1 \%)$ & -0.59 & -0.94 & 0.94 & $(1.44)$ & 0.35 & \\
\hline & & $(-0.55)^{c}$ & $(-0.92)^{c}$ & $(0.92)^{c}$ & $(1.41)^{c}$ & & \\
\hline \multirow[t]{2}{*}{$5 b^{+}$} & $1.4 \pm 0.1(89 \%)$ & -0.31 & -0.79 & $(1.38)$ & & 0.48 & \\
\hline & & $(-0.28)^{c}$ & $(-0.76)^{c}$ & $(1.35)^{c}$ & & & \\
\hline \multirow[t]{2}{*}{$8 a^{+}$} & $10.9 \pm 0.1(3 \%)$ & -0.63 & -1.08 & 0.95 & $(1.33)$ & 0.45 & \\
\hline & & $(-0.61)^{c}$ & $(-1.06)^{c}$ & $(0.93)^{c}$ & $(1.29)^{c}$ & & \\
\hline \multirow[t]{2}{*}{$8 b^{+}$} & $2.9 \pm 0.1(83 \%)$ & -0.36 & -0.99 & $(1.43)$ & $(1.76)$ & 0.63 & \\
\hline & & $(-0.34)^{c}$ & $(-0.96)^{c}$ & $(1.36)^{c}$ & $(1.68)^{c}$ & & \\
\hline \multirow[t]{2}{*}{$11 \mathrm{a}^{+}$} & $12.1 \pm 0.1(5 \%)$ & -0.67 & $(-1.48)$ & 0.84 & $(1.40)$ & 0.81 & \\
\hline & & $(-0.64)^{c}$ & $(-1.45)^{c}$ & $(0.82)^{c}$ & $(1.30)^{c}$ & & \\
\hline \multirow[t]{2}{*}{$11 b^{+}$} & $5.3 \pm 0.1(60 \%)$ & -0.37 & $(-1.19)$ & $(1.27)$ & $(1.62)$ & 0.82 & \\
\hline & & $(-0.34)^{c}$ & $(-1.15)^{c}$ & $(1.24)^{c}$ & $(1.59)^{c}$ & & \\
\hline \multirow[t]{2}{*}{$11 c^{+}$} & $11.7 \pm 0.1(5 \%)$ & -0.65 & $(-1.54)$ & 0.85 & & 0.89 & \\
\hline & & $(-0.62)^{c}$ & $(-1.42)^{c}$ & $(0.82)^{c}$ & $(1.41)^{c}$ & & \\
\hline \multirow[t]{2}{*}{$11 d^{+}$} & $8.7 \pm 0.1(1 \%)$ & -0.50 & -0.86 & 0.88 & & 0.36 & \\
\hline & & $(-0.48)^{c}$ & $(-0.84)^{c}$ & $(0.86)^{c}$ & $(1.38)^{c}$ & & \\
\hline \multirow[t]{2}{*}{$14^{+}$} & $9.3 \pm 0.1(10 \%)$ & -0.49 & $(-1.12)$ & 0.93 & $(1.48)$ & 0.63 & \\
\hline & & $(-0.47)^{c}$ & $(-1.08)^{c}$ & $(0.90)^{c}$ & $(1.41)^{c}$ & & \\
\hline
\end{tabular}


Table 2. Continued

\begin{tabular}{cccccccc}
\hline Sample & $\mathrm{p} K_{\mathrm{R}}{ }^{+}$ & $E_{1}{ }^{\text {red }}$ & $E_{2}{ }^{\text {red }}$ & $E_{1}{ }^{\text {ox }}$ & $E_{2}{ }^{\text {ox }}$ & $E_{1}{ }^{\text {red }}-E_{2}{ }^{\text {red }}$ & Ref. \\
\hline $\mathbf{1 5 a ^ { + d }}$ & 12.4 & -0.78 & $(-1.64)$ & 0.88 & $(1.38)$ & 0.86 & 10 \\
$\mathbf{1 5 b}^{+\mathrm{d}}$ & 3.4 & $(-0.49)^{\mathrm{e}}$ & $(-1.31)$ & $(1.32)$ & & 0.82 & 10 \\
\hline
\end{tabular}

${ }^{\mathrm{a}}$ The $\mathrm{p} K_{\mathrm{R}}^{+}$values were determined spectrophotometrically in a buffered solution prepared in $50 \%$ aqueous acetonitrile. ${ }^{10}$ Regenerated absorption maxima (\%) of the cations in visible region by acidification of the alkaline solution with $\mathrm{HCl}$ are shown in parentheses. ${ }^{\mathrm{b}}$ Redox potentials were measured by CV and DPV [V vs. $\mathrm{Ag} / \mathrm{AgNO}_{3}, 1 \mathrm{mM}$ in benzonitrile containing $\mathrm{Et}_{4} \mathrm{NClO}_{4}(0.1 \mathrm{M})$, Pt electrode (ID: $\left.1.6 \mathrm{~mm}\right)$, scan rate $100 \mathrm{mV} \mathrm{s}^{-1}$, and $\left.\mathrm{Fc} / \mathrm{Fc}^{+}=0.15 \mathrm{~V}\right] .{ }^{\mathrm{c}}$ The peak potentials measured by DPV are shown in parentheses. ${ }^{\mathrm{d}}$ Potentials were the value measured in acetonitrile. ${ }^{\mathrm{e}}$ The wave was accompanied by second peak at $-0.57 \mathrm{~V}$ probably due to the deposition of reduced species on the electrode in acetonitrile.

Cation $5 \mathrm{a}^{+}\left(\mathrm{pK}_{\mathrm{R}}^{+}=9.5\right)$ is not strongly destabilized by the 4-nitro substituent compared with that of $15 \mathrm{a}^{+}$ $\left(p K_{R}^{+}=12.4\right){ }^{10}$ in spite of the existence of the strong electron-withdrawing nitro substituent as an end group. Bis(3-methoxycarbonyl) derivative $5 \mathbf{b}^{+}\left(p K_{R}^{+}=1.4\right)$ exhibited significant destabilization due to the substitution of an electron-withdrawing methoxycarbonyl group at both 1-azulenyl groups, but still exhibited reasonably high $\mathrm{p} K_{\mathrm{R}}^{+}$value. Cations $\mathbf{8 \mathrm { a } ^ { + }}$ and $\mathbf{8 \mathrm { b } ^ { + }}$ is slightly stabilized by the insertion of thienylene spacer, since $8 \mathrm{a}^{+}\left(\mathrm{p} K_{\mathrm{R}}^{+}=\right.$ 10.9) and $\mathbf{8} b^{+}\left(p K_{R}^{+}=2.9\right)$ exhibited slightly larger $p K_{R}^{+}$value, compared with that of $\mathbf{5} \mathbf{a}^{+}$and $\mathbf{5} \mathbf{b}^{+}$.

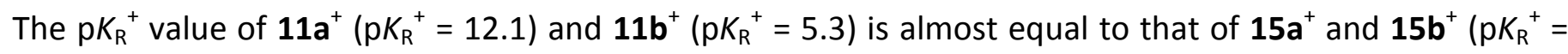
$3.4),{ }^{10}$ in spite of the existence of two phenyl substituents as end groups with allylic cationic system. As expected by destabilization by the electron-withdrawing substituents as the end groups, bisfluorophenyl substituted cation $11 \mathrm{c}^{+}\left(\mathrm{p} K_{\mathrm{R}}^{+}=11.7\right)$, bisnitrophenyl substituted cation $11 \mathbf{d}^{+}\left(\mathrm{p} K_{\mathrm{R}}^{+}=8.7\right)$, fluorenylidene substituted cation $14^{+}\left(\mathrm{pK}_{\mathrm{R}}^{+}=9.3\right)$ is less stable than $11 \mathrm{a}^{+}$, as similar to the results on the cations between $5 \mathrm{a}^{+}$ and $15 \mathrm{a}^{+}$owing to the destabilization by the electron-withdrawing groups.

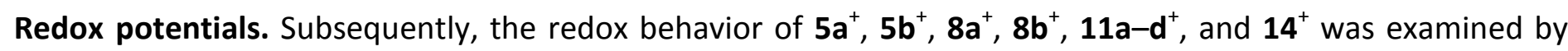
cyclic voltammetry (CV) and differential pulse voltammetry (DPV). The first and second redox potentials (in volts vs $\mathrm{Ag} / \mathrm{AgNO}_{3}$ ) of these cations are summarized in Table 2. The redox potentials observed at higher potentials are summarized in the Supporting Information. The first and second reduction waves of $\mathbf{5 a}^{+}, \mathbf{8} \mathbf{a}^{+}$, $\mathbf{1 1 a}^{+}$, and $\mathbf{1 1 \mathbf { d } ^ { + }}$ are shown in Figures 3 and 4 and those of the others are summarized in the Supporting Information.

As it is shown in Table 2, the characteristic feature of the cations with electron-accepting nitrophenyl groups was small $E_{1}^{\text {red }}-E_{2}^{\text {red }}$ values, compared with those without the electron-withdrawing group. Indeed, $\mathrm{5a}^{+}$showed a reversible two-step, two-electron reduction wave at $-0.59 \mathrm{~V}$ and $-0.94 \mathrm{~V}$ on $\mathrm{CV}$ due to the formation of a radical and an anionic species. The first reduction potentials of $\mathbf{5} \mathbf{a}^{+}$are slightly less negative compared with that of $\mathbf{1 5 \mathbf { a } ^ { + }}$; this indicates the electrochemical destabilization of the methyl cation by the 4nitro substituent as similar to the results on the $\mathrm{pK}_{\mathrm{R}}^{+}$measurements. The less negative second reduction potential of $5 \mathrm{a}^{+}$by $0.70 \mathrm{~V}$, compared with that of $15 \mathrm{a}^{+}$, corresponds to the stabilization of anionic state by the 4-nitro substituent. The potential difference between the first and the second reduction waves $(0.35 \mathrm{~V})$ is significantly small as compared with that of $15 \mathrm{a}^{+}(0.86 \mathrm{~V})$. These results should correspond to the characteristic features of the $\mathrm{C}-\mathrm{C}$ hybrid structure. The electrochemical oxidation of $\mathbf{5 a}^{+}$showed a reversible 
wave at $0.94 \mathrm{~V}$ on $\mathrm{CV}$, due to the oxidation of an azulene ring to give a dication radical. The oxidation potential is almost equal to that of $15 \mathrm{a}^{+}\left(E_{1}{ }^{\text {ox }}=0.88 \mathrm{~V}\right) .^{10}$

The first reduction potential of bis(3-methoxycarbonyl) derivative $\mathbf{5 b}^{+}$is slightly less negative compared with that of $5 \mathbf{a}^{+}$, as similar to the results on those of cations $15 \mathbf{a}^{+}$and $15 \mathbf{b}^{+}\left(E_{1}{ }^{\text {red }}=-0.49 \mathrm{~V}\right) .^{10}$ The oxidation of $\mathbf{5 b}^{+}$also exhibited a wave at $1.38 \mathrm{~V}$ on $\mathrm{CV}$ ascribed to the oxidation of an azulene ring to generate a dicationic species, but without reversibility. The reduction of $\mathbf{8} \mathbf{a}^{+}$and $\mathbf{8} \mathbf{b}^{+}$showed same tendencies for $\mathbf{5} \mathbf{a}^{+}$and $\mathbf{5} \mathbf{b}^{+}$ except for the slightly more negative reduction potentials as expected by the stabilization by the thienylene insertion.

The electrochemical reduction of $11 \mathrm{a}^{+}$showed two-step, two-electron reduction wave at $-0.67 \mathrm{~V}$ and $-1.48 \mathrm{~V}$ on $\mathrm{CV}$ due to the formation of a radical and an anionic species. The reduction potentials of $\mathbf{1 1 \mathbf { b } ^ { + }}$ are slightly less negative compared with those of $11 \mathbf{a}^{+}$; this indicates the electrochemical destabilization of the methyl cations by the methoxycarbonyl substituents as similar to the results on $\mathbf{5} \mathbf{a}^{+}$and $\mathbf{5} \mathbf{b}^{+}$.

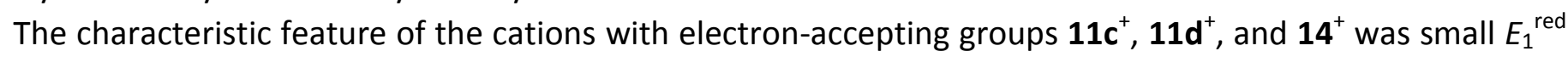
$-E_{2}{ }^{\text {red }}$ values, compared with those without the electron-withdrawing group, although difluoro derivative $11 c^{+}$ showed almost same value with that of $11 \mathrm{a}^{+}$. The less negative second reduction potential of $11 \mathbf{d}^{+}$by $0.62 \mathrm{~V}$,

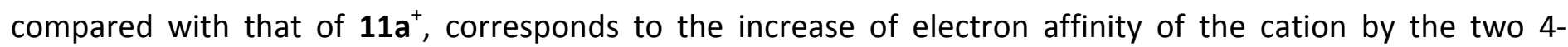
nitrophenyl substituents. The high reversibility of the CV waves and small potential difference $(0.36 \mathrm{~V})$ of $11 \mathbf{d}^{+}$ indicate the characteristic features of the presumed $\mathrm{C}-\mathrm{C}$ hybrid structure. The electrochemical oxidation of

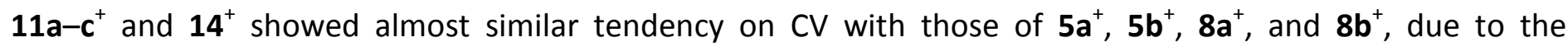
oxidation of an azulene ring to give a dication radical.

(a)

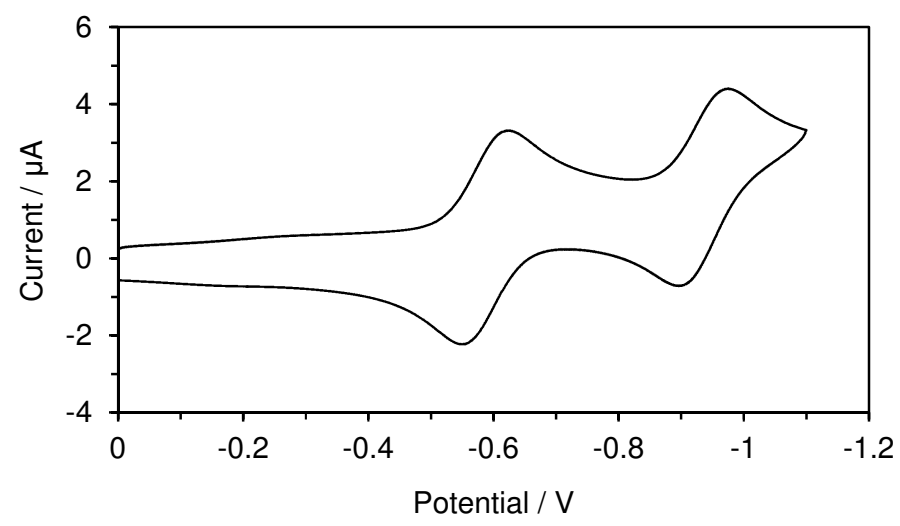

(b)

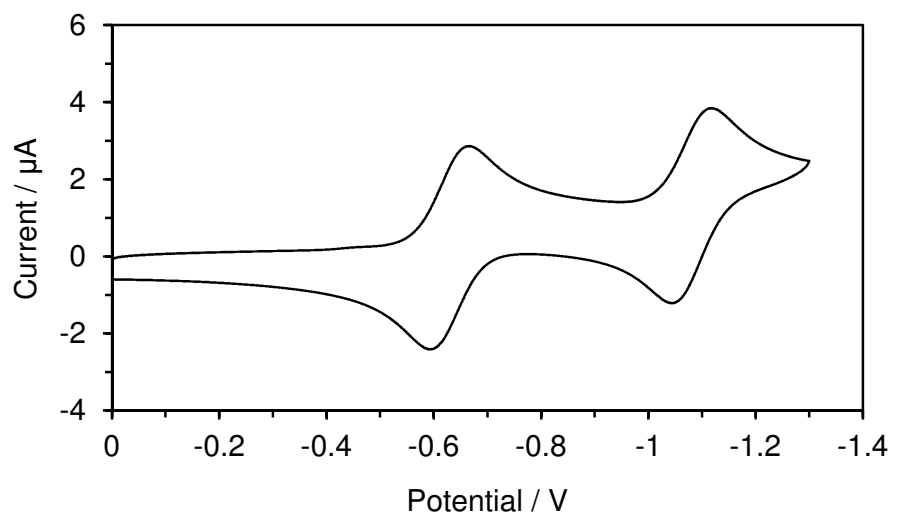

Figure 3. Cyclic voltammograms of (a) reduction of $5 a^{+}(1 \mathrm{mM})$ and $(\mathrm{b}) \mathbf{8 a ^ { + }}(1 \mathrm{mM})$ in benzonitrile containing $\mathrm{Et}_{4} \mathrm{NClO}_{4}(0.1 \mathrm{M})$ as a supporting electrolyte; scan rate, $100 \mathrm{mV} \mathrm{s}^{-1}$. 
(a)

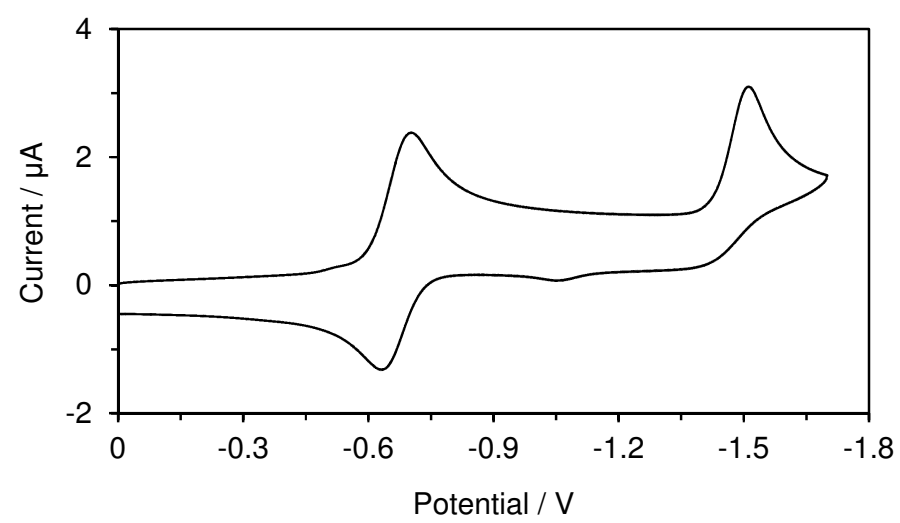

(b)

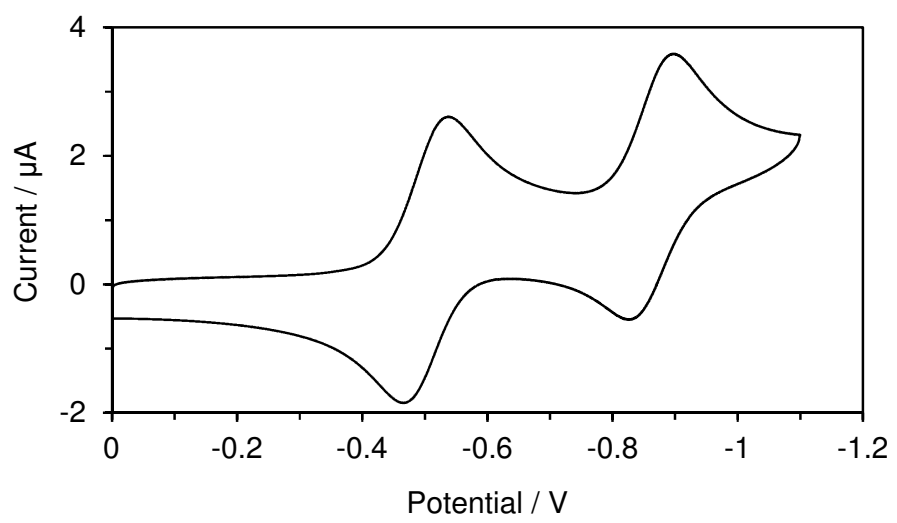

Figure 4. Cyclic voltammograms of (a) reduction of $11 \mathrm{a}^{+}(1 \mathrm{mM})$ and $(\mathrm{b}) \mathbf{1 1 \mathbf { d } ^ { + }}(1 \mathrm{mM})$ in benzonitrile containing $\mathrm{Et}_{4} \mathrm{NClO}_{4}(0.1 \mathrm{M})$ as a supporting electrolyte; scan rate, $100 \mathrm{mV} \mathrm{s}^{-1}$.

Electrochromic analysis. Visible spectra of the two-types of $\mathrm{C}-\mathrm{C}$ hybrids were monitored to clarify the color changes under the electrochemical reduction conditions. A constant-current reduction was applied to the solutions of $\mathbf{5 a}^{+}, \mathbf{5} \mathbf{b}^{+}, \mathbf{8} \mathbf{a}^{+}, \mathbf{8} \mathbf{b}^{+}, \mathbf{1 1 a}-\mathbf{d}^{+}$, and $14^{+}$with a platinum mesh for working and a wire counter electrodes.

When the visible spectra of $5 \mathrm{a}^{+}$were monitored in benzonitrile containing $\mathrm{Et}_{4} \mathrm{NClO}_{4}(0.1 \mathrm{M})$ as a supporting electrolyte at room temperature under the electrochemical reduction conditions, the strong absorption band at $710 \mathrm{~nm}$ in the visible region was gradually decreased along with the development of new absorption band at around $590 \mathrm{~nm}$ (Figure 5). Further reduction developed a broad absorption band around the new absorption band $(525 \mathrm{~nm})$. Thus, the spectral changes should correspond to the two-step, two-electron reduction wave on $\mathrm{CV}$ arising from the formation of a radical and an anionic species. The color of the solution of $\mathbf{5 a}^{+}$gradually changed from dark green to deep purple during the electrochemical reduction. Absence of a clear isosbestic point during the electrochemical reduction suggests some decomposition of the reduced species of $\mathbf{5 a}^{+}$under the spectrophotometric measurements. Indeed, reverse oxidation of the purple-colored solution did not regenerate the spectrum of $\mathbf{5 a}^{+}$(regeneration $33 \%$ ), completely, although the CV analysis revealed good reversibility in the two step reduction. Instability of the reduced species might be attributable to the reduction of nitro function under the electrochemical conditions.

Similar two-step spectral changes were observed during the electrochemical reduction of $\mathbf{5 b}^{+}$(see the Supporting Information). The dark green color of the solution of $\mathbf{5 b}^{+}$also changed to purple one during the electrochemical reduction. Reverse oxidation of the purple-colored solution regenerated the UV-vis spectra of the deep colored $\mathbf{5} \mathbf{b}^{+}$in $30 \%$. Therefore, the two step color changes of $\mathbf{5} \mathbf{a}^{+}$and $\mathbf{5} \mathbf{b}^{+}$should be concluded to the formation of presumed radical and anionic species with some instability under the electrochemical conditions. We also tried electrochemical reduction of $\mathbf{8} \mathrm{a}^{+}$and $\mathbf{8} \mathbf{b}^{+}$under visible spectral monitoring (Figure 5 for $\mathbf{8} \mathrm{a}^{+}$and see the Supporting Information for $\mathbf{8 b}^{+}$). We anticipated that the formation of the thienoquinoid forms during the redox reaction might improve their reversibility. In these cases, however, we also observed reversibility for the reduction of $\mathbf{8} \mathbf{a}^{+}$(regeneration $24 \%$ ) and $\mathbf{8} \mathbf{b}^{+}$(regeneration $51 \%$ ), insufficiently. 
(a)

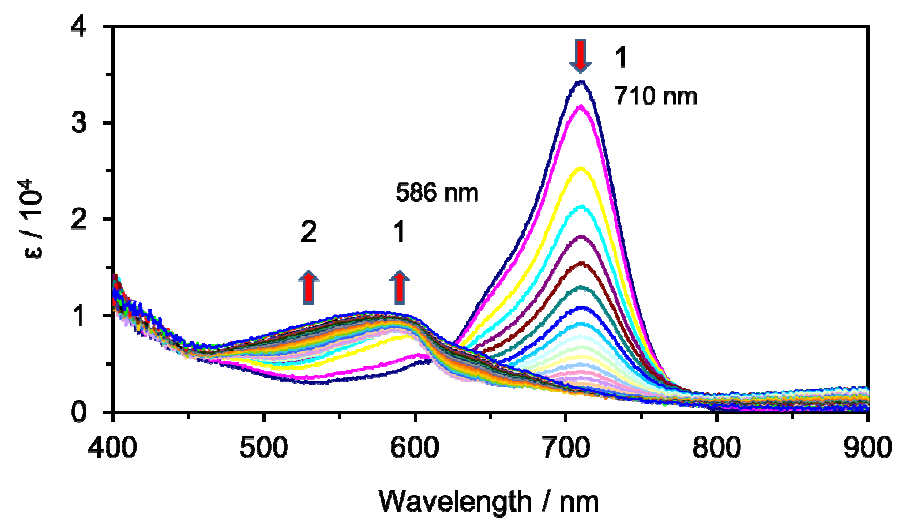

(b)

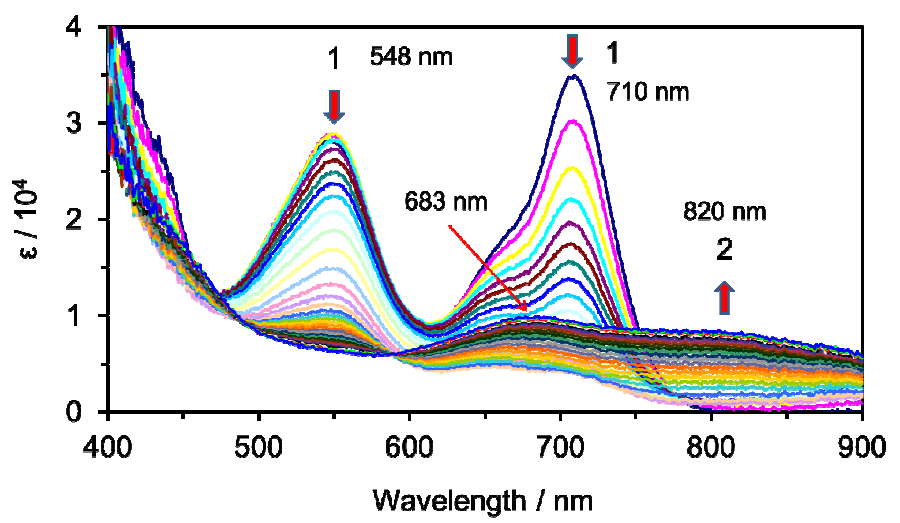

Figure 5. Continuous change in the visible spectrum of (a) cation $\mathbf{5 a}^{+}$: constant-current electrochemical reduction $(70 \mathrm{uA})$ in benzonitrile $\left(2.5 \times 10^{-4} \mathrm{M}, 2 \mathrm{~mL}\right)$ and (b) cation $8 \mathrm{a}^{+}$: constant-current electrochemical reduction $(70 \mathrm{uA})$ in benzonitrile $\left(2.6 \times 10^{-4} \mathrm{M}, 2 \mathrm{~mL}\right)$ containing $\mathrm{Et}_{4} \mathrm{NClO}_{4}(0.1 \mathrm{M})$ at 1 min intervals.

(a)

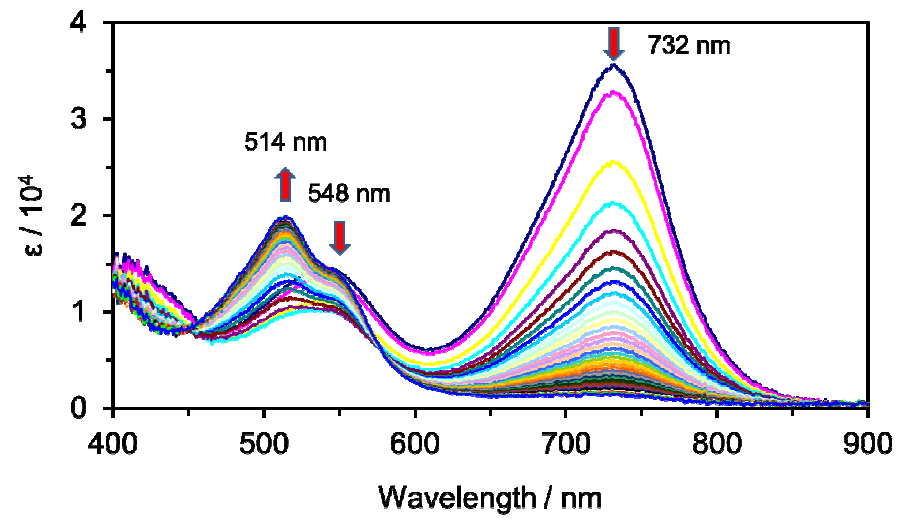

(b)

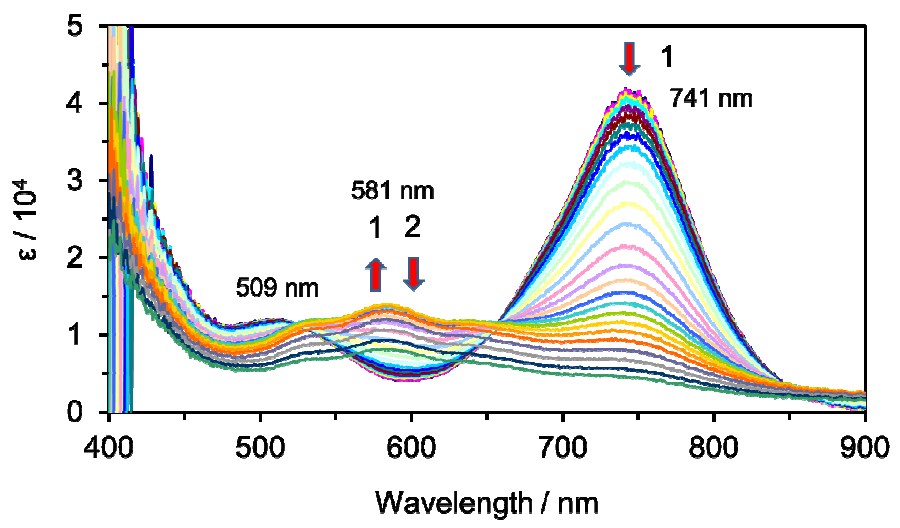

Figure 6. Continuous change in the visible spectrum of (a) cation $11 a^{+}$: constant-current electrochemical reduction $(70 \mathrm{uA})$ in benzonitrile $\left(2.9 \times 10^{-4} \mathrm{M}, 2 \mathrm{~mL}\right)$ and (b) cation $11 \mathbf{d}^{+}$: constant-current electrochemical reduction $(30 \mathrm{uA})$ in benzonitrile $\left(4.1 \times 10^{-4} \mathrm{M}, 2 \mathrm{~mL}\right)$ containing $\mathrm{Et}_{4} \mathrm{NClO}_{4}(0.1 \mathrm{M})$ at 1 min intervals.

The strong absorption band of $11 \mathrm{a}^{+}$at $732 \mathrm{~nm}$ in the visible region was gradually decreased during the electrochemical reduction (Figure 6). Absence of a clear isosbestic point suggests some instability of the reduced species of $\mathbf{1 1 \mathbf { a } ^ { + }}$ under the spectrophotometric measurements. The electrochemical reduction of $\mathbf{1 1 b}^{+}$ also caused gradual color change of the solution from purple to pink (see the Supporting Information). Reverse oxidation of the reduced solution did not regenerate the spectrum of $\mathbf{1 1 a}^{+}$(regeneration $57 \%$ ) and $\mathbf{1 1 \mathbf { b } ^ { + }}$ (regeneration 45\%), completely.

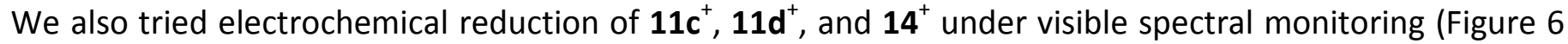
for $\mathbf{1 1} \mathbf{d}^{+}$and see the Supporting Information for $11 \mathrm{c}^{+}$and $1 \mathbf{4}^{+}$). We anticipated that the electron-withdrawing nature of the end groups should improve the two-step color changes. The purple colored solution of $11 \mathbf{c}^{+}$ exhibits color change to pink one under the reduction conditions. The spectral features of $\mathbf{1 1} \mathbf{c}^{+}$under the electrochemical reduction resembled to those of $11 \mathbf{a}^{+}$and the reversibility was still low in this case

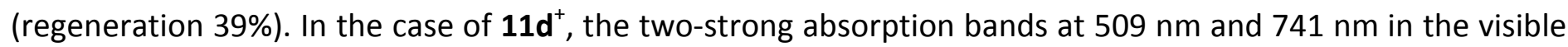


region was gradually decreased along with the development of new absorption band at around $580 \mathrm{~nm}$ under the electrochemical reduction conditions (Figure 6). Further reduction developed a broad absorption band spread into the wide range of visible region. As expected, the spectral changes should correspond to a twostep color changes arising from the formation of a radical and an anionic species. Absence of a clear isosbestic point during the electrochemical reduction suggests some decomposition during the two-step reduction of $\mathbf{1 1 d}^{+}$under the spectrophotometric measurements. Reverse oxidation of the green-colored solution did not regenerate the spectrum of $\mathbf{1 1} \mathbf{d}^{+}$(regeneration $48 \%$ ), completely, although the CV analysis revealed good reversibility in the two step reduction. Similarly, color change was observed during the electrochemical reduction of $\mathbf{1 4}^{+}$(see the Supporting Information), but still low reversibility (regeneration 61\%).

\section{Conclusions}

The scope of the creation of stabilized polyelectrochromic materials containing azulene skeletons has been demonstrated by the two-types of the $C-C$ hybrid structure $5 a^{+}, 5 b^{+}, \mathbf{8} a^{+}, \mathbf{8} b^{+}, \mathbf{1 1 a}-d^{+}$, and $14^{+}$constructed by the cyanine units with push and pull electronic nature illustrated by the general structures in Schemes 3 and 5 with oxidation levels varying from $1+$ to $1-$. The system is consisted with the polymethine dye containing the moieties of either one or two polymethine dyes as end groups. ${ }^{8-9}$ The two-types of $\mathrm{C}-\mathrm{C}$ hybrids exhibit the presumed reversible two-step, two-electron redox properties on CV in the cases of the hybrids with nitro function. Two-step color changes presumed by their $\mathrm{C}-\mathrm{C}$ hybrid structure were revealed by their electrochemical reduction, although the reversibility of the redox reaction on electrochromic measurements was still low for all cases. Thus, the electrochemical behavior was not ideal for the presumed $\mathrm{C}-\mathrm{C}$ hybrid, since the stabilization in the anionic state is insufficient by the introduction of nitro substituents, but the use of di(1azulenyl)methylium units as a stabilized redox active polymethine units would be highly effective in the point of their high stability and their strong absorption in visible region with their redox activity. Preparations of the other-types of hybrid structures by using the di(1-azulenyl)methylium units as cyanine end groups are now in progress in our groups.

\section{Experimental Section}

General. Melting points were determined on a Stuart Scientific melting point apparatus SMP3 or a Yanagimoto micro melting point apparatus MP-S3 and are uncorrected. Mass spectra were obtained with a Bruker APEX II instrument under ESI conditions or a Bruker Daltonics autoflex III TOF/TOF instrument under MALDI conditions. IR and UV/Vis spectra were measured on a BIO-RAD FTS-30 or a JUSCO FT/IR-6100 infrared spectrophotometer, and a JASCO V-670 spectrophotometer, respectively. ${ }^{1} \mathrm{H}$ NMR spectra $\left({ }^{13} \mathrm{C}\right.$ NMR spectra) were recorded on a JEOL ECA500 or a JEOL ECZR500 spectrometer at $500 \mathrm{MHz}(125 \mathrm{MHz})$. The peak assignment of ${ }^{1} \mathrm{H}$ and ${ }^{13} \mathrm{C}$ NMR spectra reported was accomplished by $\mathrm{HH}$ COSY, NOE, DEPT, HMQC, and/or $\mathrm{HMBC}$ experiments. ${ }^{1} \mathrm{H}$ chemical shifts in $\mathrm{CDCl}_{3}$ are reported in parts per million (ppm) downfield from internal tetramethylsilane. ${ }^{13} \mathrm{C}$ chemical shifts in $\mathrm{CDCl}_{3}$ are referred by the solvent signals as 77.0 ppm. Chemical shifts in $\left(\mathrm{CDCl}_{2}\right)_{2}$ are referred by the solvent signals as $5.90 \mathrm{ppm}$ in ${ }^{1} \mathrm{H}$ and $74.2 \mathrm{ppm}$ in ${ }^{13} \mathrm{C}$. Gel permeation chromatography (GPC) was performed on a JAI LC-9110 NEXT with JAIGEL-1H-3H using $\mathrm{CHCl}_{3}$ as an eluent. Column chromatography on silica gel and $\mathrm{Al}_{2} \mathrm{O}_{3}$ was performed using MERCK Silica gel 60 Art. 7734 or Cica 
Silica gel 60 Art. 37564 and MERCK Aluminium oxide 90 Art. 1097, respectively. Elemental analyses were performed at the Instrumental Analysis Center of Hirosaki University.

Bis(3,6-di-tert-butyl-1-azulenyl)(4-nitrophenyl)methane (4a). A mixture of 4-nitrobenzaldehyde (2) (151 mg, $1.00 \mathrm{mmol}$ ) and 1,6-di-tert-butylazulene (3a) $(481 \mathrm{mg}, 2.00 \mathrm{mmol})$ in acetic acid (12 mL) was stirred at room temperature for $24 \mathrm{~h}$ under an $\mathrm{Ar}$ atmosphere. The reaction mixture was poured into water and extracted with $\mathrm{CH}_{2} \mathrm{Cl}_{2}$. The organic layer was washed with $5 \% \mathrm{NaHCO}_{3}$ and water, dried over $\mathrm{MgSO}_{4}$, and concentrated under reduced pressure. The residue was purified by column chromatography on silica gel with $\mathrm{CH}_{2} \mathrm{Cl}_{2}$ and GPC with $\mathrm{CHCl}_{3}$ to afford bis(3,6-di-tert-butyl-1-azulenyl)(4-nitrophenyl)methane (4a) (464 mg, 76\%). green crystals. mp 201.0-203.2 ${ }^{\circ} \mathrm{C}(\mathrm{MeOH})$. IR (KBr disk, $\left.v_{\max } \mathrm{cm}^{-1}\right)$ : 2964 (s), 2905 (m), 2869 (m), 1603 (w), 1576 (s), 1519 (s), 1489 (w), 1479 (w), 1458 (w), 1422 (w), 1390 (w), 1363 (m), 1344 (s), 1245 (m), 1228 (m), 1197 (w), 1105 (w), 1070 (w), 1012 (w), $987(w), 852(w), 835$ (m), $726(w), 672(w), 596(w), 535(w)$. UV-vis (CH $\mathrm{Cl}_{2}$, $\left.\lambda_{\max }, \mathrm{nm}\right): 243$ (log $\varepsilon$ 4.45), 289 sh (4.80), 300 (4.80), 343 sh (3.97), 355 (4.02), 373 (3.94), 560 sh (2.68), 607 (2.82), $669 \mathrm{sh}$ (2.70), $744 \mathrm{sh}$ (2.19). ${ }^{1} \mathrm{H}$ NMR (500 MHz, CDCl $): \delta_{\mathrm{H}} 8.59$ (d, 2H, J $\left.10.7 \mathrm{~Hz}, 4-\mathrm{H}\right), 8.12(\mathrm{~d}, 2 \mathrm{H}, J 10.6$ $\mathrm{Hz}, 8-\mathrm{H}), 8.08\left(\mathrm{~d}, 2 \mathrm{H}, J 8.7 \mathrm{~Hz}, 3^{\prime}, 5^{\prime}-\mathrm{H}\right), 7.32(\mathrm{~s}, 2 \mathrm{H}, 2-\mathrm{H}), 7.26\left(\mathrm{~d}, 2 \mathrm{H}, J 8.7 \mathrm{~Hz}, 2^{\prime}, 6^{\prime}-\mathrm{H}\right), 7.21$ (dd, 2H, J 10.7, 1.8 $\mathrm{Hz}, 5-\mathrm{H}), 7.10(\mathrm{dd}, 2 \mathrm{H}, J 10.7,1.8 \mathrm{~Hz}, 7-\mathrm{H}), 6.71(\mathrm{~s}, 1 \mathrm{H}, \mathrm{CH}), 1.50(\mathrm{~s}, 18 \mathrm{H}, 3-t-\mathrm{Bu}), 1.41(\mathrm{~s}, 18 \mathrm{H}, 6-t-\mathrm{Bu}) .{ }^{13} \mathrm{C} \mathrm{NMR}$ $\left(125 \mathrm{MHz}, \mathrm{CDCl}_{3}\right.$ ): $\delta_{\mathrm{C}} 160.9$ (C-6), 154.2 (C-1'), 146.1 (C-4'), 138.0 (C-3), 135.8 (C-2), 134.9 (C-4), 134.7 (C-8a), 134.2 (C-3a), 132.0 (C-8), 129.5 (C-2',6'), 128.5 (C-1), 123.5 (C-3',5'), 119.6 (C-7), 118.8 (C-5), 42.0 (CH), 38.3 (s, 6-t-Bu), 33.2 (s, 3-t-Bu), 32.2 (q, 3-t-Bu), 31.8 (q, 6-t-Bu). HRMS (ESI): calcd for $\mathrm{C}_{43} \mathrm{H}_{51} \mathrm{NO}_{2}+\mathrm{Na}^{+} 636.3812$, found 636.3810. Anal. calcd for $\mathrm{C}_{43} \mathrm{H}_{51} \mathrm{NO}_{2}$ (613.8705): $\mathrm{C}, 84.13 ; \mathrm{H}, 8.37 ; \mathrm{N}, 2.28$. Found: $\mathrm{C}, 84.05 ; \mathrm{H}, 8.37 ; \mathrm{N}$, 2.38 .

Bis(3-methoxycarbonyl-1-azulenyl)(4-nitrophenyl)methane (4b). A mixture of 4-nitrobenzaldehyde (2) (452 $\mathrm{mg}, 2.99 \mathrm{mmol}$ ) and methyl azulene-1-carboxylate (3b) $(402 \mathrm{mg}, 2.16 \mathrm{mmol})$ in acetic acid (12 $\mathrm{mL})$ was stirred at $90{ }^{\circ} \mathrm{C}$ for 2 days under an Ar atmosphere. The reaction mixture was poured into water and extracted with $\mathrm{CH}_{2} \mathrm{Cl}_{2}$. The organic layer was washed with $5 \% \mathrm{NaHCO}_{3}$ and water, dried over $\mathrm{MgSO}_{4}$, and concentrated under reduced pressure. The residue was purified by column chromatography on silica gel with $\mathrm{CH}_{2} \mathrm{Cl}_{2}$ and recrystallization from hexane to afford bis(3-methoxycarbonyl-1-azulenyl)(4-nitrophenyl)methane (4b) (461

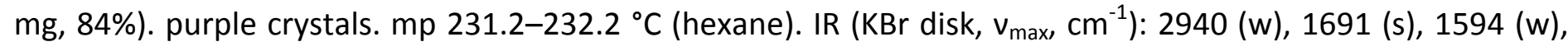
$1574(w), 1536(w), 1519(m), 1485(w), 1457(m), 1442(m), 1418(s), 1400(w), 1367(w), 1346(m), 1310(w)$, $1210(\mathrm{~s}), 1150$ (w), 1125 (w), $1103(w), 1043(\mathrm{~m}), 948(w), 866(w), 855(w), 813(w), 777(\mathrm{~m}), 741(w), 561(w)$. UV-vis $\left(\mathrm{CH}_{2} \mathrm{Cl}_{2}, \lambda_{\max }, \mathrm{nm}\right): 238$ (log $\varepsilon$ 4.75), 260 (4.57), 288 sh (4.91), 294 (4.94), 306 (4.97), 370 (4.28), 383 (4.30), $516 \mathrm{sh}$ (2.60), 554 (2.72), $597 \mathrm{sh}$ (2.63), $659 \mathrm{sh}$ (2.13). ${ }^{1} \mathrm{H} \mathrm{NMR}\left(500 \mathrm{MHz}, \mathrm{CDCl}_{3}\right): \delta_{\mathrm{H}} 9.70(\mathrm{~d}, 2 \mathrm{H}, J 9.7 \mathrm{~Hz}$, 4-H), $8.31(\mathrm{~d}, 2 \mathrm{H}, J 9.6 \mathrm{~Hz}, 8-\mathrm{H}), 8.16\left(\mathrm{~d}, 2 \mathrm{H}, J 8.6 \mathrm{~Hz}, 3^{\prime}, 5^{\prime}-\mathrm{H}\right), 7.81(\mathrm{dd}, 2 \mathrm{H}, J$ 10.0, $9.8 \mathrm{~Hz}, 6-\mathrm{H}), 7.78(\mathrm{~s}, 2 \mathrm{H}, 2-\mathrm{H})$, 7.57 (dd, 2H, J 10.0, 9.7 Hz, 5-H), 7.35 (dd, 2H, J 9.8, 9.6 Hz, 7-H), 7.34 (d, 2H, J $\left.8.6 \mathrm{~Hz}, 2^{\prime}, 6^{\prime}-\mathrm{H}\right), 6.71(\mathrm{~s}, 1 \mathrm{H}, \mathrm{CH})$, $3.86\left(\mathrm{~s}, 6 \mathrm{H}, 3-\mathrm{CO}_{2} \mathrm{Me}\right) .{ }^{13} \mathrm{C} \mathrm{NMR}\left(125 \mathrm{MHz}, \mathrm{CDCl}_{3}\right): \delta_{\mathrm{C}} 165.5\left(\mathrm{~s}, 3-\mathrm{CO}_{2} \mathrm{Me}\right), 151.6\left(\mathrm{C}-1^{\prime}\right), 146.7\left(\mathrm{C}-4^{\prime}\right), 141.7(\mathrm{C}-$ 3a), 140.6 (C-2), 139.9 (C-8a), 139.6 (C-6), 138.4 (C-4), 135.0 (C-8), 129.8 (C-1), 129.6 (C-2',6'), 128.2 (C-5), 126.6 (C-7), 124.0 (C-3',5'), 115.4 (C-3), 51.1 (q, 3- $\left.\mathrm{CO}_{2} \mathrm{Me}\right), 42.4$ (CH). HRMS (ESI): calcd for $\mathrm{C}_{31} \mathrm{H}_{23} \mathrm{NO}_{6}+\mathrm{Na}^{+}$ 528.1418, found 528.1415. Anal. calcd for $\mathrm{C}_{31} \mathrm{H}_{23} \mathrm{NO}_{6}$ (505.5174): C, 73.65; $\mathrm{H}, 4.59 ; \mathrm{N}, 2.77$. Found: $\mathrm{C}, 73.61 ; \mathrm{H}$, $4.71 ; \mathrm{N}, 2.88$.

Bis(3,6-di-tert-butyl-1-azulenyl)(4-nitrophenyl)methylium hexafluorophosphate $\left(5 \mathrm{a}^{+} \mathrm{PF}_{6}{ }^{-}\right)$. To a solution of bis(3,6-di-tert-butyl-1-azulenyl)(4-nitrophenyl)methane (4a) (201 $\mathrm{mg}, 0.327 \mathrm{mmol}$ ) in $\mathrm{CH}_{2} \mathrm{Cl}_{2}(20 \mathrm{~mL})$ was added DDQ $(87 \mathrm{mg}, 0.38 \mathrm{mmol})$ at room temperature. After the solution was stirred at the same temperature for $30 \mathrm{~min}, 60 \% \mathrm{HPF}_{6}(2 \mathrm{~mL})$ and water $(20 \mathrm{~mL})$ were added to the mixture. After stirring the mixture for an additional $10 \mathrm{~min}$, the resulting suspension was filtered with suction. The organic layer was separated, washed 
with water, dried over $\mathrm{MgSO}_{4}$, and concentrated under reduced pressure. The residue was crystallized from hexane to give bis(3,6-di-tert-butyl-1-azulenyl)(4-nitrophenyl)methylium hexafluorophosphate $\left(5^{+} \mathrm{P}^{+} \mathrm{PF}_{6}{ }^{-}\right)(143$ $\mathrm{mg}, 58 \%)$. deep green crystals. $\mathrm{mp} 272.8-275.1^{\circ} \mathrm{C}\left(\mathrm{CH}_{3} \mathrm{CN} /\right.$ hexane). IR ( $\mathrm{KBr}$ disk, $\left.\mathrm{v}_{\text {max }} \mathrm{cm}^{-1}\right): 2964(\mathrm{~m}), 2898$ (w), $2872(w), 1578(w), 1542(w), 1524(m), 1477(s), 1417(m), 1400(w), 1367(m), 1345(w), 1333(s), 1311$ (s), $1283(w), 1244(\mathrm{~s}), 1205(\mathrm{w}), 1179(\mathrm{~m}), 1120(\mathrm{~m}), 1083(\mathrm{~m}), 1047(\mathrm{w}), 1026(\mathrm{w}), 952(\mathrm{w}), 869(\mathrm{~m}), 841(\mathrm{~s})$, $810(\mathrm{~m}), 739$ (w), 707 (w), $688(w), 614(w), 558(\mathrm{~m}), 505$ (w). UV-vis $\left(\mathrm{CH}_{3} \mathrm{CN}, \lambda_{\max }, \mathrm{nm}\right): 196$ (log ع 4.68), 237 (4.75), 252 (4.75), 268 sh (4.69), 333 (4.66), 350 (4.53), 480 sh (3.78), 652 sh (4.48), 704 (4.79). ${ }^{1} \mathrm{H}$ NMR (500 $\mathrm{MHz} \mathrm{CDCl}_{3}$ ): $\delta_{\mathrm{H}} 9.04(\mathrm{~d}, 2 \mathrm{H}, J 11.0 \mathrm{~Hz}, 4-\mathrm{H}), 8.42\left(\mathrm{~d}, 2 \mathrm{H}, J 8.3 \mathrm{~Hz}, 3^{\prime}, 5^{\prime}-\mathrm{H}\right), 8.19$ (dd, 2H, J 11.0, $\left.1.8 \mathrm{~Hz}, 5-\mathrm{H}\right), 7.90$ (d, 2H, J $10.7 \mathrm{~Hz}, 8-\mathrm{H}), 7.71$ (dd, 2H, J 10.7, $1.8 \mathrm{~Hz}, 7-\mathrm{H}), 7.67$ (d, 2H, J $\left.8.3 \mathrm{~Hz}, 2^{\prime}, 6^{\prime}-\mathrm{H}\right), 7.42(\mathrm{~s}, 2 \mathrm{H}, 2-\mathrm{H}), 1.56(\mathrm{~s}$, $18 \mathrm{H}, 3-t-\mathrm{Bu}), 1.45$ (s, 18H, 6-t-Bu). ${ }^{13} \mathrm{C} \mathrm{NMR}\left(125 \mathrm{MHz}, \mathrm{CDCl}_{3}\right)$ : $\delta_{\mathrm{C}} 169.6$ (C-6), $156.2\left(\mathrm{C}^{+}\right), 149.8$ (C-3a), 149.7 (C$1^{\prime}$ or C-4'), 148.5 (C-8a), 148.3 (C-3), 147.8 (C-1' or C-4'), 141.9 (C-2), 139.4 (C-4), 138.8 (C-8), 134.8 (C-2',6'), 133.2 (C-5), 133.0 (C-7), 131.8 (C-1), 123.8 (C-3', 5'), 39.5 (s, 6-t-Bu), 33.3 (s, 3-t-Bu), 31.5 (q, 6-t-Bu), 31.0 (q, 3$t$-Bu). ${ }^{1} \mathrm{H}$ NMR $\left(500 \mathrm{MHz},\left(\mathrm{CDCl}_{2}\right)_{2}, 80^{\circ} \mathrm{C}\right): \delta_{\mathrm{H}} 8.97(\mathrm{~d}, 2 \mathrm{H}, \mathrm{J} 11.0 \mathrm{~Hz}, 4-\mathrm{H}), 8.36\left(\mathrm{~d}, 2 \mathrm{H}, J 8.6 \mathrm{~Hz}, 3^{\prime}, 5^{\prime}-\mathrm{H}\right), 8.11(\mathrm{dd}$, $2 \mathrm{H}, J 11.0,1.7 \mathrm{~Hz}, 5-\mathrm{H}), 7.78(\mathrm{~d}, 2 \mathrm{H}, J 10.7 \mathrm{~Hz}, 8-\mathrm{H}), 7.60$ (dd, 2H, J 10.7, 1.7 Hz, 7-H), $7.60\left(\mathrm{~d}, 2 \mathrm{H}, J 8.6 \mathrm{~Hz}, 2^{\prime}, 6^{\prime}-\right.$ $\mathrm{H}), 7.42(\mathrm{~s}, 2 \mathrm{H}, 2-\mathrm{H}), 1.52(\mathrm{~s}, 18 \mathrm{H}, 3-t-\mathrm{Bu}), 1.41(\mathrm{~s}, 18 \mathrm{H}, 6-t-\mathrm{Bu}) .{ }^{13} \mathrm{C} \mathrm{NMR}\left(125 \mathrm{MHz},\left(\mathrm{CDCl}_{2}\right)_{2}, 80{ }^{\circ} \mathrm{C}\right): \delta_{\mathrm{C}} 170.3(\mathrm{C}-$ 6), $156.7\left(\mathrm{C}^{+}\right), 150.3$ (C-1' or C-4'), 150.2 (C-3a), 149.1 (C-3), 148.8 (C-8a), 147.7 (C-1' or C-4'), 142.5 (C-2), 139.7 (C-4), 138.7 (C-8), 134.9 (C-2',6'), 133.4 (C-5), 132.9 (C-7), 132.1 (C-1), 124.1 (C-3', 5'), 39.7 (s, 6-t-Bu), 33.6 (s, 3$t-\mathrm{Bu}), 31.7$ (q, 6-t-Bu), 31.3 (q, 3-t-Bu). HRMS (ESI): calcd for $\mathrm{C}_{43} \mathrm{H}_{50} \mathrm{NO}_{2}{ }^{+} 612.3836$, found 612.3834. Anal. calcd for $\mathrm{C}_{43} \mathrm{H}_{50} \mathrm{~F}_{6} \mathrm{NO}_{2} \mathrm{P}$ (757.8268): C, 68.15; $\mathrm{H}, 6.65 ; \mathrm{N}, 1.85$. Found: $\mathrm{C}, 67.73 ; \mathrm{H}, 6.44 ; \mathrm{N}, 2.07$.

Bis(3-methoxycarbonyl-1-azulenyl)(4-nitrophenyl)methylium hexafluorophosphate $\left(\mathbf{5 b}^{+} \mathbf{P F}_{6}{ }^{-}\right)$. To a solution of bis(3-methoxycarbonyl-1-azulenyl)(4-nitrophenyl)methane (4b) (200 mg, $0.396 \mathrm{mmol}$ ) in $\mathrm{CH}_{2} \mathrm{Cl}_{2}(40 \mathrm{~mL}) \mathrm{was}$ added DDQ (109 $\mathrm{mg}, 0.480 \mathrm{mmol}$ ) at room temperature. After the solution was stirred at the same temperature for $30 \mathrm{~min}, 60 \% \mathrm{HPF}_{6}(4 \mathrm{~mL})$ and water $(40 \mathrm{~mL})$ were added to the mixture. After stirring the mixture for an additional $10 \mathrm{~min}$, the resulting suspension was filtered with suction. The organic layer was separated, washed with water, dried over $\mathrm{MgSO}_{4}$, and concentrated under reduced pressure. The residue was dissolved in a small amount of $\mathrm{CH}_{2} \mathrm{Cl}_{2}$ and then poured into $\mathrm{Et}_{2} \mathrm{O}$. The precipitated crystals were collected by filtration, washed with $\mathrm{Et}_{2} \mathrm{O}$, and dried in vacuo to give bis(3-methoxycarbonyl-1-azulenyl)(4nitrophenyl)methylium hexafluorophosphate $\left(\mathbf{5 b}^{+} \mathrm{PF}_{6}{ }^{-}\right)(190 \mathrm{mg}, 74 \%)$. deep red crystals. $\mathrm{mp} 173.2-173.6{ }^{\circ} \mathrm{C}$ $\left(\mathrm{CH}_{2} \mathrm{Cl}_{2} / \mathrm{Et}_{2} \mathrm{O}\right)$. IR (KBr disk, $\left.v_{\max }, \mathrm{cm}^{-1}\right): 2947$ (w), 1705 (s), $1590(\mathrm{w}), 1524(\mathrm{~m}), 1474$ (s), 1452 (s), 1417 (s), 1349 (s), $1321(\mathrm{~m}), 1301(\mathrm{w}), 1260$ (w), 1240 (s), $1228(\mathrm{~s}), 1196(\mathrm{~m}), 1162$ (s), 1089 (s), $1064(\mathrm{~m}), 1011(\mathrm{w}), 913(\mathrm{w})$, $877(\mathrm{~m}), 841$ (s), $782(w), 757$ (w), $738(w), 707$ (w), 587 (w), 557 (w), $460(w)$. UV-vis $\left(\mathrm{CH}_{2} \mathrm{Cl}_{2}, \lambda_{\max }, \mathrm{nm}\right): 201$ (log $\varepsilon$ 4.53), 230 (4.64), 262 (4.61), 293 (4.55), 303 (4.55), 348 (4.26), 367 sh (4.23), 438 (3.67), 591 sh (4.18), 637 (4.63). ${ }^{1} \mathrm{H}$ NMR $\left(500 \mathrm{MHz},\left(\mathrm{CDCl}_{2}\right)_{2}, 80{ }^{\circ} \mathrm{C}\right): \delta_{\mathrm{H}} 10.01(\mathrm{~d}, 2 \mathrm{H}, J 11.1 \mathrm{~Hz}, 4-\mathrm{H}), 8.37\left(\mathrm{~d}, 2 \mathrm{H}, J 8.5 \mathrm{~Hz}, 3^{\prime}, 5^{\prime}-\mathrm{H}\right)$, 8.30-8.23 (m, 4H, 5,6-H), $8.20(\mathrm{~s}, 2 \mathrm{H}, 2-\mathrm{H}), 8.17(\mathrm{~d}, 2 \mathrm{H}, J 10.0 \mathrm{~Hz}, 8-\mathrm{H}), 7.80(\mathrm{dd}, 2 \mathrm{H}, J 10.0,9.1 \mathrm{~Hz}, 7-\mathrm{H}), 7.62$ (d, $\left.2 \mathrm{H}, J 8.5 \mathrm{~Hz}, 2^{\prime}, 6^{\prime}-\mathrm{H}\right), 3.92\left(\mathrm{~s}, 6 \mathrm{H}, 3-\mathrm{CO}_{2} \mathrm{Me}\right) .{ }^{13} \mathrm{C} \mathrm{NMR}\left(125 \mathrm{MHz},\left(\mathrm{CDCl}_{2}\right)_{2}, 80{ }^{\circ} \mathrm{C}\right): \delta_{\mathrm{C}} 165.4\left(\mathrm{C}^{+}\right), 163.8(\mathrm{~s}, 3-$ $\mathrm{CO}_{2} \mathrm{Me}$ ), 152.5 (C-3a), 151.2 (C-1' or C-4'), 149.9 (C-8a), 149.6 (C-2), 146.6 (C-1' or C-4'), 146.5 (C-6), 143.2 (C4), 141.5 (C-8), 139.5 (C-5), 138.4 (C-7), 135.7 (C-2',6'), 132.2 (C-1), 126.4 (C-3), 124.5 (C-3',5'), 52.6 (q, 3$\mathrm{CO}_{2} \mathrm{Me}$ ). HRMS (ESI): calcd for $\mathrm{C}_{31} \mathrm{H}_{22} \mathrm{NO}_{6}{ }^{+}$504.1442, found 504.1441. Anal. calcd for $\mathrm{C}_{31} \mathrm{H}_{22} \mathrm{~F}_{6} \mathrm{NO}_{6} \mathrm{P}$ (649.4737): C, 57.33; H, 3.41; N, 2.16. Found: C, 57.20; H, 3.49; N, 2.38.

Bis(3,6-di-tert-butyl-1-azulenyl)[5-(4-nitrophenyl)-2-thienyl]methane (7a). A mixture of 5-(4nitrophenyl)thiophene-2-carbaldehyde (6) $(76 \mathrm{mg}, 0.339 \mathrm{mmol}$ ) and 1,6-di-tert-butylazulene (3a) (157 mg, $0.653 \mathrm{mmol}$ ) in acetic acid $(5 \mathrm{~mL})$ was stirred at room temperature for $24 \mathrm{~h}$ under an Ar atmosphere. The reaction mixture was poured into water and extracted with $\mathrm{CH}_{2} \mathrm{Cl}_{2}$. The organic layer was washed with $5 \%$ $\mathrm{NaHCO}_{3}$ and water, dried over $\mathrm{MgSO}_{4}$, and concentrated under reduced pressure. The residue was purified by 
column chromatography on silica gel with $\mathrm{CH}_{2} \mathrm{Cl}_{2}$ and $\mathrm{GPC}$ with $\mathrm{CHCl}_{3}$ to afford bis(3,6-di-tert-butyl-1azulenyl)[5-(4-nitrophenyl)-2-thienyl]methane (7a) (140 mg, 62\%). green crystals. mp $248.5-251.1{ }^{\circ} \mathrm{C}(\mathrm{MeOH})$. IR ( $\mathrm{KBr}$ disk, $\left.v_{\max }, \mathrm{cm}^{-1}\right): 2963(\mathrm{~s}), 2895(\mathrm{~m}), 2868(\mathrm{~m}), 1592$ (s), 1577 (s), 1514 (s), $1488(\mathrm{w}), 1458(\mathrm{w}), 1424(\mathrm{w})$, $1384(w), 1363(\mathrm{~m}), 1342$ (s), $1246(w), 1226(w), 1111(w), 1060(w), 1051(w), 984(w), 949(w), 879(w), 851$ $(\mathrm{m}), 831(\mathrm{~m}), 820(\mathrm{w}), 795(\mathrm{w}), 751(\mathrm{~m}), 681(\mathrm{w}), 669(\mathrm{w}), 451(\mathrm{w})$. UV-vis $\left(\mathrm{CH}_{2} \mathrm{Cl}_{2}, \lambda_{\max }, \mathrm{nm}\right): 244$ (log $\left.\varepsilon 4.53\right)$, 284 (4.83), 302 (4.80), 343 sh (4.36), 358 (4.46), 373 (4.45), 562 sh (2.74), 608 (2.85), 661 sh (2.76), 741 sh (2.23). ${ }^{1} \mathrm{H}$ NMR $\left(500 \mathrm{MHz}, \mathrm{CDCl}_{3}\right): \delta_{\mathrm{H}} 8.59(\mathrm{~d}, 2 \mathrm{H}, J 10.6 \mathrm{~Hz}, 4-\mathrm{H}), 8.27(\mathrm{~d}, 2 \mathrm{H}, J 10.6 \mathrm{~Hz}, 8-\mathrm{H}), 8.14(\mathrm{~d}, 2 \mathrm{H}, J 9.0$ $\left.\mathrm{Hz}, 3^{\prime \prime}, 5^{\prime \prime}-\mathrm{H}\right), 7.60(\mathrm{~s}, 2 \mathrm{H}, 2-\mathrm{H}), 7.59\left(\mathrm{~d}, 2 \mathrm{H}, J 9.0 \mathrm{~Hz}, 2^{\prime \prime}, 6^{\prime \prime}-\mathrm{H}\right), 7.26\left(\mathrm{~d}, 1 \mathrm{H}, J 3.8 \mathrm{~Hz}, 4^{\prime}-\mathrm{H}\right), 7.21$ (dd, 2H, J 10.6, $1.8 \mathrm{~Hz}, 5-\mathrm{H}), 7.15$ (dd, 2H, J 10.6, $1.8 \mathrm{~Hz}, 7-\mathrm{H}), 6.84(\mathrm{~s}, 1 \mathrm{H}, \mathrm{CH}), 6.65$ (dd, 1H, J 3.8, $\left.1.0 \mathrm{~Hz}, 3^{\prime}-\mathrm{H}\right), 1.53$ (s, $18 \mathrm{H}, 3-$ $t-\mathrm{Bu}), 1.42(\mathrm{~s}, 18 \mathrm{H}, 6-t-\mathrm{Bu}) .{ }^{13} \mathrm{C}$ NMR $\left(125 \mathrm{MHz}, \mathrm{CDCl}_{3}\right): \delta_{\mathrm{C}} 160.7$ (C-6), 154.9 (C-2'), 146.0 (C-4"), 141.1 (C-1'), 139.4 (C-5'), 137.9 (C-3), 135.4 (C-2), 134.8 (C-4), 134.45 (C-8a), 134.38 (C-3a), 131.8 (C-8), 129.1 (C-1), 126.9 $\left(C-3^{\prime}\right), 125.4\left(C-4^{\prime}\right), 125.3\left(C-2^{\prime \prime}, 6^{\prime \prime}\right), 124.3$ (C-3", $\left.5^{\prime \prime}\right), 119.7$ (C-7), 118.7 (C-5), 38.2 (s, 6-t-Bu), 37.5 (d, CH), 33.3 (s, 3-t-Bu), 32.2 (q, 3-t-Bu), 31.8 (q, 6-t-Bu). HRMS (ESI): calcd for $\mathrm{C}_{47} \mathrm{H}_{53} \mathrm{NO}_{2} \mathrm{~S}+\mathrm{Na}^{+} 718.3689$, found 718.3687. Anal. calcd for $\mathrm{C}_{47} \mathrm{H}_{53} \mathrm{NO}_{2} \mathrm{~S}$ (695.9942): C, 81.11; H, 7.68; N, 2.01; S, 4.61. Found: C, 80.81; H, 7.82; N, 2.04; S, 4.46 .

Bis(3-methoxycarbonyl-1-azulenyl)[5-(4-nitrophenyl)-2-thienyl]methane (7b). A mixture of 5-(4nitrophenyl)thiophene-2-carbaldehyde (6) (644 g, $2.76 \mathrm{mmol}$ ) and methyl azulene-1-carboxylate (3b) (1.03 g, $5.54 \mathrm{mmol})$ in acetic acid $(50 \mathrm{~mL})$ and toluene $(20 \mathrm{~mL})$ was refluxed for 8 days under an Ar atmosphere. The reaction mixture was poured into water and extracted with $\mathrm{CH}_{2} \mathrm{Cl}_{2}$. The organic layer was washed with $5 \%$ $\mathrm{NaHCO}_{3}$ and water, dried over $\mathrm{MgSO}_{4}$, and concentrated under reduced pressure. The residue was purified by column chromatography on silica gel with $\mathrm{CH}_{2} \mathrm{Cl}_{2}$ to afford bis(3-methoxycarbonyl-1-azulenyl)[5-(4nitrophenyl)-2-thienyl]methane (7b) $(572 \mathrm{mg}, 35 \%)$. reddish purple crystals. $\mathrm{mp} 230.0-232.1{ }^{\circ} \mathrm{C}$ (hexane). IR $\left(\mathrm{KBr}\right.$ disk, $\left.\mathrm{v}_{\max }, \mathrm{cm}^{-1}\right)$ : $2926(\mathrm{w}), 2837(\mathrm{w}), 1692(\mathrm{~s}), 1593(\mathrm{~m}), 1580(\mathrm{w}), 1536(\mathrm{w}), 1514(\mathrm{~m}), 1486(\mathrm{w}), 1457(\mathrm{~m})$, $1441(\mathrm{~m}), 1418$ (s), 1363 (w), 1344 (m), 1337 (s), 1310 (w), 1251 (w), 1210 (s), 1155 (w), 1110 (w), 1043 (m), $951(w), 852(m), 816(w), 776(m), 745(w), 740(w), 680(w), 566(w), 455(w)$. UV-vis $\left(\mathrm{CH}_{2} \mathrm{Cl}_{2}, \lambda_{\max }, \mathrm{nm}\right): 238$ (log $\varepsilon$ 4.63), 259 (4.44), 288 sh (4.71), 294 (4.73), 305 (4.76), 371 (4.46), 381 (4.46), 514 sh (2.78), 553 (2.89), $593 \mathrm{sh}(2.80), 657 \mathrm{sh}(2.30) .{ }^{1} \mathrm{H}$ NMR $\left(500 \mathrm{MHz}, \mathrm{CDCl}_{3}\right): \delta_{\mathrm{H}} 9.69(\mathrm{~d}, 2 \mathrm{H}, J 9.5 \mathrm{~Hz}, 4-\mathrm{H}), 8.44(\mathrm{~d}, 2 \mathrm{H}, J 9.6 \mathrm{~Hz}, 8-\mathrm{H})$, $8.15\left(\mathrm{~d}, 2 \mathrm{H}, J 9.0 \mathrm{~Hz}, 3^{\prime \prime}, 5^{\prime \prime}-\mathrm{H}\right), 8.05(\mathrm{~s}, 2 \mathrm{H}, 2-\mathrm{H}), 7.80(\mathrm{dd}, 2 \mathrm{H}, J 9.9,9.8 \mathrm{~Hz}, 6-\mathrm{H}), 7.61\left(\mathrm{~d}, 2 \mathrm{H}, J 9.0 \mathrm{~Hz}, 2^{\prime \prime}, 6^{\prime \prime}-\mathrm{H}\right)$, $7.56(\mathrm{dd}, 2 \mathrm{H}, J$ 9.9, $9.5 \mathrm{~Hz}, 5-\mathrm{H}), 7.38(\mathrm{dd}, 2 \mathrm{H}, J 9.8,9.6 \mathrm{~Hz}, 7-\mathrm{H}), 7.32\left(\mathrm{~d}, 1 \mathrm{H}, J 3.8 \mathrm{~Hz}, 4^{\prime}-\mathrm{H}\right), 6.85(\mathrm{~s}, 1 \mathrm{H}, \mathrm{CH})$, $6.77\left(\mathrm{~d}, 1 \mathrm{H}, \mathrm{J} 3.8 \mathrm{~Hz}, 3^{\prime}-\mathrm{H}\right), 3.87\left(\mathrm{~s}, 6 \mathrm{H}, 3-\mathrm{CO}_{2} \mathrm{Me}\right) .{ }^{13} \mathrm{C} \mathrm{NMR}\left(125 \mathrm{MHz}, \mathrm{CDCl}_{3}\right): \delta_{\mathrm{C}} 165.6\left(\mathrm{~s}, 3-\mathrm{CO}_{2} \mathrm{Me}\right), 151.4(\mathrm{C}-$ $\left.2^{\prime}\right), 146.3$ (C-4") 141.7 (C-3a), 140.6 (C-1'), 140.3 (C-2 and C-5'), 139.7 (C-8a), 139.5 (C-6), 138.3 (C-4), 134.9 (C-8), 130.6 (C-1), 128.1 (C-5), 127.5 (C-3'), 126.6 (C-7), 125.6 (C-4'), 125.5 (C-2", 6") , 124.3 (C-3", 5'), 115.3 (C3), 51.1 (q, 3- $\left.\mathrm{CO}_{2} \mathrm{Me}\right), 37.8(\mathrm{CH})$. HRMS (ESI): calcd for $\mathrm{C}_{35} \mathrm{H}_{25} \mathrm{NO}_{6} \mathrm{~S}+\mathrm{Na}^{+} 610.1295$, found 610.1292. Anal. calcd for $\mathrm{C}_{35} \mathrm{H}_{25} \mathrm{NO}_{6} \mathrm{~S}$ (587.6411): C, 71.54; $\mathrm{H}, 4.29 ; \mathrm{N}, 2.38$. Found: $\mathrm{C}, 71.25 ; \mathrm{H}, 4.44 ; \mathrm{N}, 2.14$.

Bis(3,6-di-tert-butyl-1-azulenyl)[5-(4-nitrophenyl)-2-thienyl]methylium hexafluorophosphate $\left(8 \mathrm{a}^{+} \mathrm{PF}_{6}{ }^{-}\right)$. $\mathrm{To}^{\mathrm{a}}$ solution of bis(3,6-di-tert-butyl-1-azulenyl)[5-(4-nitrophenyl)-2-thienyl]methane (7a) (100 mg, $0.144 \mathrm{mmol}$ ) in $\mathrm{CH}_{2} \mathrm{Cl}_{2}(15 \mathrm{~mL}$ ) was added DDQ (34 mg, $0.15 \mathrm{mmol})$ at room temperature. After the solution was stirred at the same temperature for $30 \mathrm{~min}, 60 \% \mathrm{HPF}_{6}(2 \mathrm{~mL})$ and water $(20 \mathrm{~mL})$ were added to the mixture. After stirring the mixture for an additional $10 \mathrm{~min}$, the resulting suspension was filtered with suction. The organic layer was separated, washed with water, dried over $\mathrm{MgSO}_{4}$, and concentrated under reduced pressure. The residue was dissolved in a small amount of $\mathrm{CH}_{2} \mathrm{Cl}_{2}$ and then poured into $\mathrm{Et}_{2} \mathrm{O}$. The precipitated crystals were collected by filtration, washed with $\mathrm{Et}_{2} \mathrm{O}$, and dried in vacuo to give bis(3,6-di-tert-butyl-1-azulenyl)[5-(4-nitrophenyl)-2thienyl]methylium hexafluorophosphate $\left(8 \mathrm{a}^{+} \mathrm{PF}_{6}{ }^{-}\right)(93 \mathrm{mg}, 77 \%)$. deep purple crystals. $\mathrm{mp} 208.1-211.2{ }^{\circ} \mathrm{C}$ $\left(\mathrm{CH}_{3} \mathrm{CN} / \mathrm{Et}_{2} \mathrm{O}\right)$. IR (KBr disk, $\left.\mathrm{v}_{\max } \mathrm{cm}^{-1}\right): 2963(\mathrm{~m}), 2916(\mathrm{w}), 2872(\mathrm{w}), 1594(\mathrm{w}), 1578(\mathrm{w}), 1543$ (w), 1523 (m), 
$1472(\mathrm{~s}), 1422$ (s), $1397(\mathrm{w}), 1376(\mathrm{~m}), 1360(\mathrm{~m}), 1333$ (s), $1312(\mathrm{~s}), 1263(\mathrm{w}), 1245(\mathrm{~m}), 1207$ (m), $1189(\mathrm{w})$, $1177(w), 1113(\mathrm{~m}), 1079(w), 1022(w), 950(w), 868(\mathrm{~m}), 840(\mathrm{~s}), 807(\mathrm{~m}), 743(\mathrm{w}), 705(w), 558(\mathrm{~m}), 521(w)$. UV-vis $\left(\mathrm{CH}_{3} \mathrm{CN}, \lambda_{\max }, \mathrm{nm}\right): 199 \mathrm{sh}$ (log $\varepsilon$ 4.75), 241 (4.72), 270 sh (4.64), 306 (4.60), 337 (4.50), 381 sh (4.33), 409 (4.46), $429 \mathrm{sh}$ (4.40), 540 (4.55), $650 \mathrm{sh}$ (4.40), 702 (4.69). ${ }^{1} \mathrm{H}$ NMR (500 MHz, $\left.\left(\mathrm{CDCl}_{2}\right) 2,100{ }^{\circ} \mathrm{C}\right): \delta_{\mathrm{H}} 8.97(\mathrm{~d}$, $2 \mathrm{H}, J 11.0 \mathrm{~Hz}, 4-\mathrm{H}), 8.25$ (d, 2H, J $\left.8.9 \mathrm{~Hz}, 3^{\prime \prime}, 5^{\prime \prime}-\mathrm{H}\right), 8.05$ (dd, 2H, J 11.0, $\left.1.9 \mathrm{~Hz}, 5-\mathrm{H}\right), 7.88(\mathrm{~d}, 2 \mathrm{H}, J 10.8 \mathrm{~Hz}, 8-\mathrm{H})$, $7.84\left(\mathrm{~d}, 2 \mathrm{H}, J 8.9 \mathrm{~Hz}, 2^{\prime \prime}, 6^{\prime \prime}-\mathrm{H}\right), 7.79\left(\mathrm{~d}, 1 \mathrm{H}, J 4.0 \mathrm{~Hz}, 4^{\prime}-\mathrm{H}\right), 7.75(\mathrm{~s}, 2 \mathrm{H}, 2-\mathrm{H}), 7.60$ (dd, 2H, J 10.8, 1.9 Hz, 7-H), $7.53\left(\mathrm{~d}, 1 \mathrm{H}, J 4.0 \mathrm{~Hz}, 3^{\prime}-\mathrm{H}\right), 1.58(\mathrm{~s}, 18 \mathrm{H}, 3-t-\mathrm{Bu}), 1.42(\mathrm{~s}, 18 \mathrm{H}, 6-t-\mathrm{Bu}) .{ }^{13} \mathrm{C} \mathrm{NMR}\left(125 \mathrm{MHz},\left(\mathrm{CDCl}_{2}\right)_{2}, 100{ }^{\circ} \mathrm{C}\right): \delta_{\mathrm{C}}$ 169.7 (C-6), 154.4 (C-5'), 150.6 (C ${ }^{+}$), 149.0 (C-3a), 148.6 (C-4”), 148.4 (C-8a), 148.1 (C-3), 146.0 (C-2'), 142.3 (C2), 140.2 (C-3'), 139.4 (C-4), 139.0 (C-1") 138.3 (C-8), 132.0 (C-5), 131.6 (C-7), 131.2 (C-1), 128.6 (C-4'), 127.2 $\left(\mathrm{C}-2^{\prime \prime}, 6^{\prime \prime}\right), 124.9$ (C-3", $\left.5^{\prime \prime}\right), 39.6$ (s, 6-t-Bu), 33.6 (s, 3-t-Bu), 31.7 (q, 6-t-Bu), 31.5 (q, 3-t-Bu). HRMS (ESI): calcd for $\mathrm{C}_{47} \mathrm{H}_{52} \mathrm{NO}_{2} \mathrm{~S}^{+}$694.3713, found 694.3714. Anal. calcd for $\mathrm{C}_{47} \mathrm{H}_{52} \mathrm{~F}_{6} \mathrm{NO}_{2} \mathrm{PS}$ (839.9505): C, 67.21; $\mathrm{H}, 6.24 ; \mathrm{N}$, 1.67; S, 3.82. Found: C, 67.16; H, 6.36; N, 1.61; S, 3.76.

Bis(3-methoxycarbonyl-1-azulenyl)[5-(4-nitrophenyl)-2-thienyl]methylium hexafluorophosphate $\left(8 \mathrm{~b}^{+} \mathrm{PF}_{6}^{-}\right)$. To a solution of bis(3-methoxycarbonyl-1-azulenyl)[5-(4-nitrophenyl)-2-thienyl]methane (7b) (101 mg, 0.172 $\mathrm{mmol})$ in $\mathrm{CH}_{2} \mathrm{Cl}_{2}(20 \mathrm{~mL})$ was added DDQ $(47 \mathrm{mg}, 0.21 \mathrm{mmol})$ at room temperature. After the solution was stirred at the same temperature for $30 \mathrm{~min}, 60 \% \mathrm{HPF}_{6}(2 \mathrm{~mL})$ and water $(20 \mathrm{~mL})$ were added to the mixture. After stirring the mixture for an additional $10 \mathrm{~min}$, the resulting suspension was filtered with suction. The organic layer was separated, washed with water, dried over $\mathrm{MgSO}_{4}$, and concentrated under reduced pressure. The residue was dissolved in a small amount of $\mathrm{CHCl}_{3}$ and then poured into hexane. The precipitated crystals were collected by filtration, washed with hexane, and dried in vacuo to give bis(3-methoxycarbonyl-1azulenyl)[5-(4-nitrophenyl)-2-thienyl]methylium hexafluorophosphate $\left(\mathbf{8 b}^{+} \mathrm{PF}_{6}{ }^{-}\right)$(42 $\left.\mathrm{mg}, 33 \%\right)$. deep purple crystals. $\mathrm{mp} 208.1-209.9^{\circ} \mathrm{C}\left(\mathrm{CH}_{2} \mathrm{Cl}_{2} / \mathrm{Et}_{2} \mathrm{O}\right)$. IR ( $\mathrm{KBr}$ disk, $\left.\mathrm{v}_{\max }, \mathrm{cm}^{-1}\right): 2947$ (w), 1703 (s), 1593 (w), $1580(\mathrm{w}), 1534$ $(w), 1518(\mathrm{~m}), 1459$ (s), 1417 (s), 1350 (s), 1340 (s), 1274 (w), 1241 (s), 1224 (s), 1163 (s), 1101 (w), 1085 (m), $1068(\mathrm{~m}), 1064$ (w), 1037 (w), 1012 (w), $914(w), 877$ (w), $842(\mathrm{~s}), 783(\mathrm{w}), 752(\mathrm{w}), 685(\mathrm{w}), 600(\mathrm{w}), 558(\mathrm{~m})$. UV-vis $\left(\mathrm{CH}_{3} \mathrm{CN}, \lambda_{\max }, \mathrm{nm}\right): 197$ (log $\varepsilon$ 4.72), 229 (4.73), 252 (4.64), 272 (4.62), 300 (4.64), 331 sh (4.42), $365 \mathrm{sh}$ (4.30), 385 sh (4.25), 416 sh (4.12), 536 (4.57), 630 (4.50). $\left.{ }^{1} \mathrm{H} \mathrm{NMR} \mathrm{(500} \mathrm{MHz,}\left(\mathrm{CDCl}_{2}\right){ }_{2}, 80{ }^{\circ} \mathrm{C}\right): \delta_{\mathrm{H}} 10.01(\mathrm{~d}, 2 \mathrm{H}, J$ $9.9 \mathrm{~Hz}, 4-\mathrm{H}), 8.57(\mathrm{~s}, 2 \mathrm{H}, 2-\mathrm{H}), 8.25\left(\mathrm{~d}, 2 \mathrm{H}, J 8.7 \mathrm{~Hz}, 3^{\prime \prime}, 5^{\prime \prime}-\mathrm{H}\right), 8.21$ (dd, 2H, J 9.7, 9.3 Hz, 6-H), 8.16 (dd, $2 \mathrm{H}, J$ 9.9, 9.7 Hz, 5-H), 8.14 (d, 2H, J 9.8 Hz, 8-H), 7.90 (d, 1H, J 4.2 Hz, Th), 7.86 (d, 2H, J 8.7 Hz, 2", 6"'-H), 7.73 (d, $1 \mathrm{H}$, J $4.2 \mathrm{~Hz}$, Th), 7.71 (dd, $2 \mathrm{H}, J 9.8,9.3 \mathrm{~Hz}, 7-\mathrm{H}), 3.97\left(\mathrm{~s}, 6 \mathrm{H}, 3-\mathrm{CO}_{2} \mathrm{Me}\right) .{ }^{13} \mathrm{C} \mathrm{NMR}\left(125 \mathrm{MHz},\left(\mathrm{CDCl}_{2}\right)_{2}, 80{ }^{\circ} \mathrm{C}\right): \delta_{\mathrm{C}}$ 164.2 (s, 3- $\mathrm{CO}_{2} \mathrm{Me}$ ), 160.2 (C-5'), $158.3\left(\mathrm{C}^{+}\right), 151.1$ (C-3a), 149.2 (C-8a or C-4"), 149.1 (C-8a or C-4'), 148.9 (C2), 146.0 (C-2'), 145.8 (C-6), 143.8 (d, Th), 143.0 (C-4), 140.5 (C-8), 138.1 (C-1'), 137.9 (C-5), 136.6 (C-7), 130.5 (C-1), 130.2 (d, Th), 127.8 (C-2", 6") 125.0 (C-3", 5"), 124.8 (C-3), 52.5 (q, 3-CO ${ }^{\prime \prime}$ Me). HRMS (ESI): calcd for $\mathrm{C}_{35} \mathrm{H}_{24} \mathrm{NO}_{6} \mathrm{~S}^{+}$586.1319, found 586.1318.

3,3-Bis(4-nitrophenyl)-2-propenal (9c). To a solution of 4,4'-dinitrobenzophenone (709 $\mathrm{mg}, 2.60 \mathrm{mmol}$ ) in $\mathrm{CH}_{2} \mathrm{Cl}_{2}(25 \mathrm{~mL})$ was added a solution of $\mathrm{TiCl}_{4}(1.1 \mathrm{~mL}, 10.0 \mathrm{mmol})$ in $\mathrm{CH}_{2} \mathrm{Cl}_{2}(1.1 \mathrm{~mL})$ and $\mathrm{Et}{ }_{3} \mathrm{~N}(1.4 \mathrm{~mL}, 10.1$ mmol) at $0{ }^{\circ} \mathrm{C}$ under an $\mathrm{N}_{2}$ atmosphere. The resulting mixture was stirred at $30{ }^{\circ} \mathrm{C}$ for $24 \mathrm{~h}$. The reaction mixture was poured into saturated $\mathrm{NH}_{4} \mathrm{Cl}(50 \mathrm{~mL})$ and stirred at the same temperature for $3 \mathrm{~h}$. The mixture was extracted with $\mathrm{CH}_{2} \mathrm{Cl}_{2}$. The organic layer was washed with brine, dried over $\mathrm{MgSO}_{4}$, and concentrated under reduced pressure. The residue was purified by column chromatography on silica gel with $\mathrm{CH}_{2} \mathrm{Cl}_{2}$ to afford 3,3-bis(4-nitrophenyl)-2-propenal (9c) (208 mg, 27\%). yellow crystals. mp 173.2-174.0 ${ }^{\circ} \mathrm{C}$ (MeOH). IR $\left(\mathrm{KBr}\right.$ disk, $\left.v_{\max }, \mathrm{cm}^{-1}\right): 3109(\mathrm{w}), 3077$ (w), 2926 (w), 2849 (w), 1670 (s), 1599 (w), 1518 (s), 1430 (w), 1348 (s), $1300(w), 1253(w), 1117(w), 1124(m), 1168(w), 1013(w), 921(w), 860(m), 846(m), 759(w), 746(w), 706$ (w). UV-vis $\left(\mathrm{CH}_{2} \mathrm{Cl}_{2}, \lambda_{\text {max }}, \mathrm{nm}\right): 299$ (log ع 4.65). ${ }^{1} \mathrm{H} \mathrm{NMR}\left(500 \mathrm{MHz}, \mathrm{CDCl}_{3}\right): \delta_{\mathrm{H}} 9.57(\mathrm{~d}, 1 \mathrm{H}, J$ 7.7 Hz, 1-H), 8.39 (d, $2 \mathrm{H}, J 8.8 \mathrm{~Hz}, 3^{\prime}, 5^{\prime}-\mathrm{H}$ or $\left.3^{\prime \prime}, 5^{\prime \prime}-\mathrm{H}\right), 8.27$ (d, $2 \mathrm{H}, J 9.1 \mathrm{~Hz}, 3^{\prime}, 5^{\prime}-\mathrm{H}$ or $\left.3^{\prime \prime}, 5^{\prime \prime}-\mathrm{H}\right), 7.53\left(\mathrm{~d}, 2 \mathrm{H}, J 8.8 \mathrm{~Hz}, 2^{\prime}, 6^{\prime}-\mathrm{H}\right.$ or $2^{\prime \prime}, 6^{\prime \prime}-$ 
H), $7.50\left(\mathrm{~d}, 2 \mathrm{H}, \mathrm{J} 9.1 \mathrm{~Hz}, 2^{\prime}, 6^{\prime}-\mathrm{H}\right.$ or $\left.2^{\prime \prime}, 6^{\prime \prime}-\mathrm{H}\right), 6.74(\mathrm{~d}, 1 \mathrm{H}, \mathrm{J} 7.7 \mathrm{~Hz}, 2-\mathrm{H}) .{ }^{13} \mathrm{C} \mathrm{NMR}\left(125 \mathrm{MHz}, \mathrm{CDCl}_{3}\right): \delta_{\mathrm{C}} 191.2(\mathrm{C}-$ 1), 156.2 (C-3), 149.9 (C-4' or C-4'), 148.6 (C-4' or C-4"), 144.4 (C-1' or C-1'), 141.8 (C-1' or C-1"'), 131.4 (C-

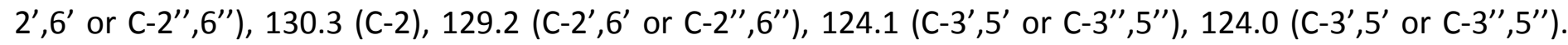
HRMS (MALDI): calcd for $\mathrm{C}_{15} \mathrm{H}_{10} \mathrm{~N}_{2} \mathrm{O}_{5}-\mathrm{H}^{-}[\mathrm{M}-\mathrm{H}]^{+}$297.0506, found 297.0468. Anal. Calcd for $\mathrm{C}_{15} \mathrm{H}_{10} \mathrm{~N}_{2} \mathrm{O}_{5}$ (298.2503): C, 60.41; H, 3.38; N, 9.39. Found: C, 60.30; H, 3.33; N, 9.43.

3,3-Bis(3,6-di-tert-butyl-1-azulenyl)-1,1-diphenylpropene (10a). A mixture of B-phenylcinnamaldehyde (9a) (208 mg, $1.00 \mathrm{mmol}$ ) and 1,6-di-tert-butylazulene (3a) $(482 \mathrm{mg}, 2.01 \mathrm{mmol}$ ) in acetic acid (12 mL) was stirred at room temperature for $24 \mathrm{~h}$ under an Ar atmosphere. The reaction mixture was poured into water and extracted with $\mathrm{CH}_{2} \mathrm{Cl}_{2}$. The organic layer was washed with $5 \% \mathrm{NaHCO}_{3}$ and water, dried over $\mathrm{MgSO}_{4}$, and concentrated under reduced pressure. The residue was purified by column chromatography on silica gel with $\mathrm{CH}_{2} \mathrm{Cl}_{2}$ and $\mathrm{GPC}$ with $\mathrm{CHCl}_{3}$ to afford 3,3-bis(3,6-di-tert-butyl-1-azulenyl)-1,1-diphenylpropene (10a) (507 mg, 76\%). blue crystals. $\mathrm{mp} 210.1-211.1^{\circ} \mathrm{C}(\mathrm{MeOH})$. IR (KBr disk, $\left.v_{\max }, \mathrm{cm}^{-1}\right): 3079(\mathrm{w}), 3050(\mathrm{w}), 3018(\mathrm{w}), 2963$ (s), $2904(\mathrm{~m}), 2868(\mathrm{~m}), 1576(\mathrm{~s}), 1507(\mathrm{w}), 1492(\mathrm{w}), 1455(\mathrm{~m}), 1441(\mathrm{w}), 1424(\mathrm{~m}), 1390(\mathrm{~m}), 1363(\mathrm{~s}), 1245$ (m), $1228(\mathrm{~m}), 1198(\mathrm{w}), 1072(\mathrm{w}), 874(\mathrm{w}), 833(\mathrm{~m}), 766(\mathrm{w}), 702(\mathrm{~m}), 673(\mathrm{w}), 580(\mathrm{w}), 531(\mathrm{w}), 458(\mathrm{w}), 442$ (w). UV-vis $\left(\mathrm{CH}_{2} \mathrm{Cl}_{2}, \lambda_{\max }, \mathrm{nm}\right): 246$ (log $\varepsilon$ 4.57), 288 (4.83), 302 sh (4.80), 345 sh (3.92), 357 (4.00), 375 (3.94), 560 sh (2.57), 604 (2.74), 674 sh (2.63), 748 sh (2.04). ${ }^{1} \mathrm{H} \mathrm{NMR}\left(500 \mathrm{MHz}, \mathrm{CDCl}_{3}\right): \delta_{\mathrm{H}} 8.52$ (d, $2 \mathrm{H}, J 10.6 \mathrm{~Hz}, 4^{\prime}-$ $\mathrm{H}), 7.81\left(\mathrm{~d}, 2 \mathrm{H}, J 10.6 \mathrm{~Hz}, 8^{\prime}-\mathrm{H}\right), 7.66\left(\mathrm{~s}, 2 \mathrm{H}, 2^{\prime}-\mathrm{H}\right), 7.40-7.39(\mathrm{~m}, 3 \mathrm{H}, \mathrm{Ph}), 7.22-7.18(\mathrm{~m}, 7 \mathrm{H}, \mathrm{Ph}), 7.12(\mathrm{dd}, 2 \mathrm{H}, J$ 10.6, $\left.1.9 \mathrm{~Hz}, 5^{\prime}-\mathrm{H}\right), 6.92$ (dd, 2H, J 10.6, $\left.1.9 \mathrm{~Hz}, 7^{\prime}-\mathrm{H}\right), 6.81(\mathrm{~d}, 1 \mathrm{H}, J 10.5 \mathrm{~Hz}, 2-\mathrm{H}), 5.95(\mathrm{~d}, 1 \mathrm{H}, J 10.5 \mathrm{~Hz}, 3-\mathrm{H})$, $1.54\left(\mathrm{~s}, 18 \mathrm{H}, 3^{\prime}-t-\mathrm{Bu}\right), 1.40\left(\mathrm{~s}, 18 \mathrm{H}, 6^{\prime}-t-\mathrm{Bu}\right) .{ }^{13} \mathrm{C} \mathrm{NMR}\left(125 \mathrm{MHz}, \mathrm{CDCl}_{3}\right): \delta_{\mathrm{C}} 160.2$ (C-6'), $142.8\left(\mathrm{C}-1^{\prime \prime}\right.$ or C-1'”), 140.2 (C-1" or C-1'”'), 138.3 (C-1), 137.9 (C-3'), 134.7 (C-2'), 134.3 (C-4'), 134.14 (C-3'a), 134.08 (C-8'a), 132.9 (C-2), 132.3 (C-8'), 130.7 (C-1'), 130.6 (d, Ph), 128.2 (d, Ph), 128.0 (d, Ph), 127.7 (d, Ph), 127.2 (d, Ph), 126.8 (d, $\mathrm{Ph}), 118.9$ (C-7'), 118.0 (C-5'), 38.1 (s, 6'-t-Bu), 36.8 (C-3), 33.3 (s, 3'-t-Bu), 32.2 (q, 3'-t-Bu), 31.8 (q, 6'-t-Bu). HRMS (ESI): calcd for $\mathrm{C}_{51} \mathrm{H}_{58}+\mathrm{Na}^{+}$693.4431, found 693.4427. Anal. calcd for $\mathrm{C}_{51} \mathrm{H}_{58}(671.0062): \mathrm{C}, 91.29 ; \mathrm{H}$, 8.71. Found: $\mathrm{C}, 91.04 ; \mathrm{H}, 8.56$.

3,3-Bis(3-methoxycarbonyl-1-azulenyl)-1,1-diphenylpropene (10b). A mixture of B-phenylcinnamaldehyde (9a) $(514 \mathrm{mg}, 2.47 \mathrm{mmol}$ ) and methyl azulene-1-carboxylate (3b) (300 mg, $1.61 \mathrm{mmol}$ ) in acetic acid (20 mL) was refluxed for 2 days under an Ar atmosphere. The reaction mixture was poured into water and extracted with $\mathrm{CH}_{2} \mathrm{Cl}_{2}$. The organic layer was washed with $5 \% \mathrm{NaHCO}_{3}$ and water, dried over $\mathrm{MgSO}_{4}$, and concentrated under reduced pressure. The residue was purified by column chromatography on silica gel with $\mathrm{CH}_{2} \mathrm{Cl}_{2}$ and ethyl acetate to afford 3,3-bis(3-methoxycarbonyl-1-azulenyl)-1,1-diphenylpropene (10b) (244 mg, $27 \%$ ).

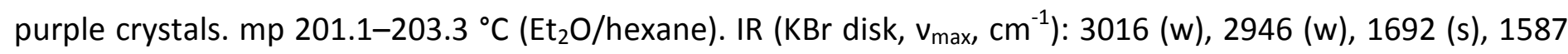
$(w), 1577(w), 1536(w), 1513(w), 1489(w), 1457(s), 1441(s), 1418(s), 1371(w), 1309(w), 1207(s), 1154(w)$, $1136(w), 1042(w), 944(w), 886(w), 871(w), 863(w), 777(m), 749(m), 703(m), 621(w), 561(w), 538(w)$. UV-vis $\left(\mathrm{CH}_{2} \mathrm{Cl}_{2}, \lambda_{\max }, \mathrm{nm}\right): 239$ (log $\varepsilon$ 4.72), 261 sh (4.54), 289 sh (4.80), 294 (4.81), 306 (4.82), 372 (4.12), 385 (4.16), $519 \mathrm{sh}$ (2.83), 559 (2.94), $596 \mathrm{sh}$ (2.86), 664 (2.34). ${ }^{1} \mathrm{H}$ NMR $\left(500 \mathrm{MHz}, \mathrm{CDCl}_{3}\right): \delta_{\mathrm{H}} 9.65(\mathrm{~d}, 2 \mathrm{H}, J 9.5 \mathrm{~Hz}$, $4^{\prime}-\mathrm{H}$ ), 8.19 (s, 2H, 2'-H), 8.01 (s, 2H, J $\left.9.5 \mathrm{~Hz}, 8^{\prime}-\mathrm{H}\right), 7.73$ (dd, 2H, J 9.8, 9.8 Hz, 6'-H), 7.51 (dd, 2H, J 9.8, 9.5 Hz, $\left.5^{\prime}-\mathrm{H}\right), 7.40-7.34\left(\mathrm{~m}, 3 \mathrm{H}, 4^{\prime \prime}-\mathrm{H}\right.$ or $4^{\prime \prime \prime}-\mathrm{H}$ and $3^{\prime \prime}, 5^{\prime \prime}-\mathrm{H}$ or $\left.3^{\prime \prime \prime}, 5^{\prime \prime \prime}-\mathrm{H}\right), 7.25-7.16\left(\mathrm{~m}, 9 \mathrm{H}, 7^{\prime}-\mathrm{H}, 2^{\prime \prime}, 6^{\prime \prime}-\mathrm{H}, 2^{\prime \prime \prime}, 6^{\prime \prime \prime}-\mathrm{H}\right.$, and $4^{\prime \prime}-\mathrm{H}$ or $4^{\prime \prime \prime}-\mathrm{H}$ and $3^{\prime \prime}, 5^{\prime \prime}-\mathrm{H}$ or $\left.3^{\prime \prime \prime}, 5^{\prime \prime \prime}-\mathrm{H}\right), 6.73(\mathrm{~d}, 1 \mathrm{H}, \mathrm{J} 10.3 \mathrm{~Hz}, 2-\mathrm{H}), 5.94(\mathrm{~d}, 1 \mathrm{H}, \mathrm{J} 10.3 \mathrm{~Hz}, 3-\mathrm{H}), 3.90(\mathrm{~s}$,

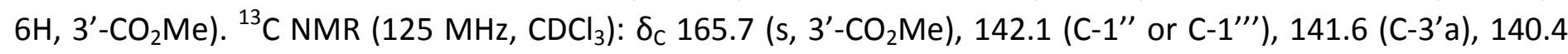
(C-1), 139.8 (C-8'a), 139.7 (C-1'” or C-1'”'), 139.4 (C-2'), 139.1 (C-6'), 137.8 (C-4'), 135.2 (C-8'), 132.0 (C-1'), 130.9 (C-2), 130.1 (d, Ph), 128.4 (d, Ph), 128.1 (d, Ph), 127.8 (d, Ph), 127.64 (d, Ph), 127.62 (C-5'), 127.3 (d, Ph), 126.1 (C-7'), 115.4 (C-3'), 51.0 (q, 3'-CO 3 $_{2} \mathrm{Me}$ ), 37.1 (C-3). HRMS (ESI): calcd for $\mathrm{C}_{39} \mathrm{H}_{30} \mathrm{O}_{4}+\mathrm{Na}^{+}$585.2036, found 585.2034. Anal. calcd for $\mathrm{C}_{39} \mathrm{H}_{30} \mathrm{O}_{4}$ (562.6531): C, 83.25; $\mathrm{H}, 5.37$. Found: $\mathrm{C}, 83.03 ; \mathrm{H}, 5.58$. 
3,3-Bis(3,6-di-tert-butyl-1-azulenyl)-1,1-bis(4-fluorophenyl)propene $\quad$ (10c). A mixture of 3,3-bis(4fluorophenyl)-2-propenal (9c) (218 mg, $0.893 \mathrm{mmol}$ ) and 1,6-di-tert-butylazulene (3a) (421 mg, $1.75 \mathrm{mmol}$ ) in acetic acid $(10 \mathrm{~mL})$ was stirred at room temperature for 2 days under an Ar atmosphere. The reaction mixture was poured into water and extracted with $\mathrm{CH}_{2} \mathrm{Cl}_{2}$. The organic layer was washed with $5 \% \mathrm{NaHCO}_{3}$ and water, dried over $\mathrm{MgSO}_{4}$, and concentrated under reduced pressure. The residue was purified by column chromatography on silica gel with $\mathrm{CH}_{2} \mathrm{Cl}_{2}$ /hexane (1:5) and $\mathrm{GPC}$ with $\mathrm{CHCl}_{3}$ to afford 3,3-bis(3,6-di-tert-butyl-1azulenyl)-1,1-bis(4-fluorophenyl)propene (10c) (264 mg, 43\%). blue crystals. mp 143.0-144.2 ${ }^{\circ} \mathrm{C}(\mathrm{MeOH})$. IR $\left(\mathrm{KBr}\right.$ disk, $\left.v_{\max } \mathrm{cm}^{-1}\right): 2964(\mathrm{~s}), 2895(\mathrm{~m}), 2869(\mathrm{~m}), 1602(\mathrm{w}), 1576(\mathrm{~s}), 1509(\mathrm{~s}), 1456(\mathrm{~m}), 1424(\mathrm{~m}), 1387(\mathrm{~m})$, $1363(\mathrm{~m}), 1228$ (s), 1200 (w), 1158 (m), 1086 (w), 1064 (w), 1010 (w), 872 (w), 834 (s), 669 (w), 570 (w). UV-vis $\left(\mathrm{CH}_{2} \mathrm{Cl}_{2}, \lambda_{\max }, \mathrm{nm}\right): 246$ (log $\varepsilon$ 4.42), 288 (4.70), $300 \mathrm{sh}$ (4.67), $344 \mathrm{sh}$ (3.80), 357 (3.88), 374 (3.81), $564 \mathrm{sh}$ (2.58), 613 (2.71), 675 sh (2.60), 749 sh (2.10). ${ }^{1} \mathrm{H}$ NMR (500 MHz, CDCl $\left.{ }_{3}\right): \delta_{\mathrm{H}} 8.53\left(\mathrm{~d}, 2 \mathrm{H}, J 10.6 \mathrm{~Hz}, 4^{\prime}-\mathrm{H}\right), 7.79$ (d, 2H, J $\left.10.7 \mathrm{~Hz}, 8^{\prime}-\mathrm{H}\right), 7.64\left(\mathrm{~s}, 2 \mathrm{H}, 2^{\prime}-\mathrm{H}\right), 7.15-7.12\left(\mathrm{~m}, 6 \mathrm{H}, 5^{\prime}-\mathrm{H}, 2^{\prime \prime}, 6^{\prime \prime}-\mathrm{H}\right.$, and 2'"', 6'"'-H), 7.07 (dd, 2H, $J 8.7$, $8.7 \mathrm{~Hz}, 3^{\prime \prime}, 5^{\prime \prime}-\mathrm{H}$ or $\left.3^{\prime \prime \prime}, 5^{\prime \prime \prime}-\mathrm{H}\right), 6.94\left(\mathrm{dd}, 2 \mathrm{H}, J 10.6,1.9 \mathrm{~Hz}, 7^{\prime}-\mathrm{H}\right), 6.91$ (dd, 2H, J 8.7, 8.7 Hz, 3", 5"'-H or 3'”, 5'”'$\mathrm{H}), 6.74(\mathrm{~d}, 1 \mathrm{H}, J 10.4 \mathrm{~Hz}, 2-\mathrm{H}), 5.90(\mathrm{~d}, 1 \mathrm{H}, J 10.4 \mathrm{~Hz}, 3-\mathrm{H}), 1.54\left(\mathrm{~s}, 18 \mathrm{H}, 3^{\prime}-t-\mathrm{Bu}\right), 1.40$ (s, 18H, 6'-t-Bu). ${ }^{13} \mathrm{C} \mathrm{NMR}$ $\left(125 \mathrm{MHz}, \mathrm{CDCl}_{3}\right): \delta_{\mathrm{C}} 162.2$ (J $246.6 \mathrm{~Hz}, \mathrm{C}-4^{\prime \prime}$ or C-4"'”), 162.1 (J $246.6 \mathrm{~Hz}, \mathrm{C}-4^{\prime \prime}$ or C-4"'’), 160.4 (C-6'), 138.7 (J $3.2 \mathrm{~Hz}, \mathrm{C}-1^{\prime \prime}$ or C-1'”'), 138.0 (C-3'), 136.4 (C-1), 135.9 (J $3.2 \mathrm{~Hz}, \mathrm{C}-1^{\prime \prime}$ or C-1'”'), 134.5 (C-2'), 134.4 (C-4'), 134.2

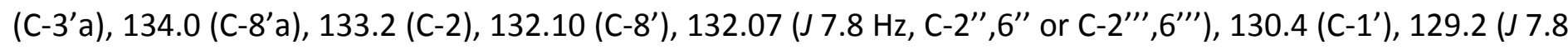
$\mathrm{Hz}, \mathrm{C}-2^{\prime \prime}, 6^{\prime \prime}$ or C-2'"',6"') 118.9 (C-7'), 118.2 (C-5'), 115.2 (J $21.0 \mathrm{~Hz}, \mathrm{C}-3^{\prime \prime}, 5^{\prime \prime}$ or C-3'"', 5'”), 114.8 (J $21.0 \mathrm{~Hz}, \mathrm{C}-$ $3^{\prime \prime}, 5^{\prime \prime}$ or C-3"', $\left.5^{\prime \prime \prime}\right), 38.2$ (s, 6'-t-Bu), 36.8 (C-3), 33.3 (s, 3'-t-Bu), 32.2 (q, 3'-t-Bu), 31.8 (q, 6'-t-Bu). HRMS (ESI): calcd for $\mathrm{C}_{51} \mathrm{H}_{56} \mathrm{~F}_{2}+\mathrm{Na}^{+}$729.4242, found 729.4240. Anal. calcd for $\mathrm{C}_{51} \mathrm{H}_{56} \mathrm{~F}_{2}$ (706.9871): C, 86.64; $\mathrm{H}, 7.98$. Found: C, 86.39; H, 8.09.

3,3-Bis(3,6-di-tert-butyl-1-azulenyl)-1,1-bis(4-nitrophenyl)propene (10d). A mixture of 3,3-bis(4-nitrophenyl)2-propenal (9c) (208 mg, $0.697 \mathrm{mmol}$ ), 1,6-di-tert-butylazulene (3a) (329 mg, $1.37 \mathrm{mmol}$ ) in acetic acid (12 mL) was stirred at $35{ }^{\circ} \mathrm{C}$ for 4 days under an $\mathrm{Ar}$ atmosphere. The reaction mixture was poured into water and extracted with $\mathrm{CH}_{2} \mathrm{Cl}_{2}$. The organic layer was washed with $5 \% \mathrm{NaHCO}_{3}$ and water, dried over $\mathrm{MgSO}_{4}$, and concentrated under reduced pressure. The residue was purified by column chromatography on silica gel with $\mathrm{CH}_{2} \mathrm{Cl}_{2} /$ hexane (1:1) and recystallization from ethyl acetate/methanol to afford 3,3-bis(3,6-di-tert-butyl-1azulenyl)-1,1-bis(4-nitrophenyl)propene (10d) (157 mg, 30\%). green crystals. mp 158.0-158.9 ${ }^{\circ} \mathrm{C}(\mathrm{MeOH}) . \mathrm{IR}$ $\left(\mathrm{KBr}\right.$ disk, $\left.\mathrm{v}_{\text {max }}, \mathrm{cm}^{-1}\right): 2962(\mathrm{~m}), 2950(\mathrm{w}), 2931(\mathrm{w}), 1577(\mathrm{~m}), 1520(\mathrm{~s}), 1454(\mathrm{w}), 1417(\mathrm{w}), 1384(\mathrm{w}), 1360(\mathrm{~m})$, 1341 (s), 1242 (w), 1226 (w), 1109 (w), 1069 (w), 855 (w), 834 (w), 704 (w). UV-vis $\left(\mathrm{CH}_{2} \mathrm{Cl}_{2}, \lambda_{\max }, \mathrm{nm}\right): 243$ (log ع 4.59), 284 sh (4.84), 293 (4.86), 303 (4.88), 356 sh (4.19), 373 (4.09), 558 sh (2.87), 607 sh (2.82), 669 sh (2.65), 749 sh (2.08). ${ }^{1} \mathrm{H}$ NMR $\left(500 \mathrm{MHz}, \mathrm{CDCl}_{3}\right): \delta_{\mathrm{H}} 8.56\left(\mathrm{~d}, 2 \mathrm{H}, J 10.7 \mathrm{~Hz}, 4^{\prime}-\mathrm{H}\right), 8.24\left(\mathrm{~d}, 2 \mathrm{H}, J 8.7 \mathrm{~Hz}, 3^{\prime \prime}, 5^{\prime \prime}-\mathrm{H}\right.$ or $\left.3^{\prime \prime \prime}, 5^{\prime \prime \prime}-\mathrm{H}\right), 8.10\left(\mathrm{~d}, 2 \mathrm{H}, \mathrm{J} 9.0 \mathrm{~Hz}, 3^{\prime \prime}, 5^{\prime \prime}-\mathrm{H}\right.$ or $\left.3^{\prime \prime \prime}, 5^{\prime \prime \prime}-\mathrm{H}\right), 7.72\left(\mathrm{~d}, 2 \mathrm{H}, \mathrm{J} 10.6 \mathrm{~Hz}, 8^{\prime}-\mathrm{H}\right), 7.63\left(\mathrm{~s}, 2 \mathrm{H}, 2^{\prime}-\mathrm{H}\right), 7.30(\mathrm{~d}$, $2 \mathrm{H}$, J $8.7 \mathrm{~Hz}, 2^{\prime \prime}, 6^{\prime \prime}-\mathrm{H}$ or $\left.2^{\prime \prime \prime}, 6^{\prime \prime \prime}-\mathrm{H}\right), 7.29\left(\mathrm{~d}, 2 \mathrm{H}, J 9.0 \mathrm{~Hz}, 2^{\prime \prime}, 6^{\prime \prime}-\mathrm{H}\right.$ or $\left.2^{\prime \prime \prime}, 6^{\prime \prime \prime}-\mathrm{H}\right), 7.20$ (dd, 2H, J 10.7, 1.8 Hz, 5'-H), 7.08 (d, 1H, J $10.2 \mathrm{~Hz}, 2-\mathrm{H}), 6.97$ (dd, 2H, J 10.6, $\left.1.8 \mathrm{~Hz}, 7^{\prime}-\mathrm{H}\right), 5.87$ (d, 1H, J $\left.10.2 \mathrm{~Hz}, 3-\mathrm{H}\right), 1.55$ (s, 18H, 3'-t-Bu),

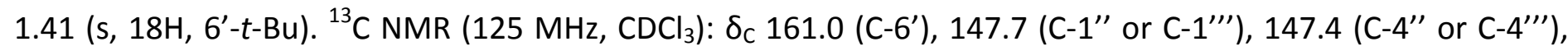
146.8 (C-4" or C-4'”'), 145.8 (C-1" or C-1'"'), 138.5 (C-2), 138.3 (C-3'), 135.2 (C-1), 134.8 (C-4'), 134.3 (C-3'a),

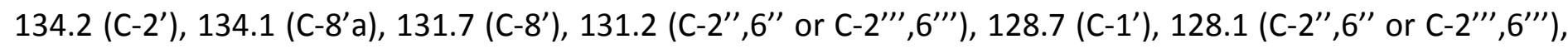
$123.8\left(\mathrm{C}-3^{\prime \prime}, 5^{\prime \prime}\right.$ or C-3"', $\left.5^{\prime \prime \prime}\right), 123.6$ (C-3"',5" or C-3"', $\left.5^{\prime \prime \prime}\right), 119.3$ (C-7'), 118.7 (C-5'), 38.2 (s, 6'-t-Bu), 37.1 (C-3), 33.3 (s, 3'-t-Bu), 32.2 (q, 3'-t-Bu), 31.8 (q, 6'-t-Bu). HRMS (ESI): calcd for $\mathrm{C}_{51} \mathrm{H}_{56} \mathrm{~N}_{2} \mathrm{O}_{4}+\mathrm{Na}^{+} 783.4132$, found 783.4130. Anal. Calcd for $\mathrm{C}_{51} \mathrm{H}_{56} \mathrm{~N}_{2} \mathrm{O}_{4}$ (761.0013): $\mathrm{C}, 80.49 ; \mathrm{H}, 7.42 ; \mathrm{N}, 3.68$. Found: $\mathrm{C}, 80.17 ; \mathrm{H}, 7.24 ; \mathrm{N}, 3.54$.

3,3-Bis(3,6-di-tert-butyl-1-azulenyl)-1,1-diphenylpropenylium hexafluorophosphate $\left(11 \mathrm{a}^{+} \mathrm{PF}_{6}{ }^{-}\right)$. To a solution of 3,3-bis(3,6-di-tert-butyl-1-azulenyl)-1,1-diphenylpropene (10a) (200 mg, $0.298 \mathrm{mmol})$ in $\mathrm{CH}_{2} \mathrm{Cl}_{2}(30 \mathrm{~mL}) \mathrm{was}$ added DDQ (81 mg, $0.36 \mathrm{mmol}$ ) at room temperature. After the solution was stirred at the same temperature 
for $30 \mathrm{~min}, 60 \% \mathrm{HPF}_{6}(3 \mathrm{~mL})$ and water $(20 \mathrm{~mL})$ were added to the mixture. After stirring the mixture for an additional $10 \mathrm{~min}$, the resulting suspension was filtered with suction. The organic layer was separated, washed with water, dried with $\mathrm{MgSO}_{4}$, and concentrated under reduced pressure. The residue was crystallized from hexane to give 3,3-bis(3,6-di-tert-butyl-1-azulenyl)-1,1-diphenylpropenylium hexafluorophosphate $\left(\mathbf{1 1 a}^{+} \mathrm{PF}_{6}{ }^{-}\right)$ (179 mg, 74\%). deep purple powder. $\mathrm{mp} 152.3-154.0{ }^{\circ} \mathrm{C}\left(\mathrm{Et}_{2} \mathrm{O} /\right.$ hexane). IR $\left(\mathrm{KBr}\right.$ disk, $\left.\mathrm{v}_{\max } \mathrm{cm}^{-1}\right): 2963(\mathrm{~m})$, $2896(w), 2872$ (w), 1577 (w), 1545 (w), 1490 (m), 1476 (s), 1440 (m), 1416 (s), $1396(w), 1366$ (m), 1335 (s), $1311(\mathrm{~s}), 1281(w), 1239(\mathrm{~m}), 1232(\mathrm{~m}), 1200(w), 1181(w), 1178(w), 1101(w), 1076(w), 1018(w), 984(w)$, 956 (w), 874 (w), 839 (s), 807 (m), 699 (w), 557 (m). UV-vis ( $\mathrm{CH}_{3} \mathrm{CN}, \lambda_{\max }, \mathrm{nm}$ ): 195 (log ع 4.75), 241 (4.67), 309 (4.51), $323 \mathrm{sh}$ (4.48), 416 (4.09), $435 \mathrm{sh}$ (4.02), 534 (4.18), 722 (4.58). ${ }^{1} \mathrm{H} \mathrm{NMR}\left(500 \mathrm{MHz},\left(\mathrm{CDCl}_{2}\right)_{2}, 120^{\circ} \mathrm{C}\right): \delta_{\mathrm{H}}$ $8.75\left(\mathrm{~d}, 2 \mathrm{H}, \mathrm{J} 10.9 \mathrm{~Hz}, 4^{\prime}-\mathrm{H}\right), 8.47$ (d, 2H, J $\left.10.7 \mathrm{~Hz}, 8^{\prime}-\mathrm{H}\right), 7.94\left(\mathrm{~d}, 2 \mathrm{H}, J 10.9 \mathrm{~Hz}, 5^{\prime}-\mathrm{H}\right), 7.71(\mathrm{~s}, 1 \mathrm{H}, 2-\mathrm{H}), 7.67$ (d, $\left.2 \mathrm{H}, J 10.7 \mathrm{~Hz}, 7^{\prime}-\mathrm{H}\right), 7.62\left(\mathrm{~s}, 2 \mathrm{H}, 2^{\prime}-\mathrm{H}\right), 7.50-7.45(\mathrm{~m}, 5 \mathrm{H}, \mathrm{Ph}), 6.82-6.74(\mathrm{~m}, 5 \mathrm{H}, \mathrm{Ph}), 1.47\left(\mathrm{~s}, 18 \mathrm{H}, 3^{\prime}-t-\mathrm{Bu}\right), 1.44$ (s, 18H, 6'-t-Bu). ${ }^{13} \mathrm{C}$ NMR $\left(125 \mathrm{MHz},\left(\mathrm{CDCl}_{2}\right)_{2}, 120{ }^{\circ} \mathrm{C}\right): \delta_{\mathrm{C}} 168.9$ (C-6'), 161.5 (C-1), 156.7 (C-3), 148.5 (C-3'a), 148.0 (C-8'a), 147.8 (C-3'), 142.1 (C-2'), 141.7 (C-1'” or C-1'”'), 139.1 (C-1"' or C-1'”'), 138.5 (C-4'), 137.8 (C-8'), 131.7 (C-1'), 131.6 (C-5'), 131.5 (C-7'), 131.1 (d, Ph), 130.4 (d, Ph), 130.2 (C-2), 129.6 (d, Ph), 129.3 (d, Ph), 128.7 (d, Ph), 127.9 (d, Ph), 39.4 (s, 6'-t-Bu), 33.5 (s, 3'-t-Bu), 31.7 (q, 6'-t-Bu), 31.2 (q, 3'-t-Bu). HRMS (ESI): calcd for $\mathrm{C}_{51} \mathrm{H}_{57}{ }^{+} 669.4455$, found 669.4454. Anal. calcd for $\mathrm{C}_{51} \mathrm{H}_{57} \mathrm{~F}_{6} \mathrm{P} \cdot 1 / 2 \mathrm{H}_{2} \mathrm{O}$ (814.9625): $\mathrm{C}, 74.34 ; \mathrm{H}, 7.09$. Found: $\mathrm{C}, 74.45 ; \mathrm{H}, 6.82$.

3,3-Bis(3-methoxycarbonyl-1-azulenyl)-1,1-diphenylpropenylium hexafluorophosphate (11- $\left.{ }^{+} \mathrm{PF}_{6}^{-}\right)$. To a mixture of 3,3-bis(3-methoxycarbonyl-1-azulenyl)-1,1-diphenylpropene (10b) (201 mg, $0.357 \mathrm{mmol}$ ) and 60\% $\mathrm{HPF}_{6}(3 \mathrm{~mL})$ in $\mathrm{CH}_{2} \mathrm{Cl}_{2}(30 \mathrm{~mL})$ and water $(30 \mathrm{~mL})$ was added DDQ $(97 \mathrm{mg}, 0.43 \mathrm{mmol})$ at room temperature. The resulting mixture was stirred at room temperature for $30 \mathrm{~min}$. The resulting suspension was filtered with suction. The organic layer was separated, dried with $\mathrm{MgSO}_{4}$, and concentrated under reduced pressure. The residue was recrystallized from $\mathrm{Et}_{2} \mathrm{O} /$ hexane to give 3,3-bis(3-methoxycarbonyl-1-azulenyl)-1,1diphenylpropenylium hexafluorophosphate $\left(\mathbf{1 1 b}^{+} \mathrm{PF}_{6}{ }^{-}\right)$(232 $\left.\mathrm{mg}, 92 \%\right)$. purple crystals. mp $189.2-190.3{ }^{\circ} \mathrm{C}$ (Et ${ }_{2} \mathrm{O} /$ hexane). IR (KBr disk, $\left.v_{\max } \mathrm{cm}^{-1}\right): 2932(\mathrm{w}), 2816(\mathrm{w}), 1704$ (s), $1568(\mathrm{w}), 1537(\mathrm{w}), 1512(\mathrm{~m}), 1481(\mathrm{w})$, 1466 (s), 1446 (s), 1415 (s), 1398 (w), 1363 (s), 1294 (w), 1224 (s), 1163 (s), 1090 (m), 1067 (w), 1025 (w), 870 $(\mathrm{m}), 841$ (s), $787(\mathrm{w}), 701(\mathrm{~m}), 699(\mathrm{w}), 558(\mathrm{~m}), 455(\mathrm{w})$. UV-vis $\left(\mathrm{CH}_{3} \mathrm{CN}, \lambda_{\max }, \mathrm{nm}\right): 193$ (log $\varepsilon$ 4.80), 228 (4.64), 253 sh (4.55), 269 sh (4.50), 303 (4.48), 365 sh (4.09), 543 (4.27), 655 (4.40). ${ }^{1} \mathrm{H} \mathrm{NMR} \mathrm{(500} \mathrm{MHz,}\left(\mathrm{CDCl}_{2}\right)_{2}, 80$ $\left.{ }^{\circ} \mathrm{C}\right): \delta_{\mathrm{H}} 9.75\left(\mathrm{~d}, 2 \mathrm{H}, J 10.0 \mathrm{~Hz}, 4^{\prime}-\mathrm{H}\right), 8.69\left(\mathrm{~d}, 2 \mathrm{H}, J 9.9 \mathrm{~Hz}, 8^{\prime}-\mathrm{H}\right), 8.37\left(\mathrm{~s}, 2 \mathrm{H}, 2^{\prime}-\mathrm{H}\right), 8.18\left(\mathrm{dd}, 2 \mathrm{H}, J 9.8,9.7 \mathrm{~Hz}, 6^{\prime}-\right.$ H), 8.07 (dd, 2H, J 10.0, 9.8 Hz, 5'-H), 7.83 (s, 1H, 2-H), 7.82 (dd, 2H, J 9.9, 9.7 Hz, 7'-H), 7.57-7.45 (m, 5H, Ph"'), 6.83-6.72 (m, 5H, Ph"'), $3.90\left(\mathrm{~s}, 6 \mathrm{H}, 33^{\prime}-\mathrm{CO}_{2} \mathrm{Me}\right) .{ }^{13} \mathrm{C} \mathrm{NMR}\left(125 \mathrm{MHz},\left(\mathrm{CDCl}_{2}\right)_{2}, 80{ }^{\circ} \mathrm{C}\right): \delta_{\mathrm{C}} 168.4,164.9,164.0$, $150.9,148.83,148.82,145.1,142.0,141.0,140.3,138.3,137.7,136.6,132.8,131.4,130.8,130.6,130.2,129.7$, 129.6, 128.3, 124.6, 52.4. HRMS (ESI): calcd for $\mathrm{C}_{39} \mathrm{H}_{29} \mathrm{O}_{4}{ }^{+}$561.2060, found 561.2062. Anal. calcd for $\mathrm{C}_{39} \mathrm{H}_{29} \mathrm{~F}_{6} \mathrm{O}_{4} \mathrm{P}$ (706.6093): C, 66.29; $\mathrm{H}, 4.14$. Found: $\mathrm{C}, 66.03 ; \mathrm{H}, 4.38$.

3,3-Bis(3,6-di-tert-butyl-1-azulenyl)-1,1-bis(4-fluorophenyl)propenylium hexafluorophosphate $\left(\mathbf{1 1 c}^{+} \mathrm{PF}_{6}{ }^{-}\right)$. To $^{\circ}$ a solution of 3,3-bis(3,6-di-tert-butyl-1-azulenyl)-1,1-bis(4-fluorophenyl)propene (10c) (150 mg, $0.212 \mathrm{mmol})$ in $\mathrm{CH}_{2} \mathrm{Cl}_{2}(20 \mathrm{~mL})$ was added DDQ $(59 \mathrm{mg}, 0.26 \mathrm{mmol})$ at room temperature. After the solution was stirred at the same temperature for $30 \mathrm{~min}, 60 \% \mathrm{HPF}_{6}(2 \mathrm{~mL})$ and water $(20 \mathrm{~mL})$ were added to the mixture. After stirring the mixture for an additional $10 \mathrm{~min}$, the resulting suspension was filtered with suction. The organic layer was separated, washed with water, dried with $\mathrm{MgSO}_{4}$, and concentrated under reduced pressure. The residue was crystallized from hexane to give 3,3-bis(3,6-di-tert-butyl-1-azulenyl)-1,1-bis(4fluorophenyl)propenylium hexafluorophosphate $\left(\mathbf{1 1 c}^{+} \mathrm{PF}_{6}{ }^{-}\right)(172 \mathrm{mg}, 95 \%)$. deep purple crystals. $\mathrm{mp} 170.1-$ $171.0{ }^{\circ} \mathrm{C}$ (hexane). IR (KBr disk, $\left.v_{\max }, \mathrm{cm}^{-1}\right): 2965(\mathrm{~m}), 2900(\mathrm{w}), 2782(\mathrm{w}), 1596(\mathrm{w}), 1574(\mathrm{w}), 1545(\mathrm{w}), 1503$ $(\mathrm{m}), 1477$ (s), $1441(\mathrm{~m}), 1416(\mathrm{~m}), 1400(\mathrm{w}), 1367(\mathrm{~m}), 1336$ (s), $1312(\mathrm{~m}), 1281$ (w), 1232 (s), 1203 (w), 1184 
(w), $1176(w), 1160(w), 1120(w), 1105(w), 1081(w), 1021(w), 991(w), 956(w), 869(w), 840(s), 810(w)$, $802(w), 705$ (w), $566(w), 558(m)$. UV-vis $\left(\mathrm{CH}_{3} \mathrm{CN}, \lambda_{\max }, \mathrm{nm}\right): 196$ (log $\varepsilon$ 4.81), 243 (4.73), 313 (4.55), 323 sh (4.55), 415 (4.17), 434 sh (4.10), 535 (4.23), 724 (4.63). ${ }^{1} \mathrm{H}$ NMR $\left(500 \mathrm{MHz},\left(\mathrm{CDCl}_{2}\right) 2,80{ }^{\circ} \mathrm{C}\right): \delta_{\mathrm{H}} 8.74(\mathrm{~d}, 2 \mathrm{H}, J$ $\left.10.8 \mathrm{~Hz}, 4^{\prime}-\mathrm{H}\right), 8.42\left(\mathrm{br}, 2 \mathrm{H}, 8^{\prime}-\mathrm{H}\right), 7.94\left(\mathrm{~d}, 2 \mathrm{H}, \mathrm{J} 10.8 \mathrm{~Hz}, 5^{\prime}-\mathrm{H}\right), 7.68\left(\mathrm{~d}, 2 \mathrm{H}, J 10.5 \mathrm{~Hz}, 7^{\prime}-\mathrm{H}\right), 7.64(\mathrm{~s}, 1 \mathrm{H}, 2-\mathrm{H})$, $7.56\left(\mathrm{~s}, 2 \mathrm{H}, 2^{\prime}-\mathrm{H}\right), 7.47$ (dd, $2 \mathrm{H}, J 8.4,5.3 \mathrm{~Hz}, 2^{\prime \prime}, 6^{\prime \prime}-\mathrm{H}$ or $\left.2^{\prime \prime \prime}, 6^{\prime \prime \prime}-\mathrm{H}\right), 7.14$ (dd, $2 \mathrm{H}, J 8.4,8.4 \mathrm{~Hz}, 3^{\prime \prime}, 5^{\prime \prime}-\mathrm{H}$ or

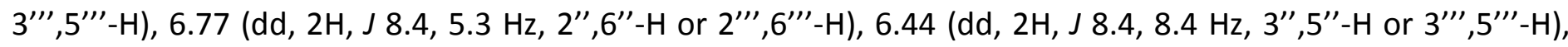
1.45 (s, 18H, $\left.3^{\prime}-t-B u\right), 1.41$ (s, 18H, 6'-t-Bu). ${ }^{13} \mathrm{C} \mathrm{NMR}\left(125 \mathrm{MHz},\left(\mathrm{CDCl}_{2}\right)_{2}, 80{ }^{\circ} \mathrm{C}\right): \delta_{\mathrm{C}} 168.9\left(\mathrm{C}-6^{\prime}\right), 164.6(\mathrm{~J} 253.7$ $\mathrm{Hz}, \mathrm{C}-4^{\prime \prime}$ or C-4"'), 162.5 (J $251.3 \mathrm{~Hz}, \mathrm{C}-4^{\prime \prime}$ or C-4'”'), 158.6 (C-1), 155.7 (C-3), 148.5 (C-3'a), 147.9 (C-3' or C-8'a), 147.8 (C-3' or C-8'a), 141.8 (C-2'), 138.7 (C-4'), 137.9 (C-8'), 137.7 (J 3.0 Hz, C-1" or C-1'”'), 135.0 (J 3.3 Hz, C-1'”

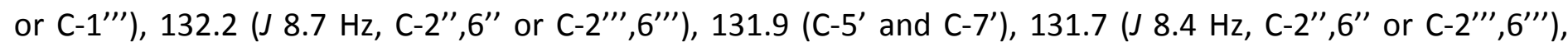

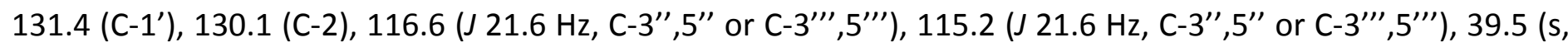
$\left.6^{\prime}-t-\mathrm{Bu}\right), 33.4$ (s, 3'-t-Bu), 31.8 (q, 6'-t-Bu), 31.2 (q, 3'-t-Bu). HRMS (ESI): calcd for $\mathrm{C}_{51} \mathrm{H}_{55} \mathrm{~F}_{2}^{+} 705.4266$, found 705.4264. Anal. calcd for $\mathrm{C}_{51} \mathrm{H}_{55} \mathrm{~F}_{8} \mathrm{P} \cdot 1 / 2 \mathrm{H}_{2} \mathrm{O}$ (850.9434): $\mathrm{C}, 71.23 ; \mathrm{H}, 6.56$. Found: $\mathrm{C}, 71.25 ; \mathrm{H}, 6.29$.

3,3-Bis(3,6-di-tert-butyl-1-azulenyl)-1,1-bis(4-nitrophenyl)propenylium hexafluorophosphate $\left(\mathbf{1 1 d}^{+} \mathbf{P F}_{6}^{-}\right)$. To a mixture of 3,3-bis(3,6-di-tert-butyl-1-azulenyl)-1,1-bis(4-nitrophenyl)propene (10d) (75 mg, $99 \mu \mathrm{mol})$ and $60 \% \mathrm{HPF}_{6}(2 \mathrm{~mL})$ in $\mathrm{CH}_{2} \mathrm{Cl}_{2}(10 \mathrm{~mL})$ and water $(20 \mathrm{~mL})$ was added DDQ $(30 \mathrm{mg}, 0.13 \mathrm{mmol})$ at room temperature. The resulting mixture was stirred at room temperature for $30 \mathrm{~min}$. The resulting suspension was filtered with suction. The organic layer was separated, washed with water, dried with $\mathrm{MgSO}_{4}$, and concentrated under reduced pressure. The residue was recrystallized from ethanol to give 3,3-bis(3,6-di-tertbutyl-1-azulenyl)-1,1-bis(4-nitrophenyl)propenylium hexafluorophosphate $\left(\mathbf{1 1 d}^{+} \mathrm{PF}_{6}{ }^{-}\right)$(59 $\mathrm{mg}$, 66\%). deep

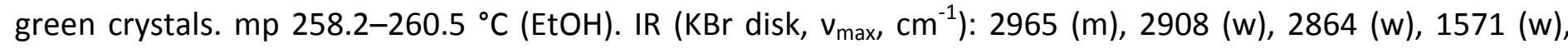
$1519(\mathrm{~m}), 1475(\mathrm{~m}), 1415(\mathrm{~m}), 1366(\mathrm{~m}), 1335(\mathrm{~s}), 1310(\mathrm{~m}), 1237(\mathrm{~m}), 1205(\mathrm{w}), 1178(\mathrm{~m}), 1112(\mathrm{~m}), 1082(\mathrm{~m})$, $1023(w), 956(w), 840(s), 800(w), 699(w), 557(m)$. UV-vis $\left(\mathrm{CH}_{3} \mathrm{CN}, \lambda_{\max }, \mathrm{nm}\right): 194$ (log $\varepsilon$ 4.64), 235 (4.49),

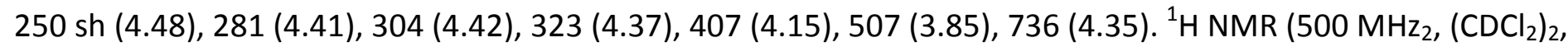
$\left.100{ }^{\circ} \mathrm{C}\right): \delta_{\mathrm{H}} 8.75\left(\mathrm{~d}, 2 \mathrm{H}, J 10.9 \mathrm{~Hz}, 4^{\prime}-\mathrm{H}\right), 8.42\left(\mathrm{~d}, 2 \mathrm{H}, J 10.7 \mathrm{~Hz}, 8^{\prime}-\mathrm{H}\right), 8.25\left(\mathrm{~d}, 2 \mathrm{H}, J 8.3 \mathrm{~Hz}, 3^{\prime \prime}, 5^{\prime \prime}-\mathrm{H}\right.$ or 3"', 5'”'-H), 8.02 (s, 1H, 2-H), 7.98 (d, 2H, J $\left.10.9 \mathrm{~Hz}, 5^{\prime}-\mathrm{H}\right), 7.79$ (d, 2H, J $\left.10.7 \mathrm{~Hz}, 7^{\prime}-\mathrm{H}\right), 7.64$ (d, 2H, J 8.3 Hz, 2", 6"'-H or $\left.2^{\prime \prime \prime}, 6^{\prime \prime \prime}-\mathrm{H}\right), 7.55\left(\mathrm{~d}, 2 \mathrm{H}, \mathrm{J} 8.1 \mathrm{~Hz}, 3^{\prime \prime}, 5^{\prime \prime}-\mathrm{H}\right.$ or $\left.3^{\prime \prime \prime}, 5^{\prime \prime \prime}-\mathrm{H}\right), 7.55\left(\mathrm{~s}, 2 \mathrm{H}, 2^{\prime}-\mathrm{H}\right), 6.89\left(\mathrm{~d}, 2 \mathrm{H}, J 8.1 \mathrm{~Hz}, 2^{\prime \prime}, 6^{\prime \prime}-\mathrm{H}\right.$ or $\left.2^{\prime \prime \prime}, 6^{\prime \prime \prime}-\mathrm{H}\right), 1.46$ (s, 18H, 3'-t-Bu), $1.43\left(\mathrm{~s}, 18 \mathrm{H}, 6^{\prime}-t-\mathrm{Bu}\right) .{ }^{13} \mathrm{C} \mathrm{NMR}\left(125 \mathrm{MHz}_{2},\left(\mathrm{CDCl}_{2}\right)_{2}, 100{ }^{\circ} \mathrm{C}\right): \delta_{\mathrm{C}} 169.9\left(\mathrm{C}-6^{\prime}\right)$, 153.8 (C-1), 152.9 ( $\left.C^{+}\right), 149.3$ (C-4" or C-4'”'), 149.0 (C-3' or C-3'a), 148.9 (C-3' or C-3'a), 148.1 (C-8'a), 147.3 (C-

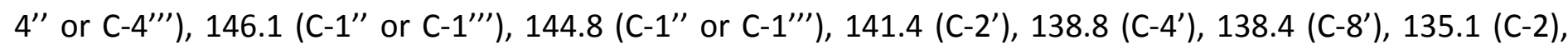

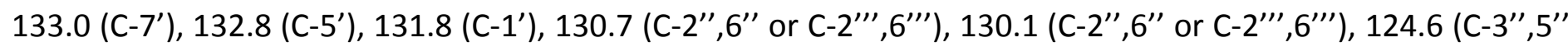

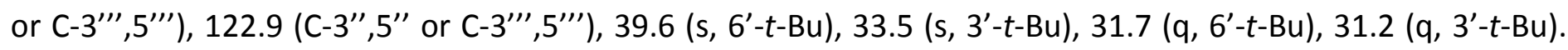
HRMS (ESI): calcd for $\mathrm{C}_{51} \mathrm{H}_{55} \mathrm{~N}_{2} \mathrm{O}_{4}{ }^{+}$759.4156, found 759.4154. Anal. Calcd for $\mathrm{C}_{51} \mathrm{H}_{55} \mathrm{~F}_{6} \mathrm{~N}_{2} \mathrm{O}_{4} \mathrm{P}$ (904.9576): C, 67.69; H, 6.13; N, 3.10. Found: C, 67.68; H, 5.92; N, 3.06.

9-[2,2-Bis(3,6-di-tert-butyl-1-azulenyl)ethylidene]-9H-fluorene (13). A mixture of $9 H$-fluoren-9-ylidene acetaldehyde (12) $(99 \mathrm{mg}, 0.48 \mathrm{mmol}$ ) and 1,6-di-tert-butylazulene (3a) (228 mg, $0.948 \mathrm{mmol}$ ) in acetic acid (6 $\mathrm{mL}$ ) was stirred at room temperature for $24 \mathrm{~h}$ under an Ar atmosphere. The reaction mixture was poured into water and extracted with $\mathrm{CH}_{2} \mathrm{Cl}_{2}$. The organic layer was washed with $5 \% \mathrm{NaHCO}_{3}$ and water, dried over $\mathrm{MgSO}_{4}$, and concentrated under reduced pressure. The residue was purified by column chromatography on silica gel with $\mathrm{CH}_{2} \mathrm{Cl}_{2}$ /hexane (1:5) and recrystallization from $\mathrm{Et}_{2} \mathrm{O} /$ hexane to afford 9-[2,2-bis(3,6-di-tert-butyl-1azulenyl)ethylidene]-9H-fluorene (13) $(204 \mathrm{mg}, 64 \%)$. blue crystals. mp $\left.255.4-256.7^{\circ} \mathrm{C} \mathrm{(Et}{ }_{2} \mathrm{O} / \mathrm{hexane}\right) . \mathrm{IR}(\mathrm{KBr}$ disk, $v_{\max }, \mathrm{cm}^{-1}$ ): $3060(\mathrm{w}), 2963$ (s), $2904(\mathrm{~m}), 2868(\mathrm{~m}), 1576(\mathrm{~s}), 1508(\mathrm{w}), 1475$ (w), 1455 (m), 1443 (m), 1439 $(w), 1424(\mathrm{~m}), 1390(\mathrm{~m}), 1361(\mathrm{~s}), 1294(\mathrm{w}), 1245(\mathrm{~m}), 1227(\mathrm{~m}), 1198(\mathrm{w}), 1070(\mathrm{w}), 872(\mathrm{w}), 833(\mathrm{~s}), 823(\mathrm{w})$, 776 (s), 730 (s), 669 (w), 614 (w), 528 (w), 442 (s). UV-vis $\left(\mathrm{CH}_{2} \mathrm{Cl}_{2}, \lambda_{\max }, \mathrm{nm}\right): 239$ (log ع 4.69), 249 (4.65), 259 
(4.65), 293 (4.80), 299 (4.80), 343 sh (4.04), 355 (4.07), 375 (4.00), 564 sh (2.74), 610 (2.86), 673 sh (2.75), 750 sh (2.21). ${ }^{1} \mathrm{H}$ NMR $\left(500 \mathrm{MHz}, \mathrm{CDCl}_{3}\right): \delta_{\mathrm{H}} 8.56(\mathrm{~d}, 2 \mathrm{H}, J 10.7 \mathrm{~Hz}, 4-\mathrm{H}), 8.19(\mathrm{~d}, 2 \mathrm{H}, J 10.6 \mathrm{~Hz}, 8-\mathrm{H}), 7.90(\mathrm{~d}, 1 \mathrm{H}, J$ $\left.7.8 \mathrm{~Hz}, 8^{\prime}-\mathrm{H}\right), 7.76\left(\mathrm{~d}, 1 \mathrm{H}, J 7.4 \mathrm{~Hz}, 5^{\prime}-\mathrm{H}\right), 7.71\left(\mathrm{~d}, 1 \mathrm{H}, J 7.6 \mathrm{~Hz}, 4^{\prime}-\mathrm{H}\right), 7.70\left(\mathrm{~d}, 1 \mathrm{H}, J 7.7 \mathrm{~Hz}, 1^{\prime}-\mathrm{H}\right), 7.58(\mathrm{~s}, 2 \mathrm{H}, 2-\mathrm{H})$, 7.33 (dd, $\left.1 \mathrm{H}, J 7.5,7.4 \mathrm{~Hz}, 6^{\prime}-\mathrm{H}\right), 7.30$ (dd, $\left.1 \mathrm{H}, J 7.6,7.4 \mathrm{~Hz}, 3^{\prime}-\mathrm{H}\right), 7.29$ (d, 1H, 10'-H), 7.24 (dd, 1H, J 7.8, 7.4 Hz, 2'-H), $7.21\left(\mathrm{dd}, 1 \mathrm{H}, J\right.$ 7.8, $\left.7.5 \mathrm{~Hz}, 7^{\prime}-\mathrm{H}\right), 7.17$ (dd, 2H, J 10.7, 1.8 Hz, 5-H), 7.03 (dd, 2H, J 10.6, 1.8 Hz, 7-H), 6.99 (d, $1 \mathrm{H}, \mathrm{CH}), 1.51$ (s, 18H, 3-t-Bu), 1.39 (s, 18H, 6-t-Bu). ${ }^{13} \mathrm{C} \mathrm{NMR}\left(125 \mathrm{MHz}, \mathrm{CDCl}_{3}\right): \delta_{\mathrm{C}} 160.5$ (C-6), 141.0 (C-4'b), 134.0 (C-9'a), 138.8 (C-4'a), 137.9 (C-3), 137.3 (C-8'a), 134.9 (C-8a), 134.8 (C-2), 134.5 (C-4), 134.3 (C-3a), 133.9 (C-10'), 133.3 (C-9'), 132.2 (C-8), 129.6 (C-1), 127.6 (C-6'), 127.3 (C-3'), 127.2 (C-7'), 126.7 (C-2'), 125.4 (C-8'), 120.4 (C-1'), 119.7 (C-5'), 119.5 (C-7), 119.4 (C-4'), 118.4 (C-5), 38.2 (s, 6-t-Bu), 36.9 (CH), 33.3 (s, 3-t-Bu), 32.2 (q, 3-t-Bu), 31.8 (q, 6-t-Bu). HRMS (ESI): calcd for $\mathrm{C}_{51} \mathrm{H}_{56}+\mathrm{Na}^{+} 691.4274$, found 691.4272. Anal. calcd for $\mathrm{C}_{51} \mathrm{H}_{56}$ (668.9903): C, 91.56; H, 8.44. Found: C, 91.30; H, 8.53.

1,1-Bis(3,6-di-tert-butyl-1-azulenyl)-2-(9H-fluorenylidene)ethylium hexafluorophosphate $\left(14^{+} \mathrm{PF}_{6}^{-}\right)$. To a

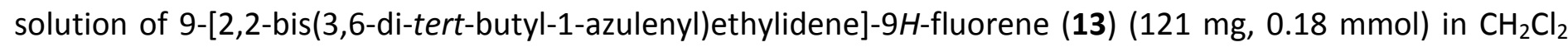
$(20 \mathrm{~mL})$ was added DDQ (56 mg, $0.25 \mathrm{mmol})$ at room temperature. After the solution was stirred at the same temperature for $30 \mathrm{~min}, 60 \% \mathrm{HPF}_{6}(2 \mathrm{~mL})$ and water $(20 \mathrm{~mL})$ were added to the mixture. After stirring the mixture for an additional $10 \mathrm{~min}$, the resulting suspension was filtered with suction. The organic layer was separated, washed with water, dried with $\mathrm{MgSO}_{4}$, and concentrated under reduced pressure. The residue was recrystallized from $\mathrm{Et}_{2} \mathrm{O} /$ hexane to give 1,1-bis(3,6-di-tert-butyl-1-azulenyl)-2-(9H-fluorenylidene)ethylium hexafluorophosphate $\left(14^{+} \mathrm{PF}_{6}{ }^{-}\right)(130 \mathrm{mg}, \mathbf{8 8 \%})$. deep purple powder. $\mathrm{mp} 182.2-186.3^{\circ} \mathrm{C}\left(\mathrm{Et}_{2} \mathrm{O} / \mathrm{hexane}\right) . \mathrm{IR}(\mathrm{KBr}$ disk, $\left.v_{\max } \mathrm{cm}^{-1}\right)$ : $2964(\mathrm{~m}), 2898(\mathrm{w}), 2871(\mathrm{w}), 1576(\mathrm{~m}), 1544(\mathrm{w}), 1478(\mathrm{~s}), 1450(\mathrm{w}), 1416(\mathrm{~s}), 1396(\mathrm{w}), 1367$ $(\mathrm{m}), 1332(\mathrm{~s}), 1311(\mathrm{~s}), 1279(\mathrm{w}), 1240(\mathrm{~m}), 1205(\mathrm{~m}), 1184(\mathrm{~m}), 1178(\mathrm{~m}), 1112(\mathrm{~m}), 1082(\mathrm{~m}), 1025(\mathrm{w}), 990$ $(w), 953(w), 869(m), 841(s), 806(m), 782(w), 726(w), 705(w), 558(m)$. UV-vis $\left(\mathrm{CH}_{3} \mathrm{CN}, \lambda_{\max }, \mathrm{nm}\right): 206$ (log $\varepsilon$ 4.68), 230 (4.76), 248 (4.80), 254 sh (4.79), 280 (4.63), 317 (4.47), 412 (4.14), 446 (4.02), 544 (4.15), 729 (4.49).

${ }^{1} \mathrm{H}$ NMR $\left(500 \mathrm{MHz},\left(\mathrm{CDCl}_{2}\right)_{2}, 80{ }^{\circ} \mathrm{C}\right): \delta_{\mathrm{H}} 8.90(\mathrm{~d}, 2 \mathrm{H}, J 11.1 \mathrm{~Hz}, 4-\mathrm{H}), 8.55(\mathrm{~d}, 2 \mathrm{H}, J 10.4 \mathrm{~Hz}, 8-\mathrm{H}), 8.04\left(\mathrm{~s}, 1 \mathrm{H}, 10^{\prime}-\right.$ H), $8.03(\mathrm{dd}, 2 \mathrm{H}, J 11.1,1.9 \mathrm{~Hz}, 5-\mathrm{H}), 7.86\left(\mathrm{~d}, 1 \mathrm{H}, J 7.6 \mathrm{~Hz}, 1^{\prime}-\mathrm{H}\right), 7.72(\mathrm{~s}, 2 \mathrm{H}, 2-\mathrm{H}), 7.68(\mathrm{dd}, 2 \mathrm{H}, J 10.4,1.9 \mathrm{~Hz}, 7-$ H), 7.62 (d, 1H, J $\left.7.4 \mathrm{~Hz}, 4^{\prime}-\mathrm{H}\right), 7.49$ (d, 1H, J $\left.7.4 \mathrm{~Hz}, 5^{\prime}-\mathrm{H}\right), 7.46$ (dd, 1H, J 7.5, 7.4 Hz, 3'-H), 7.37 (dd, 1H, J 7.6, $\left.7.5 \mathrm{~Hz}, 2^{\prime}-\mathrm{H}\right), 7.08$ (dd, 1H, J 7.5, 7.4 Hz, 6'-H), 6.50 (dd, 1H, J 7.9, 7.5 Hz, 7'-H), 5.89 (d, 1H, J 7.9 Hz, 8'-H), 1.47 $(\mathrm{s}, 18 \mathrm{H}, 3-t-\mathrm{Bu}), 1.41(\mathrm{~s}, 18 \mathrm{H}, 6-t-\mathrm{Bu}) .{ }^{13} \mathrm{C} \mathrm{NMR}\left(125 \mathrm{MHz},\left(\mathrm{CDCl}_{2}\right)_{2}, 80{ }^{\circ} \mathrm{C}\right): \delta_{\mathrm{C}} 169.4(\mathrm{C}-6), 153.5\left(\mathrm{C}^{+}\right), 151.4(\mathrm{C}-$ 9'), 149.2 (C-3a), 148.9 (C-3), 147.9 (C-8a), 143.1 (C-4'b), 142.5 (C-2), 140.9 (C-4'a), 139.2 (C-4), 139.1 (C-9'a), 138.2 (C-8), 135.5 (C-8'a), 132.6 (C-5), 132.3 (C-7), 132.0 (C-1), 131.9 (C-3'), 131.1 (C-6'), 128.4 (C-2'), 127.4 (C7'), 126.4 (C-8'), 126.2 (C-10'), 122.6 (C-1'), 120.6 (C-4'), 120.5 (C-5'), 39.6 (s, 6-t-Bu), 33.6 (s, 3-t-Bu), 31.7 (q, 3-t-Bu), 31.4 (q, 6-t-Bu). HRMS (ESI): calcd for $\mathrm{C}_{51} \mathrm{H}_{55}{ }^{+}$667.4298, found 667.4300. Anal. calcd for $\mathrm{C}_{51} \mathrm{H}_{55} \mathrm{~F}_{6} \mathrm{P}$ (812.9466): C, 75.35; H, 6.82. Found: C, 75.64; H, 6.69.

\section{Acknowledgements}

The present work was supported by JSPS KAKENHI Grant Number JP24550037.

\section{Supplementary Material}

Experimental details for physical measurements, $\mathrm{p} K_{\mathrm{R}}^{+}$data, CV and DVP waves, and spectroelectrograms of $\mathbf{5} \mathbf{a}^{+}, \mathbf{5} \mathbf{b}^{+}, \mathbf{8} \mathbf{a}^{+}, \mathbf{8} \mathbf{b}^{+}, \mathbf{1 1 a}-\mathbf{d}^{+}$, and $\mathbf{1 4 ^ { + }}$, and copies of ${ }^{1} \mathrm{H}$ and ${ }^{13} \mathrm{C}$ NMR spectra of reported compounds. 


\section{References}

1. Monk, P. M. S.; Mortimer, R. J.; Rosseinsky, D. R. Electrochromism: Fundamentals and Applications; VCH: Weinheim, Germany, 1995.

https://doi.org/10.1002/9783527615377

2. Mortimer, R. J. Chem. Soc. Rev. 1997, 26, 147-156.

https://doi.org/10.1039/cs9972600147

3. Deuchert, K.; Hünig, S. Angew. Chem., Int. Ed. Engl. 1978, 17, 875-886.

https://doi.org/10.1002/anie.197808753

4. Hünig, S.; Kemmer, M.; Wenner, H.; Perepichka, I. F.; Bäuerle, P.; Emge, A.; Gescheid, G. Chem. Eur. J. 1999, 5, 1969-1973.

https://doi.org/10.1002/(SICI)1521-3765(19990702)5:7<1969::AID-CHEM1969>3.0.CO;2-5

5. Hünig, S.; Kemmer, M.; Wenner, H.; Barbosa, F.; Gescheidt, G.; Perepichka, I. F.; Bäuerle, P.; Emge, A.; Peters, K. Chem. Eur. J. 2000, 6, 2618-2632.

https://doi.org/10.1002/1521-3765(20000717)6:14<2618::AID-CHEM2618>3.0.CO;2-W

6. Hünig, S.; Perepichka, I. F.; Kemmer, M.; Wenner, H.; Bäuerle, P.; Emge, A. Tetrahedron 2000, 56, 42034211.

https://doi.org/10.1016/S0040-4020(00)00345-8

7. Hünig, S.; Langels, A.; Schmittel, M.; Wenner, H.; Perepichka, I. F.; Peters, K. Eur. J. Org. Chem. 2001, 1393-1399.

https://doi.org/10.1002/1099-0690(200104)2001:7<1393::AID-EJOC1393>3.0.CO;2-Z

8. Ito, S.; Morita, N.; Kubo, T. J. Syn. Org. Chem. 2004, 62, 766-777.

https://doi.org/10.5059/vukigoseikyokaishi.62.766

9. Ito, S.; Morita, N. Eur. J. Org. Chem. 2009, 4567-4579.

https://doi.org/10.1002/ejoc.200900393

10. Ito, S.; Morita, N.; Asao, T. Bull. Chem. Soc. Jpn. 1995, 68, 1409-1436.

https://doi.org/10.1246/bcsi.68.1409

11. Ito, S.; Kobayashi, H.; Kikuchi, S.; Morita, N.; Asao, T. Bull. Chem. Soc. Jpn. 1996, 69, 3225-3237. https://doi.org/10.1246/bcsj.69.3225

12. Ito, S.; Kikuchi, S.; Morita, N.; Asao, T. Bull. Chem. Soc. Jpn. 1999, 72, 839-849.

https://doi.org/10.1246/bcsj.72.839

13. Ito, S.; Kikuchi, S.; Morita, N.; Asao, T. J. Org. Chem. 1999, 64, 5815-5821.

https://doi.org/10.1021/jo990029p

14. Ito, S.; Morita, N.; Asao, T. Bull. Chem. Soc. Jpn. 2000, 73, 1865-1874.

https://doi.org/10.1246/bcsj.73.1865

15. Ito, S.; Kubo, T.; Kondo, M.; Kabuto, C.; Morita, N.; Asao, T.; Fujimori, K.; Watanabe, M.; Harada, N.; Yasunami, M. Org. Biomol. Chem. 2003, 1, 2572-2580.

https://doi.org/10.1039/b302688d

16. Ito, S.; Kawakami, J.; Tajiri, A.; Ryuzaki, D.; Morita, N.; Asao, T.; Watanabe, M.; Harada, N. Bull. Chem. Soc. Jpn. 2005, 78, 2051-2065.

https://doi.org/10.1246/bcsj.78.2051

17. Ito, S.; Akimoto, K.; Kawakami, J.; Tajiri, A.; Shoji, T.; Satake, H.; Morita, N. J. Org. Chem. 2007, 72, 162172.

https://doi.org/10.1021/jo0618324 
18. Stella, L.; Janousek, Z.; Merényi, R.; Viehe, H. G. Angew. Chem., Int. Ed. Engl. 1978, 17, $691-692$. https://doi.org/10.1002/anie.197806911

19. Viehe, H. G.; Merényi, R.; Stella, L.; Janousek, Z. Angew. Chem., Int. Ed. Engl. 1979, 18, 917-932. https://doi.org/10.1002/anie.197909171

20. Viehe, H. G.; Janousek, Z.; Merényi, R. Acc. Chem. Res. 1985, 18, 148-154. https://doi.org/10.1021/ar00113a004

21. Ito, S.; Kubo, T.; Morita, N.; Ikoma, T.; Tero-Kubota, S.; Tajiri, A. J. Org. Chem. 2003, 68, 9753-9762. https://doi.org/10.1021/jo0350530

22. Takahashi, K.; Nihira, T. Tetrahedron Lett. 1989, 30, 5903-5906. https://doi.org/10.1016/S0040-4039(01)93501-4

23. Takahashi, K.; Nihira, T.; Tomitani, K. J. Chem. Soc., Chem. Commun. 1993, 1617-1619. https://doi.org/10.1039/c39930001617

24. Ito, S.; Kikuchi, S.; Okujima, T.; Morita, N.; Asao, T. J. Org. Chem. 2001, 66, 2470-2479. https://doi.org/10.1021/jo001709r

25. Shoji, T.; Higashi, J.; Ito, S.; Okujima, T.; Morita, N. Eur. J. Org. Chem. 2011, 584-592. https://doi.org/10.1002/ejoc.201001212

26. Hosoya, T.; Aoyama, H.; Ikemoto, T.; Kihara, Y.; Hiramatsu, T.; Kondo, M.; Suzuki, M. Bioorg. Med. Chem. 2003, 11, 663-673. https://doi.org/10.1016/S0968-0896(02)00600-4

27. Bharathi, P.; Periasamy, M. Org. Lett. 1999, 1, 857-859. https://doi.org/10.1021/ol990745d

28. Adams, D. J.; Clark, J. H.; McFarland, H. J. Fluorine Chem. 1998, 92, 127-129. https://doi.org/10.1016/S0022-1139(98)00274-7 